Check for updates

Cite this: RSC Adv., 2019, 9, 18467

Received 14th April 2019

Accepted 30th May 2019

DOI: 10.1039/c9ra02813g

rsc.li/rsc-advances

\section{Recent advances in the synthesis and synthetic applications of Betti base (aminoalkylnaphthol) and bis-Betti base derivatives}

\begin{abstract}
Abolfazl Olyaei (iD)*a and Mahdieh Sadeghpour ${ }^{b}$
The multicomponent reaction between 2-naphthol, arylaldehydes and ammonia yields aminobenzylnaphthols in a process known as the Betti reaction, which was first uncovered at the beginning of the 20th century. Various methods have been reported for the synthesis of aminobenzylnaphthol (Betti base) and bis-Betti base derivatives using various types of naphthols, aromatic amines, heteroaromatic amines, and aliphatic and cyclic amines instead of ammonia or diamines and aliphatic and aromatic aldehydes or dialdehyde compounds under various conditions in recent years. The Betti reaction produces racemic and non-racemic aminobenzylnaphthol ligands. It is also clear that the most important area of application of the non-racemic aminonaphthols prepared in this manner is their use in asymmetric synthesis, either as chiral ligands or as chiral auxiliaries. The functional groups in these Mannich products offer many ring closure possibilities. Some of these products or the starting bifunctional compounds possess biological activity. Herein, we present a selection of the relevant studies on this topic.
\end{abstract}

\section{Introduction}

Senator Mario Betti (1875-1942) (Fig. 1) was a distinguished Italian chemist, ${ }^{1,2}$ very active at the beginning of the 20th

${ }^{a}$ Department of Chemistry, Payame Noor University (PNU), PO Box 19395-4697, Tehran,Iran.E-mail: olyaei_a@pnu.ac.ir

${ }^{b}$ Department of Chemistry, Takestan Branch, Islamic Azad University, Takestan, Iran century. In 1892 Betti registered as a student at the chemistry school of the University of Pisa. In 1897, Betti obtained his degree with a thesis on the reaction of methylisoxazolones with aldehydes and co-authored with Roberto Schiff the first two papers of his career. ${ }^{3,4}$ In 1898, Betti moved to the University of Florence as an assistant of Ugo Schiff, who was founder and director of the Institute of Chemistry. In the Florence laboratories, Betti developed his interests in stereochemistry with

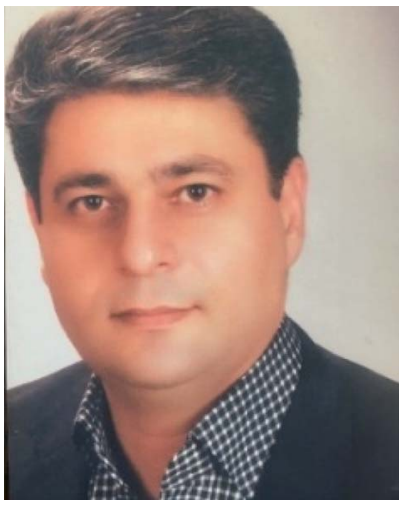

Associate Professor Dr Abolfazl Olyaei was born in Tabriz, Iran in 1975. He received his BSc degree in pure chemistry in the University of Tabriz in 1999. He received his MSc in 2001 and his PhD in 2007 in organic chemistry under the supervision of Professor Mohammad Raouf Darvich and Professor Mehdi Ghandi, both in Tehran University, Tehran, Iran. He was an Assistance Professor in the University of Payame Noor in 2007 and now he is an Associate Professor in that university. His research interests include organic synthesis, organic materials, green chemistry, catalysis and organocatalysis and application of materials and organo-materials in different sciences.

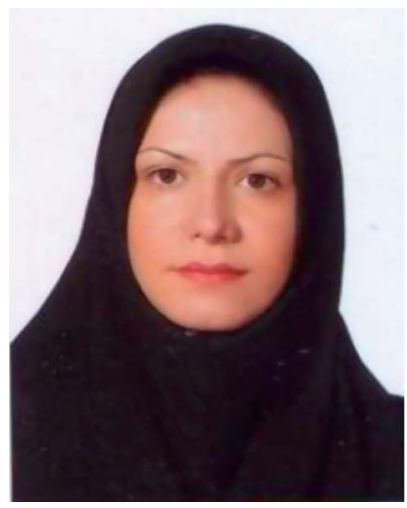

Assistance Professor Dr Mahdieh Sadeghpour was born in Qazvin, Iran in 1978. She received her BSc degree in pure chemistry in Alzahra University, Tehran, Iran in 2001 and her MSc in 2004 in organic chemistry under the supervision of Associate Professor Nikoo Sedighi in Tehran University, Tehran, Iran. She graduated with a PhD in 2009 in organic chemistry under the supervision of Professor Abbas Shokravi and Associate Professor Abolfazl Olyaei in Kharazmi University, Tehran, Iran. Now she is an Assistance Professor in Islamic Azad University of Takestan Branch. Her research interests include organic synthesis, green chemistry and application of materials and nanomaterials in different sciences. 
important studies on the relationship between optical rotatory power and the structure of groups connected with the stereocentre. ${ }^{5}$ Noyori considered him to be the real pioneer of asymmetric synthesis, ${ }^{6}$ since Betti reacted methylmagnesium iodide and benzaldehyde in the presence of $N, N$-dimethylbornylamine.

On performing these studies, a great advantage was achieved by the synthetic versatility of the reaction, nowadays known as the Betti reaction, that in the original version produced $1-(\alpha-$ aminobenzyl)-2-naphthol (1) (Fig. 2), starting with 2-naphthol, benzaldehyde, and ammonia. ${ }^{7}$ The product began to be known by the name of the author (i.e. Betti base) and the multicomponent process was published in Organic Syntheses, ${ }^{8}$ a prestigious international book series, where only independently checked synthetic procedures are reported. Finally, the base was also easily resolved into its optical isomers by means of tartaric acid. ${ }^{9}$

Also, he worked at the universities of Cagliari, Siena, Genoa and finally Bologna, where he was the successor of Giacomo Ciamician. In 1939, he was appointed a Senator of the Kingdom of Italy.

The purpose of the present review is to summarize the utility of the Betti bases and bis-Betti bases with emphasis on recent synthesis and synthetic applications.

\section{The Betti reaction}

This synthetic strategy originated between the end of the 19th and the beginning of the 20th century when research in several laboratories was performed on reactions between ammonia, or amines, formaldehyde and enolisable carbonyl compounds. ${ }^{\mathbf{1 0}}$ The first two components yield an imine that reacts with the carbonyl compound. These procedures are commonly classified as Mannich aminoalkylations, after the systematic work of the latter author, which began in 1912, thus subsequent to Betti's research. ${ }^{7,9,11}$ Eventually, Betti also reported ${ }^{7}$ that the product 2 (Scheme 1) could be obtained from a three-component condensation of 2-naphthol, an ethanolic solution of ammonia and 2 equiv. of benzaldehyde ( $91 \%$ yield). Actually, the product of the reaction is represented by the forms $2 \mathbf{a}$ and 2b in equilibrium. ${ }^{12}$ The intermediate 2 was treated with hydrochloric acid to obtain the salt of the Betti base $\mathbf{1 a} \mathrm{HCl}$

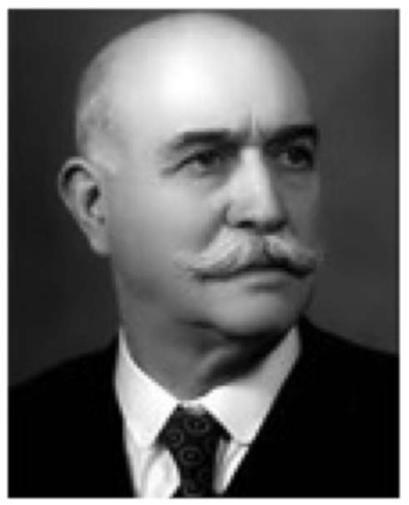

Fig. 1 Italian Senator Mario Betti.

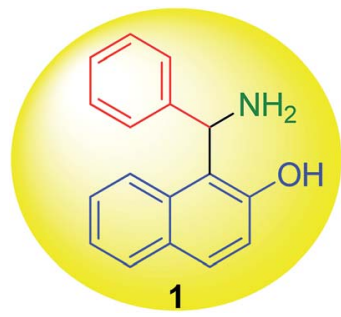

Fig. 2 The Betti base structure.

( $91 \%$ yield, Scheme 1). Addition of a solution of sodium hydroxide to chloride yielded Betti base 1 (75\% yield). ${ }^{7,13}$

\section{Synthesis and synthetic applications of Betti base derivatives}

In 1930, after a long period of silence, work was performed by Littman and Brode, who used different secondary amines such as dimethylamine and piperidine instead of ammonia in a onepot multicomponent process. ${ }^{\mathbf{1 4}}$ In this reaction, dimethylamino derivative of the Betti base 3 and 1-(1-piperidylbenzyl)-2naphthol (4) were obtained (Scheme 2). ${ }^{\mathbf{1 4}}$ According to Littman and Brode, secondary amines should react with benzaldehyde via the formation of a benzylidinediamine. This intermediate attacks 2-naphthol and yields aminobenzylnaphthol, after the elimination of an amine molecule.

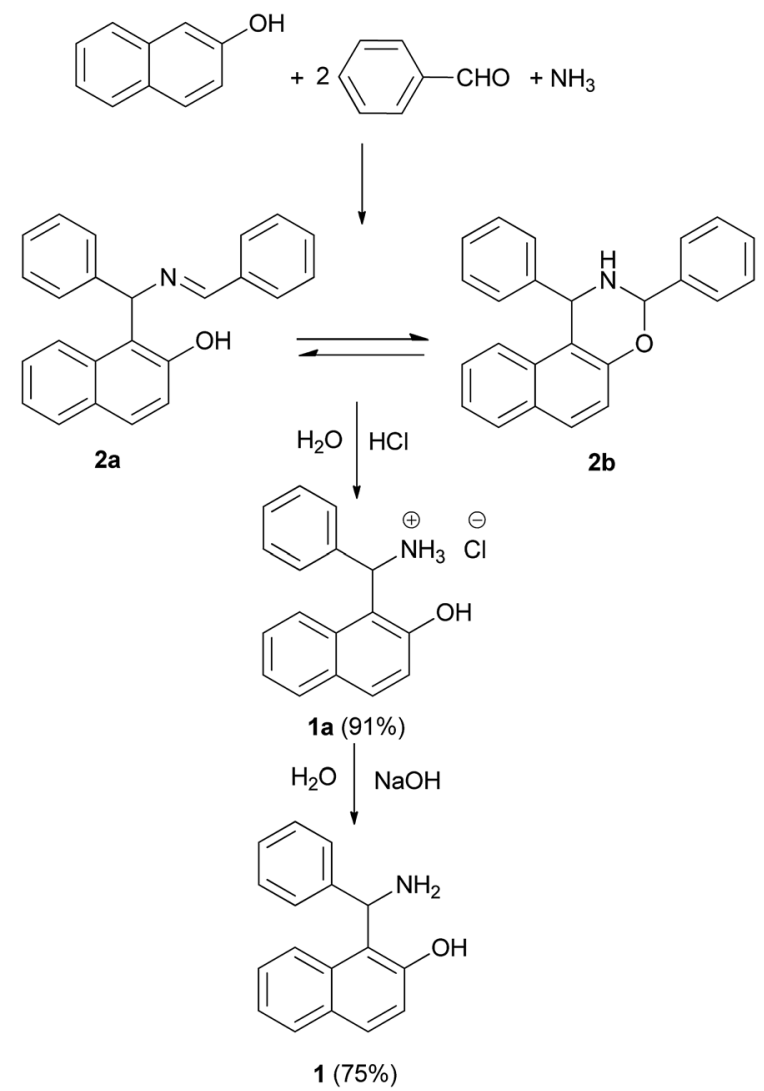

Scheme 1 The Betti reaction. 


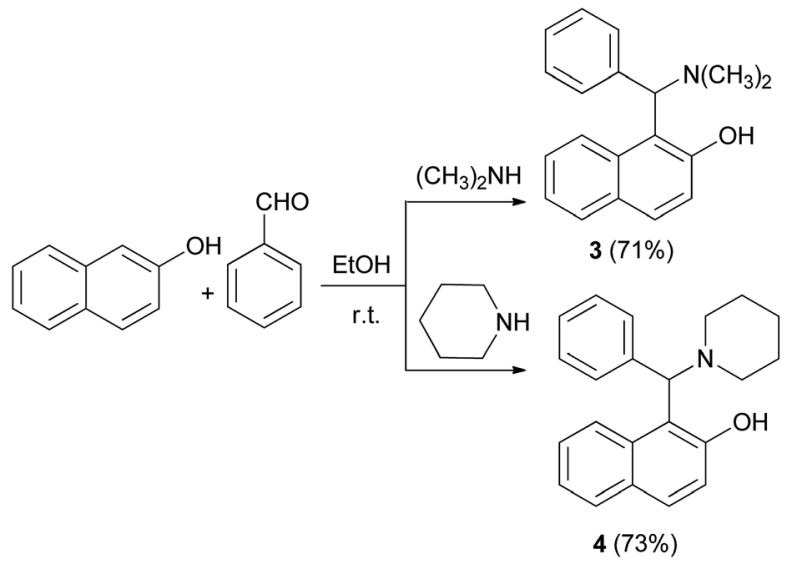

Scheme 2 The Betti reaction with secondary amines.<smiles>Oc1ccc2ccccc2c1C(/N=C/c1ccccc1)c1ccccc1</smiles>

(S)-(+1)-5

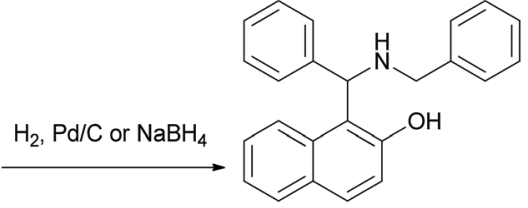

$(S)-(+1)-6$

Scheme 3 Synthesis of the $N$-benzyl derivative 6

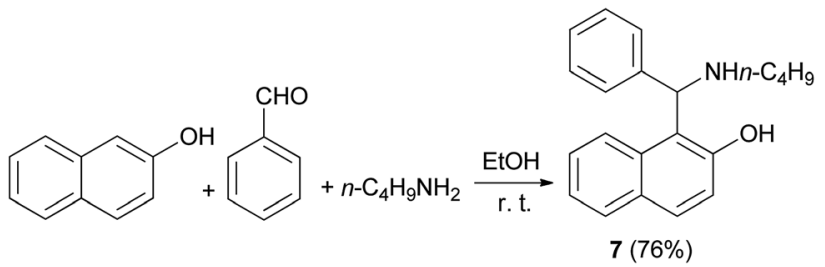

Scheme 4 Synthesis of the $N$-butyl derivative 7.<smiles>N[C](c1ccccc1)c1c(O)ccc2ccccc12</smiles>

$($ S)-(+)-1<smiles>CCN(CC)CCN(c1ccccc1)c1c(O)ccc2ccccc12</smiles>

$(+)-7(60 \%)$

Scheme 5 Synthesis of chiral aminonaphthol (+)-7.

Two decades ago, Cardellicchio et $a .^{15}$ reported a protocol for the resolution of the Betti base and the absolute configuration of the Betti base hydrobromide was established by means

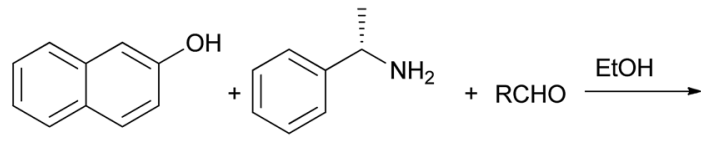<smiles>[R]C(N[C@@H](C)c1ccccc1)c1c(O)ccc2ccccc12</smiles>

$70 \%$

9: $\mathrm{R}=$ Phenyl

10: $R=$ ' propy
Scheme 6 Synthesis of chiral aminonaphthol 11.

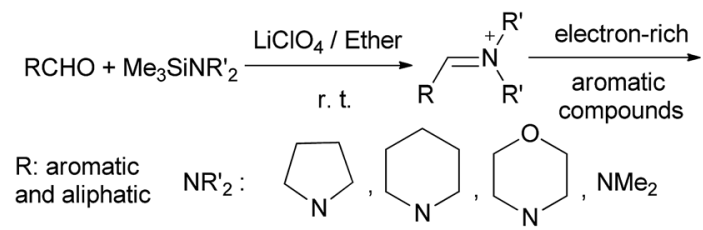

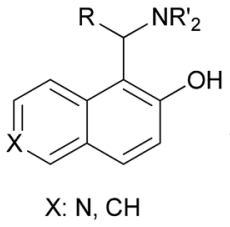

12

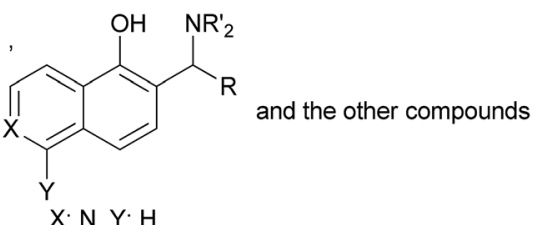

$\mathrm{X}: \mathrm{CH}, \mathrm{Y}: \mathrm{H}$ or $\mathrm{OH}$

12
Scheme $7 \quad \mathrm{LiClO}_{4}$-mediated aminoalkylation of electron-rich aromatic compounds.

of X-ray diffractometry. Also, a series of optically active derivatives such as the $\mathrm{N}, \mathrm{N}$-dimethyl and the $\mathrm{N}, \mathrm{N}, \mathrm{O}$-trimethyl derivatives were prepared in racemic form by means of the Betti reaction and were resolved into two enantiomers with an extremely easy and efficient procedure. The configuration of each base was determined by correlation with the configuration of the Betti amine. In their work, the $N$-benzyl derivative 6 was easily obtained by reducing $(S)-(+)-5$ with hydrogen in the presence of $\mathrm{Pd} / \mathrm{C}$, or with $\mathrm{NaBH}_{4}$ (Scheme 3).

In 1999, Naso and coworkers reported a procedure for the synthesis of 1 -( $\alpha$ - $N$-butylaminobenzyl)-2-naphthol (7) via condensation of 2-naphthol, benzaldehyde and $n$-butylamine in EtOH (95\%) at room temperature for 6 days, obtaining the corresponding product in $76 \%$ yield (Scheme 4 ).

Also, in order to establish the configuration of product 7, the Betti base $(S)-(+)$-1 was treated with $n$-butanal, yielding the oxazine $(-)-8$, which was reduced to $(+)-7$ by $\mathrm{NaBH}_{4}$; thus the $(S)$ configuration has been assigned to compound (+)-7 and consequently the $(R)$ configuration to $(-)-7$ (Scheme 5). The chiral non-racemic aminonaphthols 7 were tested as complexing agents in the catalytic enantioselective addition of diethylzinc to arylaldehydes. The use of these bases gave high ee 


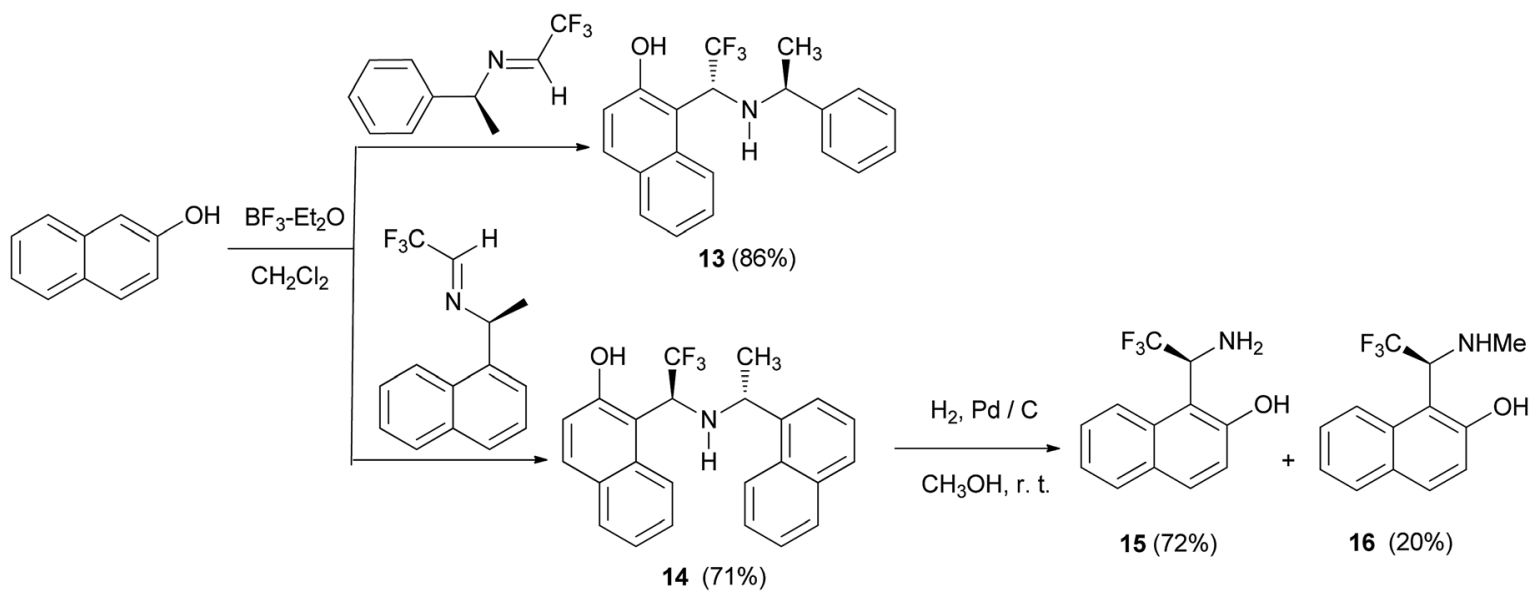

Scheme 8 Diastereoselective synthesis of Betti bases 13-16.

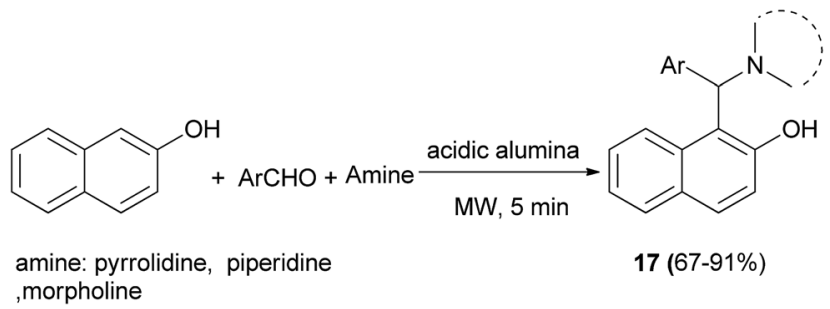

Scheme 9 Aminoalkylation of 2-naphthol on acidic alumina promoted by microwave irradiation.<smiles>N[C@@H](c1ccccc1)c1c(O)ccc2ccccc12</smiles>

(s)-1

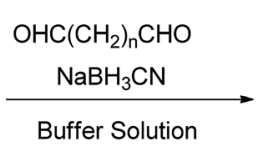

$0^{\circ} \mathrm{C} / 1.5 \mathrm{~h}$

$n=1-3$<smiles>Oc1ccc2ccccc2c1[C@H](c1ccccc1)N1CCNC1</smiles>

$18(94-98 \%)$
Scheme 10 Synthesis of chiral ligands (S)-18.

values (up to $>99 \%$ ). An important role was played by the solvent. Toluene or hexane gave the best results and THF lowered the ee values of the resulting alcohol. ${ }^{\mathbf{1 6}}$

Wang et al. ${ }^{17}$ have obtained optically active aminonaphthols $\mathbf{9}$ and 10 through the reaction of 2-naphthol, benzaldehyde, and $(S)$-methylbenzylamine in EtOH at room temperature for 6 days in $70 \%$ yield. Moreover, $N$-methylation of 9 with paraformaldehyde and $\mathrm{NaBH}_{4}$ in THF at room temperature gave 1$\left((S)\right.$-phenyl $\left(\left(\left(1^{\prime} S\right)-1^{\prime}\right.\right.$-phenylethyl)methylamino)methyl)-2-

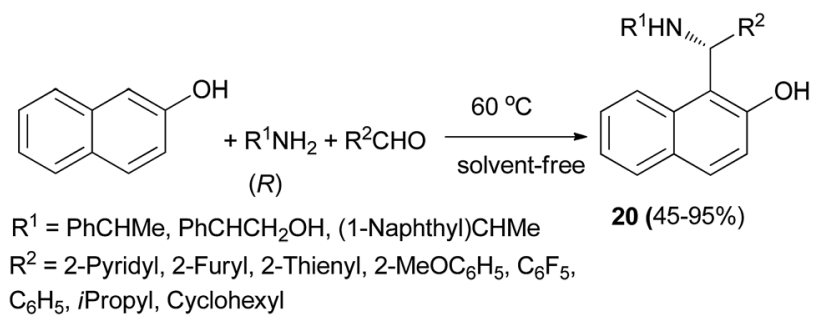

Scheme 11 Synthesis of secondary aminoalkylnaphthols 20<smiles>[R]c1ccc([C@H](NC(C)c2ccccc2)c2c(O)ccc3ccccc23)cc1</smiles>

$(R, R)-23$

$\mathrm{R}^{3}=\mathrm{H}, \mathrm{Me}$

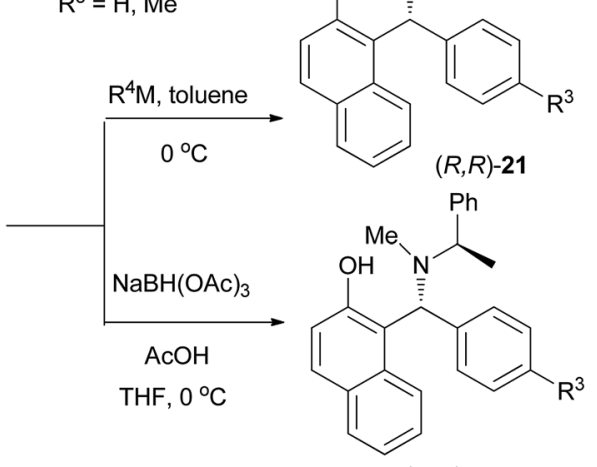

$(R, R)-22$

Scheme 12 Synthesis of tertiary aminoalkylnaphthols 21 and 22.

naphthol (11) in 65\% yield (Scheme 6). Aminonaphthol 11 (15 mol\%) catalyzed the enantioselective ethylation of arylaldehydes to secondary alcohols (70-98\% yields) with high 


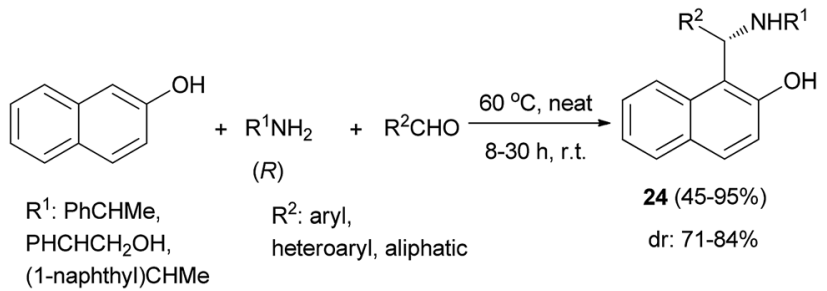

Scheme 13 Synthesis of secondary aminoalkylnaphthols 24 .

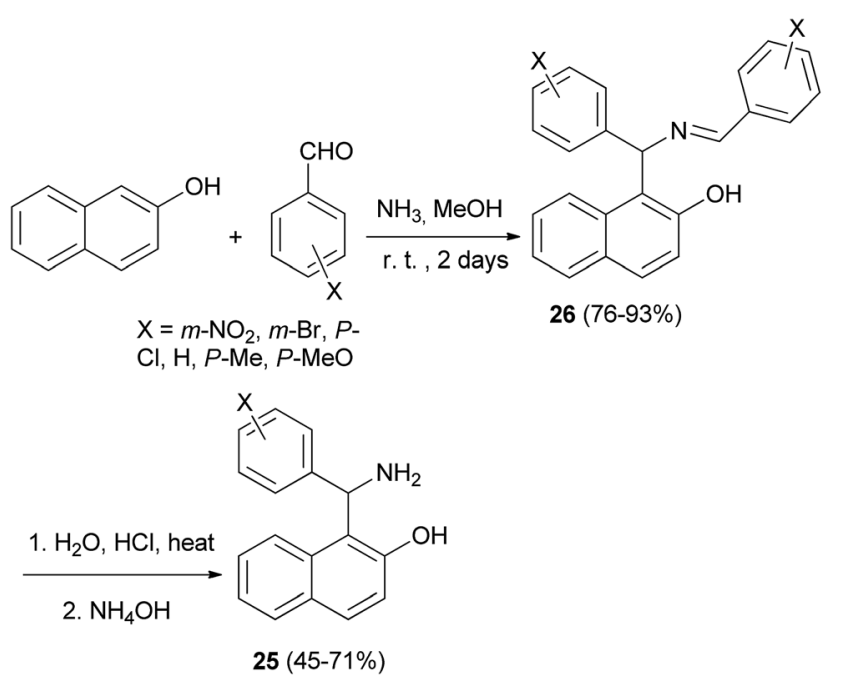

Scheme 14 Synthesis of aminoalkylnaphthols 25 .

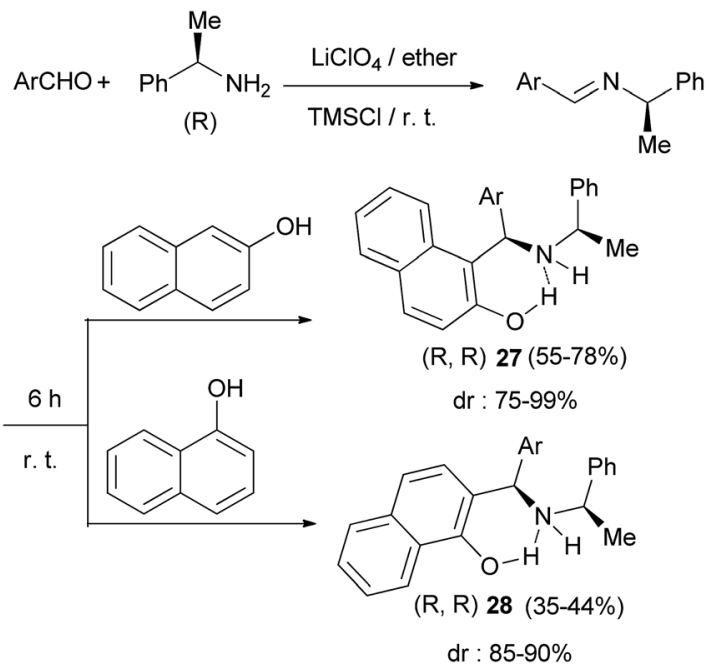

Scheme $15 \mathrm{LiClO}_{4}$-mediated stereoselective aminoalkylation of naphthols with chiral amine.

enantioselectivities (up to 99.8\%) in toluene at room temperature for $24 \mathrm{~h}$.

Saidi et al. ${ }^{18}$ described an efficient three-component and onepot method for aminoalkylation of electron-rich aromatic compounds using aldehydes, (trimethylsilyl)dialkylamines, and an electron-rich aromatic compound such as 1-naphthol, 2-

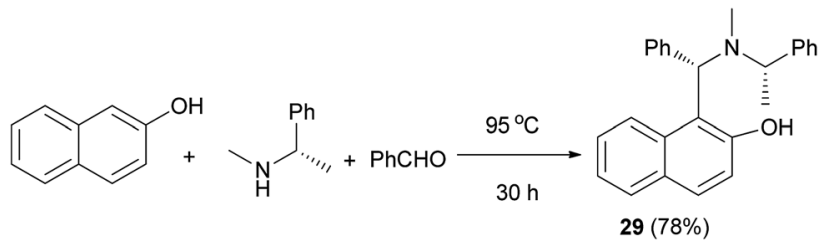

Scheme 16 One-step synthesis of aminonaphthol 29.

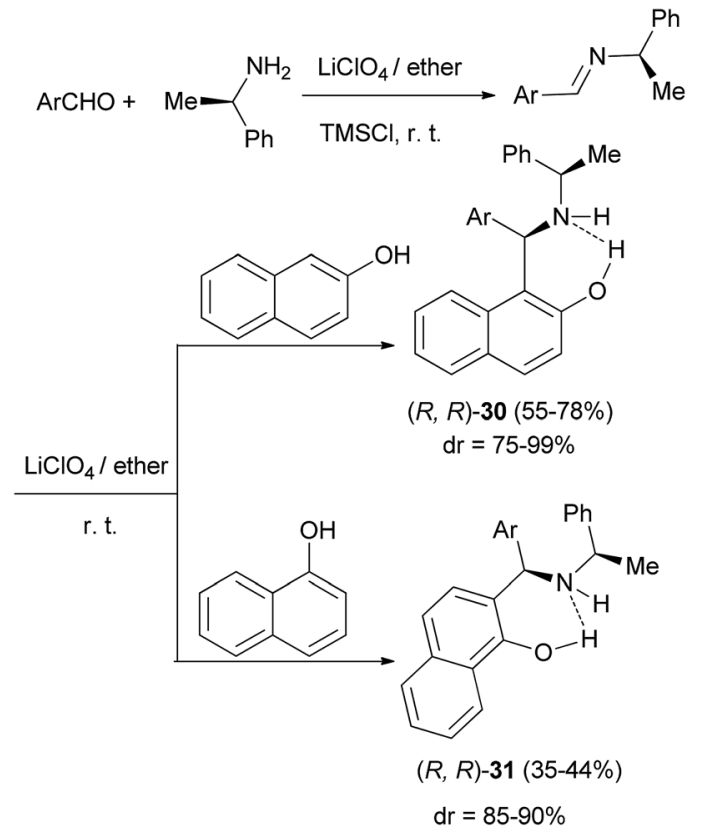

Scheme $17 \mathrm{LiClO}_{4}$-mediated stereoselective aminoalkylation of naphthols with chiral amine.

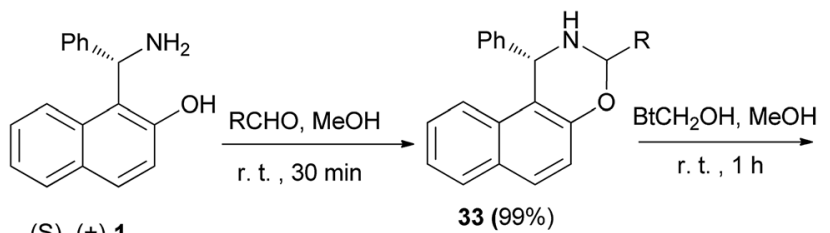

(S)- (+)-1

$\mathrm{R}=\mathrm{alkyl}, \mathrm{H}$

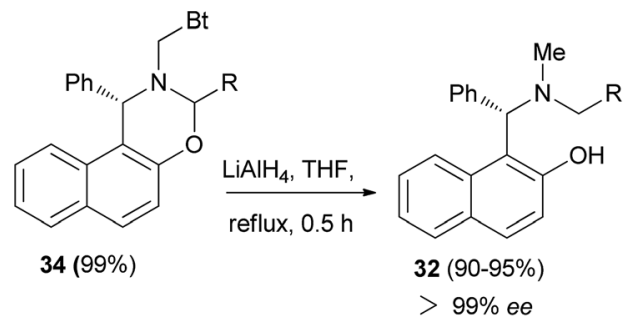

Scheme 18 Synthesis of chiral $N$-methyl- $N$-alkyl Betti bases 32.

naphthol, 1,5-dihydroxynaphthalene, 2,4-dimethylphenol, 6hydroxyisoquinoline, 7-hydroxycoumarin, indole or $\mathrm{N}$-methylindole, at room temperature for 1-6 h in a concentrated solution of lithium perchlorate in diethyl ether. The reaction give good yields up to $95 \%$ of aminoalkylated aromatic and aliphatic 
<smiles>N[C@H](c1ccccc1)c1c(O)ccc2ccccc12</smiles>

(S)-1.L-(+)-Tartaric Acid $\mathrm{Bt}$,

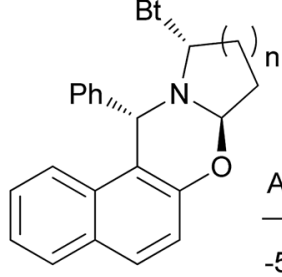

$37, \mathrm{n}=2$<smiles>O=C(O)[C@H](O)[C@@H](O)C(=O)O</smiles>

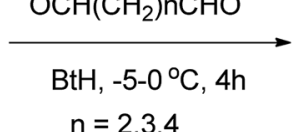

$n=2,3,4$

Ar<smiles>[3H]C1CCCCN1</smiles><smiles>CC1CC2Oc3ccc4ccccc4c3[C@@H](c3ccccc3)N2C1Br</smiles>

$37(91-93 \%)$<smiles>Oc1ccc2ccccc2c1[C@@H](c1ccccc1)N1CCNC1</smiles>

$35(89-94 \%)$<smiles>Oc1ccc2ccccc2c1[C@@H](c1ccccc1)N1CCCCC1Br</smiles>

$36(84-92 \%)$

Scheme 19 Synthesis of homochiral 1-[ $\alpha$-(1-azacycloalkyl)benzyl]-2-naphthols 35 and 36.

compounds $\mathbf{1 2}$ and with moderate yield (35\%) in the case of aliphatic aldehydes (Scheme 7).

Gong et al. ${ }^{19}$ demonstrated diastereoselective Friedel-Crafts reaction of 2-naphthol with $\alpha$-trifluoromethylimines derived from chiral amines. The reactions proceeded readily at room temperature for $48 \mathrm{~h}$ in the presence of $\mathrm{BF}_{3} \cdot \mathrm{Et}_{2} \mathrm{O}$, resulting in the corresponding chiral Betti bases 13 and $\mathbf{1 4}$ in yields of 86\% and $71 \%$, respectively. Then, hydrogenolysis of $\mathbf{1 4}$ was carried out in methanol at room temperature under a hydrogen atmosphere in the presence of $\mathrm{Pd} / \mathrm{C}$. Under these conditions, compound 14 gave 1-(1-amino-2,2,2-trifluoro)ethylnaphthalen2-ol (15) (72\%) and 1-(2,2,2-trifluoro-1-methylamino) ethylnaphthalen-2-ol (16) (20\%) (Scheme 8).

The Mannich reaction on acidic alumina assisted by microwave irradiation was reported for the aminoalkylation of 2naphthol with aromatic aldehydes and secondary amines such as piperidine, pyrrolidine and morpholine for $5 \mathrm{~min}$ under

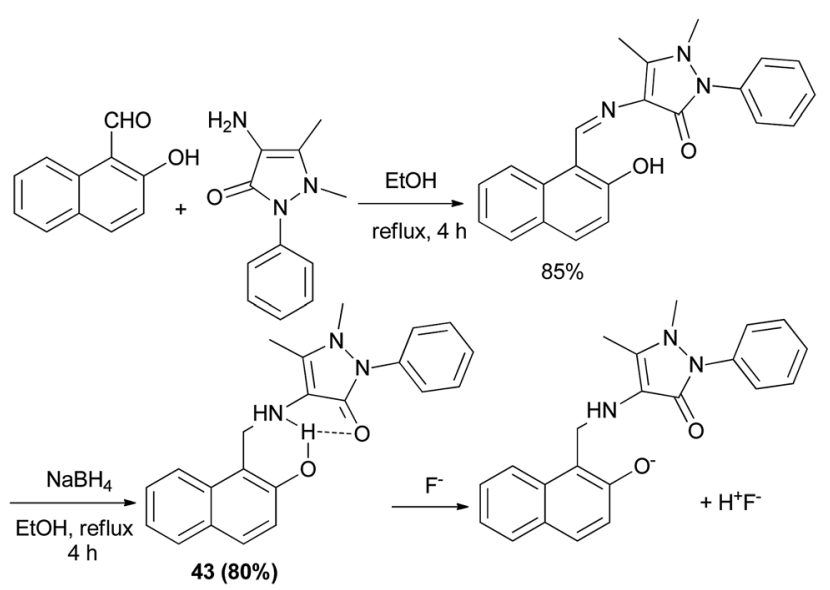

Scheme 21 Synthesis of fluorescent chemosensor containing aminonaphthol 43.

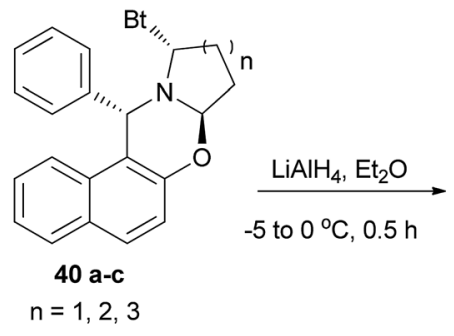<smiles>Oc1ccc2ccccc2c1[C@@H](c1ccccc1)N1CCCC1</smiles>

39 a-c (9-94\%)

$n=1,2,3$<smiles>Br[C@H]1CCC[C@@H]2Oc3ccc4ccccc4c3[C@@H](c3ccccc3)N12</smiles>

40b

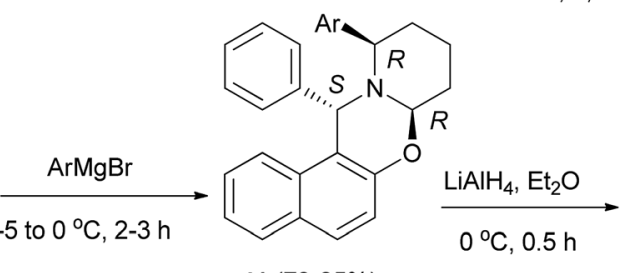

$41(73-85 \%)$<smiles>Oc1ccc2ccccc2c1[C@@H](c1ccccc1)N1CCCC[C@H]1Br</smiles>

$42(84-92 \%)$

Scheme 20 Synthesis of aminonaphthols 39 and 42. 
<smiles>O=Cc1cccc2ccccc12</smiles><smiles>CN[C@@H](C)c1ccccc1</smiles>

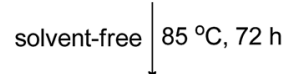<smiles>C[C@@H](c1ccccc1)N(C)[C@H](c1cccc2ccccc12)c1c(O)ccc2ccccc12</smiles><smiles>[131Sn]</smiles><smiles>[R]c1ccc(C=O)cc1</smiles>
$\mathrm{PhB}(\mathrm{OH})_{2}, \mathrm{Et}_{2} \mathrm{Zn}, 44$ DiMPEG $(10 \mathrm{~mol} \%)$ toluene, $-15^{\circ} \mathrm{C}, 15 \mathrm{~h}$

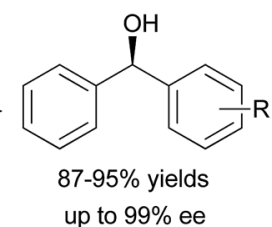

Scheme 22 Synthesis of chiral tertiary aminonaphthol 44 and catalyzed enantioselective phenyl transfer to aryl aldehydes.<smiles>N[C@H](c1ccccc1)c1c(O)ccc2ccccc12</smiles>

(S) L-(+)-tartaric acid $20 \mathrm{~min}$ $92 \%$

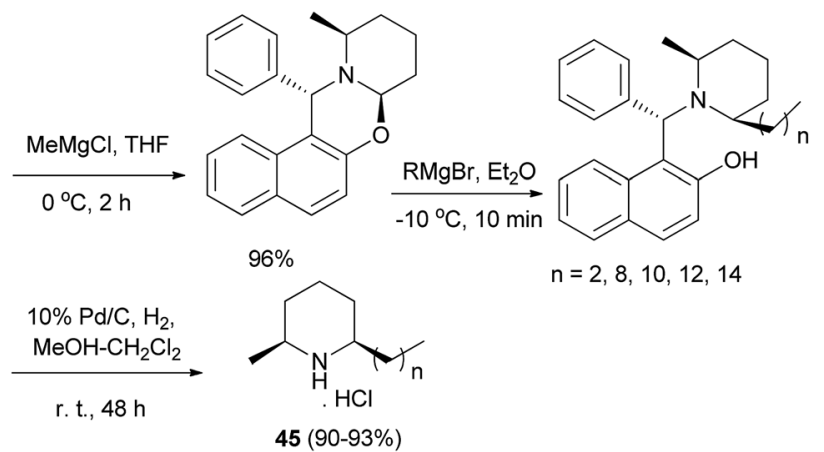

Scheme 23 Total syntheses of enantiopure $(2 S, 6 R)$-dihydropinidine and $(2 S, 6 R)$-isosolenopsins 45 .

solvent-free condition, resulting in the desired products $\mathbf{1 7}$ in 67-91\% yields (Scheme 9). ${ }^{20}$

A procedure for selective direct $N, N$-alkylation of the chiral Betti base was developed, and a family of chiral ligands, $(S)-1-(\alpha-$ cycloaminobenzyl)-2-naphthols 18, were prepared. Initially, oxazine derivatives 19 were achieved by the condensation of $(S)$ 1-( $\alpha$-aminobenzyl)-2-naphthol and bis-aldehydes in the presence of $\mathrm{NaBH}_{3} \mathrm{CN}$ in a buffer solution (aqueous EtOH solution of $\left.\mathrm{Na}_{2} \mathrm{HPO}_{4}-\mathrm{KH}_{2} \mathrm{PO}_{4}\right)$ at $0{ }^{\circ} \mathrm{C}$ in $1.5 \mathrm{~h}$. Subsequently, compounds 19 were treated with $\mathrm{LiAlH}_{4}$, the $\mathrm{C}-\mathrm{O}$ bond being cleaved selectively to yield the desired products 18 in $94-98 \%$

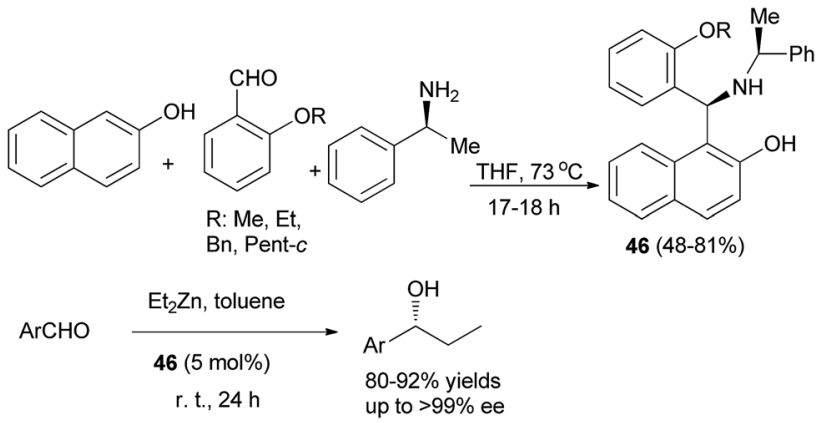

Scheme 24 Chiral aminonaphthol 46-catalyzed enantioselective carbonyl addition of diethylzinc to aromatic aldehydes.

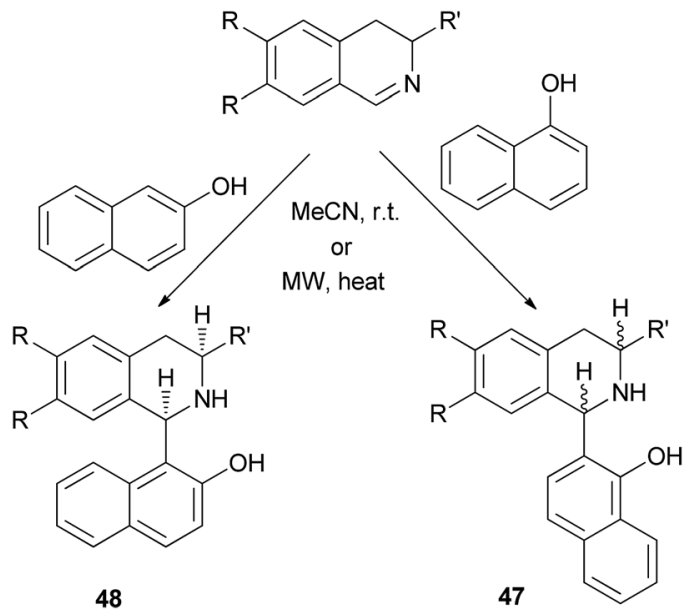

R': $\mathrm{H}, \mathrm{Me}$

R': $\mathrm{H}, \mathrm{Me}$

$\mathrm{R}: \mathrm{H}, \mathrm{OMe}$

$\mathrm{R}: \mathrm{H}, \mathrm{OMe}$

Scheme 25 Synthesis of 1 -( $\alpha$ - or $\beta$-hydroxynaphthyl)-1,2,3,4-tetrahydroisoquinolines 47 and 48 .

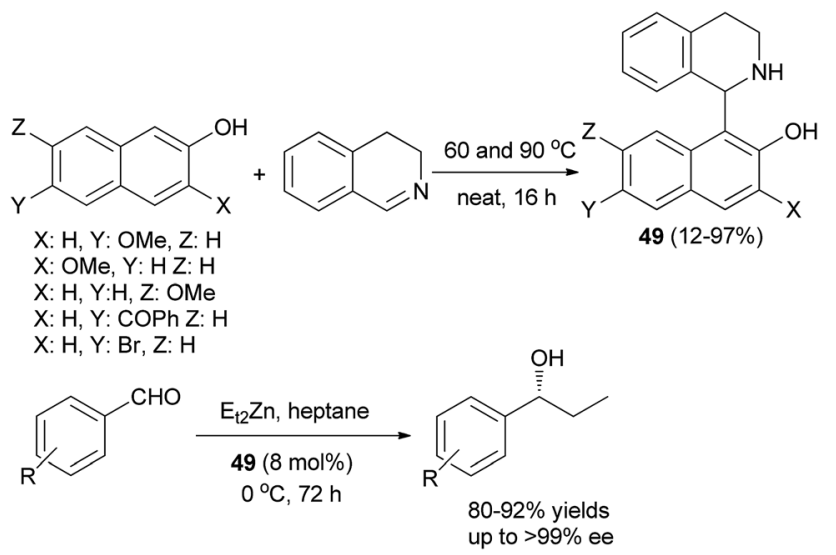

Scheme 26 Synthesis of THIQNOL (49) and catalyzed asymmetric addition of diethylzinc to aldehydes.

yields at $-10{ }^{\circ} \mathrm{C}$ in $1.5 \mathrm{~h}$ without any loss of enantiomeric excess (Scheme 10). ${ }^{21}$

A practical procedure for the stereoselective synthesis of a group of functionalized secondary and tertiary 
<smiles></smiles><smiles>[X]=CN</smiles>

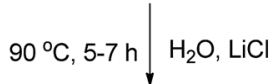<smiles></smiles>

Scheme 27 Water-promoted one-pot synthesis of compound 50

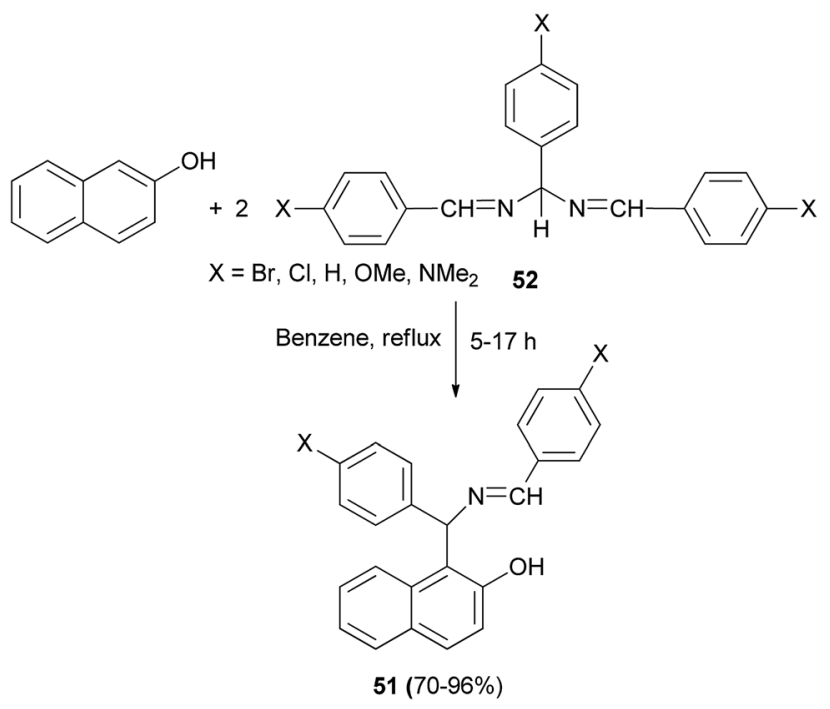

Scheme 28 Synthesis of benzylidene derivatives 51 .

aminoalkylnaphthols (20, 21 and 22) was employed by Palmieri et $a .^{22} \mathrm{~A}$ series of secondary aminoalkylnaphthols were prepared by heating a mixture of 2-naphthol, $(R)$-amines and aldehydes at $60{ }^{\circ} \mathrm{C}$ in 8-30 h, under solvent-free conditions with yields from 45 to $95 \%$ (Scheme 11). Then, selective $N$-alkylation was carried out by cyclization of compounds 23 with formaldehyde, followed by reduction or alkylation with organometallic reagents $\left(\mathrm{R}^{4} \mathrm{M}\right)$, resulting in the corresponding chiral tertiary aminonaphthols 21 and 22 (Scheme 12). The catalytic activity of this class of compounds was used in the addition of diethylzinc to benzaldehyde in toluene at room temperature, resulting in moderate to good enantioselectivities (12-89\% ee) and 26-97\% yields.

A practical procedure for the stereoselective synthesis of a group of functionalized aminoalkylnaphthols (24) in 45-95\% yields was reported, involving heating a mixture of 2-naphthol, secondary amines $(R)$ and aldehydes at $60{ }^{\circ} \mathrm{C}$ within $8-30 \mathrm{~h}$ under solvent-free conditions (Scheme 13). It is noteworthy that the aminonaphthols obtained as the major diastereomer ( $\mathrm{dr}$ : $71-84 \%$ ) in the solvent-free synthesis have the best asymmetric induction properties in the alkylation reaction. ${ }^{22}$

Condensation of 2-naphthol and substituted benzaldehydes in the presence of $25 \%$ methanolic ammonia, and subsequent acidic hydrolysis afforded the aminoalkylnaphthols 25 in 45$71 \%$ yields. The crystalline product 26 separated out after 2 days, which was suspended in $20 \% \mathrm{HCl}$ and the mixture was stirred and refluxed for $3 \mathrm{~h}$ (Scheme 14)..$^{23}$

The Mannich reaction of 2-naphthol and 1-naphthol with in situ prepared imines from $(R)$-1-phenylethylamine and aromatic aldehydes in $5 \mathrm{M}$ ethereal lithium perchlorate at room temperature in the presence of TMSCl under an argon atmosphere within $6 \mathrm{~h}$ afforded the corresponding aminoalkylated products 27 and 28 in moderate to good yields (35-78\%) with moderate to very high diastereoselectivities (75-99\%) (Scheme 15). ${ }^{24}$

Chan et $a l .{ }^{25}$ reported a one-step procedure for the synthesis of optically active tertiary aminonaphthol 29 via benzaldehyde, $(S)-(-)-N, R$-dimethylbenzylamine and 2-naphthol at $95{ }^{\circ} \mathrm{C}$ for $30 \mathrm{~h}$ in $78 \%$ yield (Scheme 16). Optically active tertiary aminonaphthol 29 (15 mol\%) was found to catalyze the enantioselective alkenylation of various aldehydes in toluene at $-30{ }^{\circ} \mathrm{C}$ for $15 \mathrm{~h}$ with high ee values (up to $>99 \%$ ), which provides

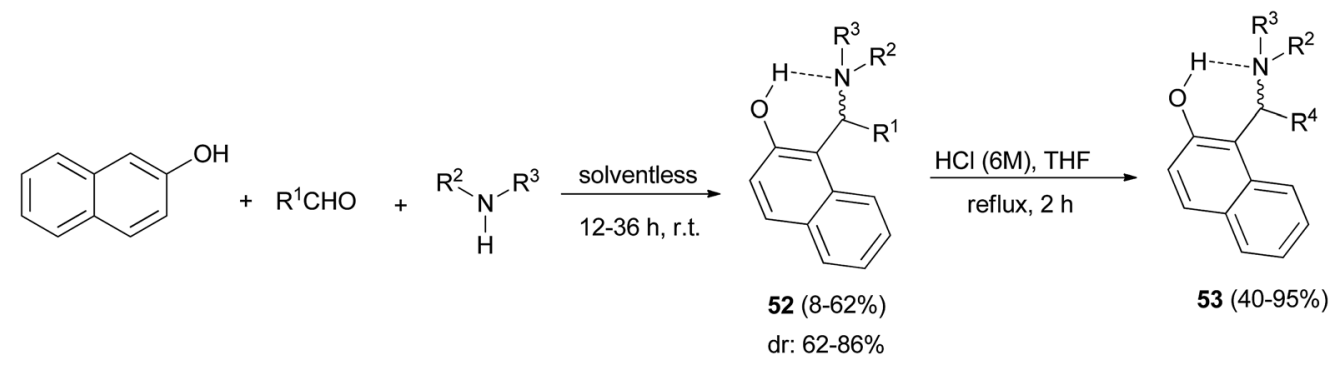<smiles>[R]C=O</smiles>

(R)<smiles>O=CC1CCCN1C(=O)OCc1ccccc1</smiles>

(S)<smiles>CCCCOC(=O)N1C(C=O)COC1(C)C</smiles>

$(S)$<smiles>CCCCOC(=O)N[C@@H](C=O)Cc1ccccc1</smiles>

(S)

Scheme 29 Stereoselective synthesis of aminoalkylnaphthols 52 and 53. 


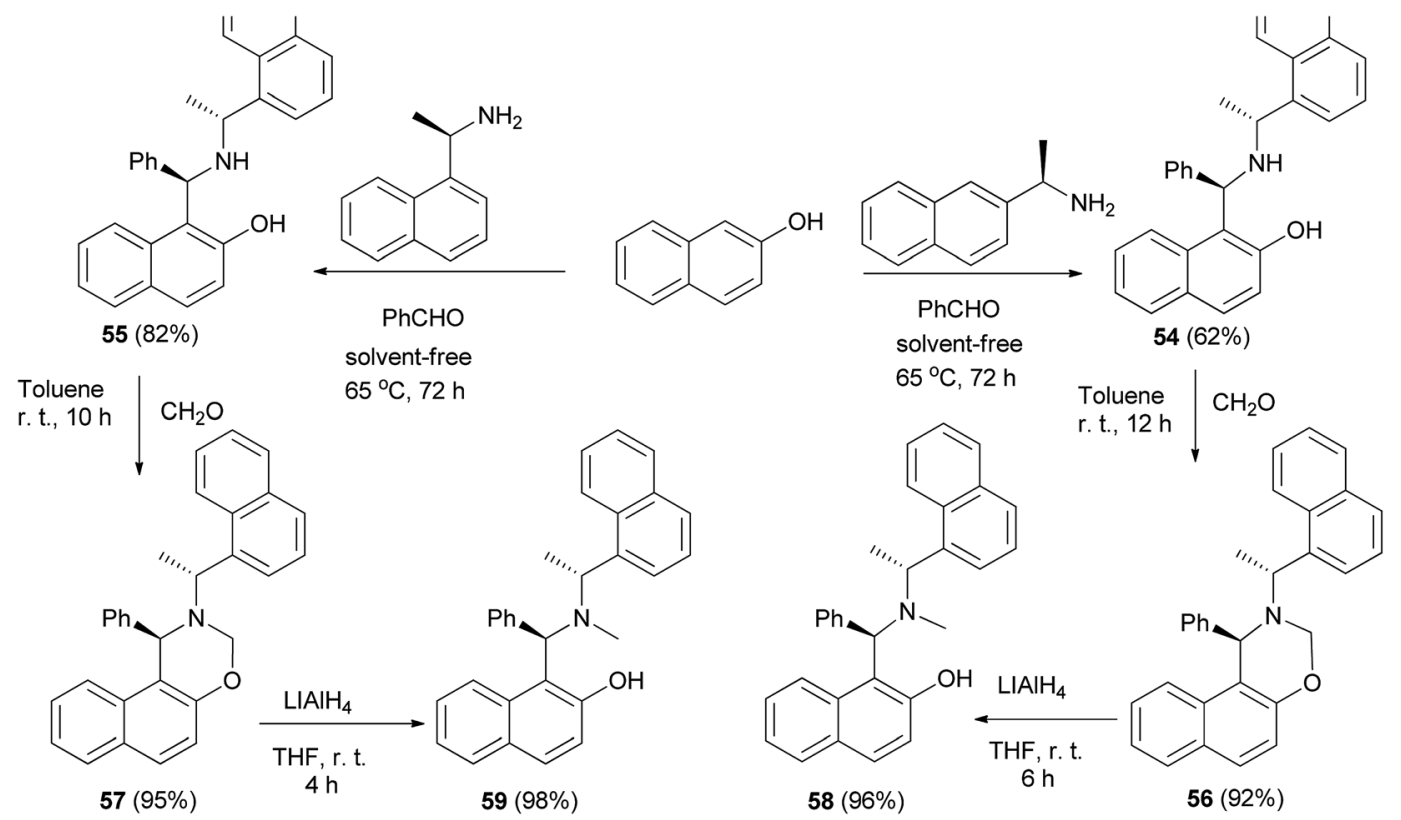

Scheme 30 Synthesis of optically active aminonaphthols.

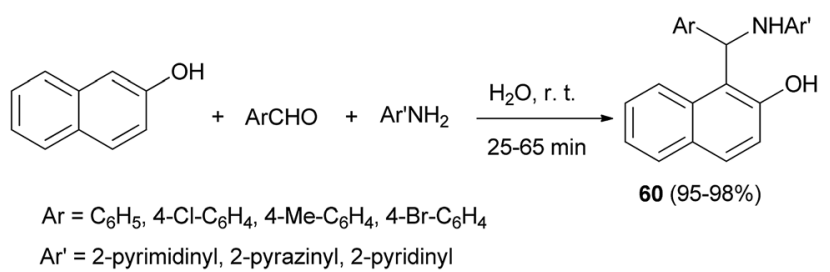

Scheme 31 Synthesis of aminonaphthols 60 in water.

a practical method for the synthesis of chiral $(E)$-allyl alcohols in $77-95 \%$ yields.

Saidi et al. ${ }^{26}$ reported a one-pot, three-component Mannich reaction of 2-naphthol or 1-naphthol with $(R)$-1-phenylethylamine and an aromatic aldehyde in concentrated ethereal lithium perchlorate solution at room temperature, which afforded highly diastereoselective access to the requisite 2-

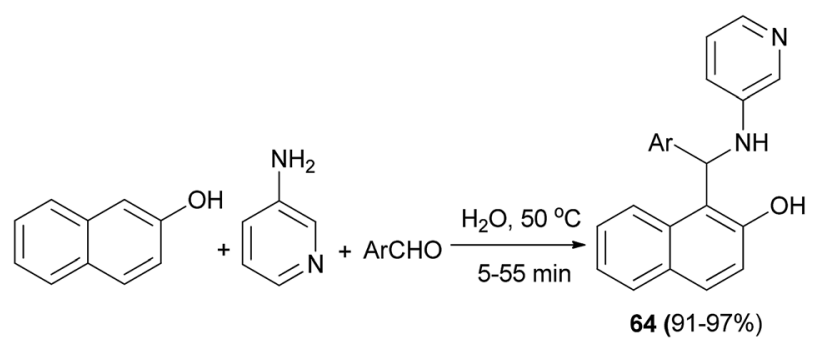

Scheme 33 Synthesis of $N$-heteroarylaminonaphthols 64 .

aminoalkylated products $\mathbf{3 0}$ and $\mathbf{3 1}$ in high to low yields, respectively (Scheme 17).

In 2004, a one-pot preparation of chiral $N$-methyl- $N$-alkyl Betti bases 32 was reported involving a highly regioselective $N$ alkylation of $(S)-(+)$-Betti base. The strategy involved formation

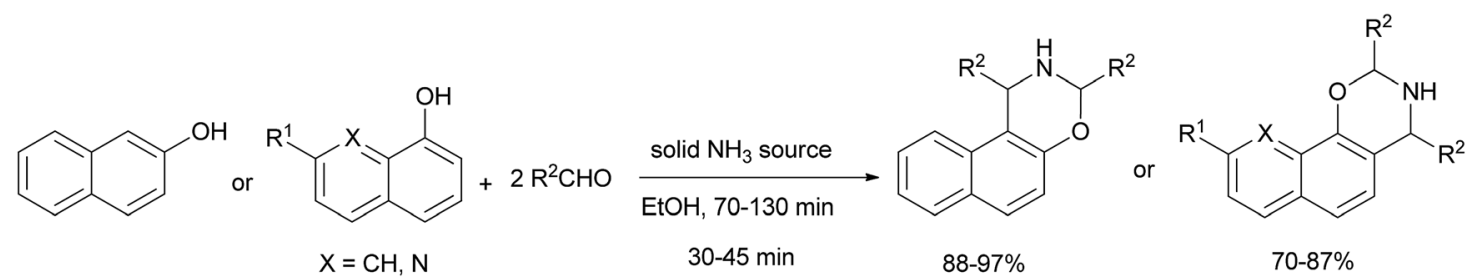

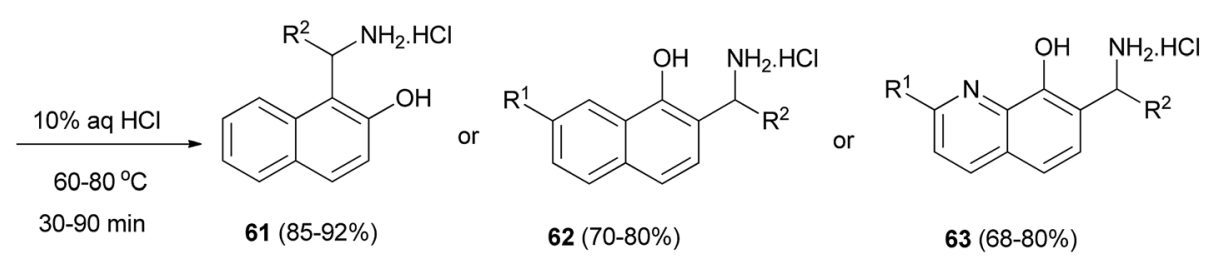

Scheme 32 Microwave-assisted synthesis of (aminoalkyl)naphthols 61, 62 and (aminoalkyl)quinolinols 63 


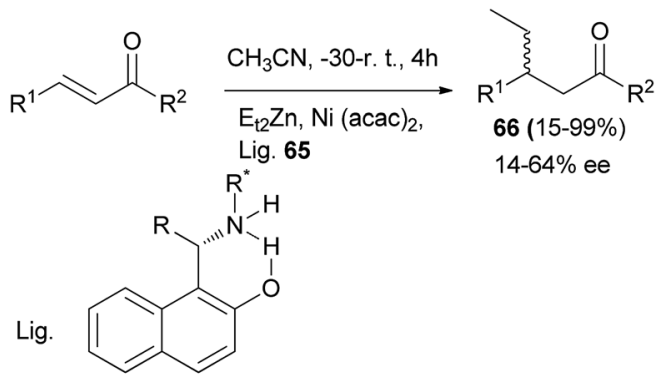

65

Scheme 34 Enantioselective addition of diethylzinc to chalcones using ligand 65 .

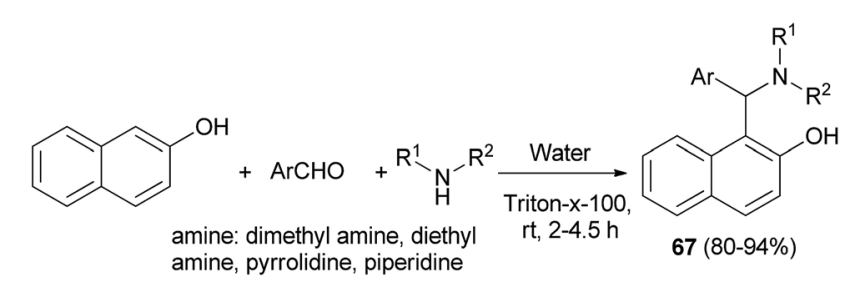

Scheme 35 Triton X-100-catalyzed synthesis of Betti bases 67

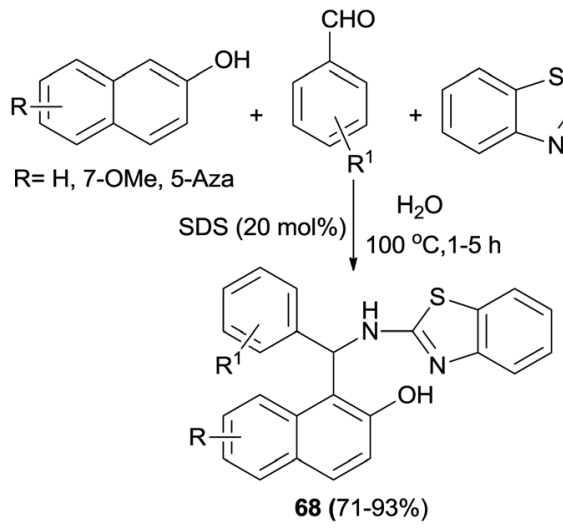

Scheme 36 Sodium dodecylsulfate-assisted synthesis of 1-(benzothiazolylamino)methyl-2-naphthols 68 in water.

of an oxazine ring (33), obtained by condensation of $(S)-(+)$-Betti base and aldehydes, and $N$-methylation with $\mathrm{BtCH}_{2} \mathrm{OH}$ under neutral conditions to yield oxazine 34. Chiral $N$-methyl- $N$-alkyl

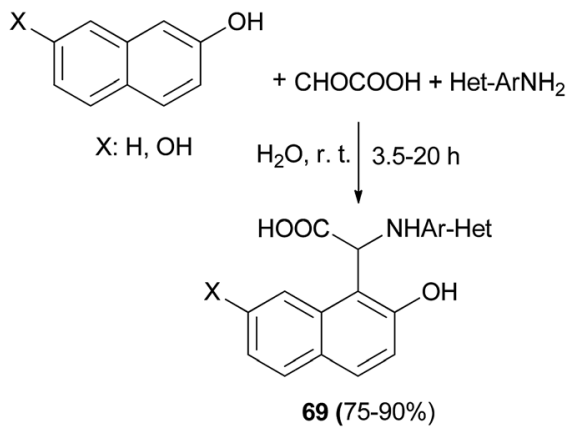

Scheme 37 Synthesis of $\alpha$-naphthylglycine derivatives 69 in water.

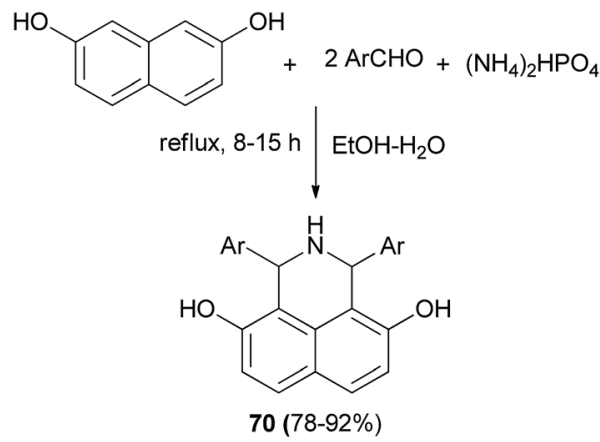

Scheme 38 Symmetric aminoalkylation of 2,7-naphthalenediol.

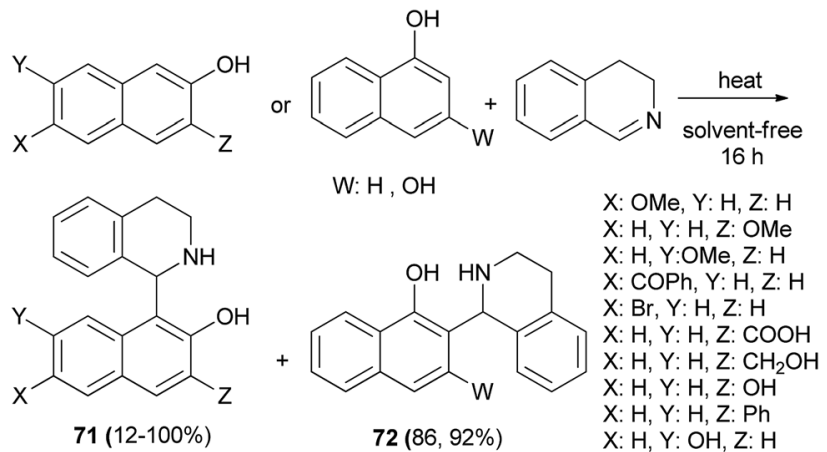

Scheme 39 Synthesis of 1-naphthoyltetrahydroisoquinolines 71 and 72.

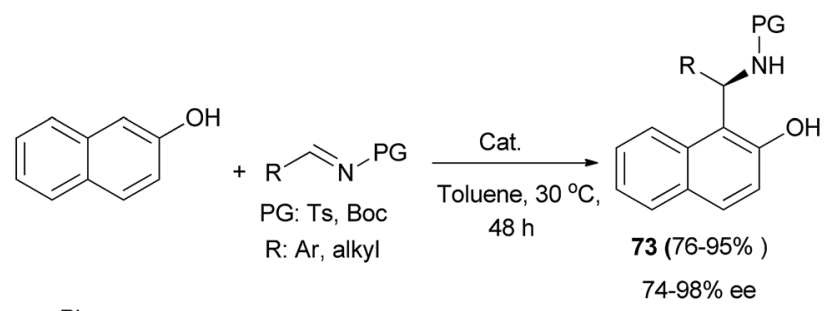

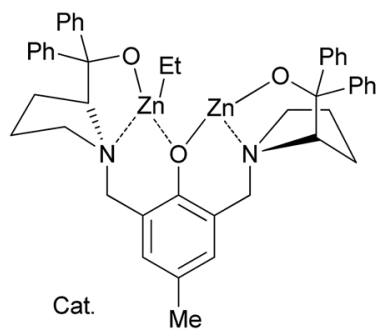

Scheme 40 Asymmetric synthesis of Betti base derivatives 73 .

Betti base 32 was then obtained by simultaneously cleaving the $\mathrm{C}-\mathrm{Bt}$ bond and $\mathrm{C}-\mathrm{O}$ bond in the structure of 34 via $\mathrm{LiAlH}_{4}$ (Scheme 18). ${ }^{27}$

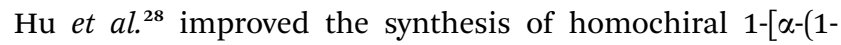
azacycloalkyl)benzyl]-2-naphthols 35 and 1-[ $\alpha$-(2-arylpiperidyl) benzyl]-2-naphthols 36 by employing diastereomerically pure $\alpha$-benzotriazolyl-1-azacycloalka[2,1- $b][1,3]$ oxazines 37 and 38 as homochiral precursors, which were obtained by condensation 
<smiles>[R]c1cc2ccccc2cc1O</smiles>

(S)-(R) $74(40-69 \%)$

R: $\mathrm{H}, \mathrm{Ar}, \mathrm{CH}_{2} \mathrm{OH}$

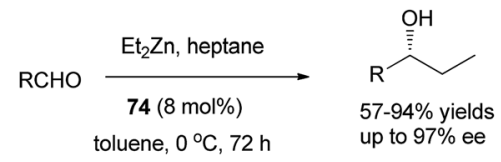

Scheme 41 Synthesis of Betti bases 74 and their use in the asymmetric addition of diethylzinc to aldehydes.<smiles>[R20]CC(/C=C(C)/C=C/C(=O)C(C)CC(CC=O)C(O)C(C)C(C)CC(=O)OC(CC)C(C)O)C(C)O</smiles><smiles>NC(c1cccc(Br)c1)c1c(O)ccc2ccccc12</smiles>

$\mathrm{HCOOH}, \mathrm{EtOH}$ r. t., $24 \mathrm{~h}$

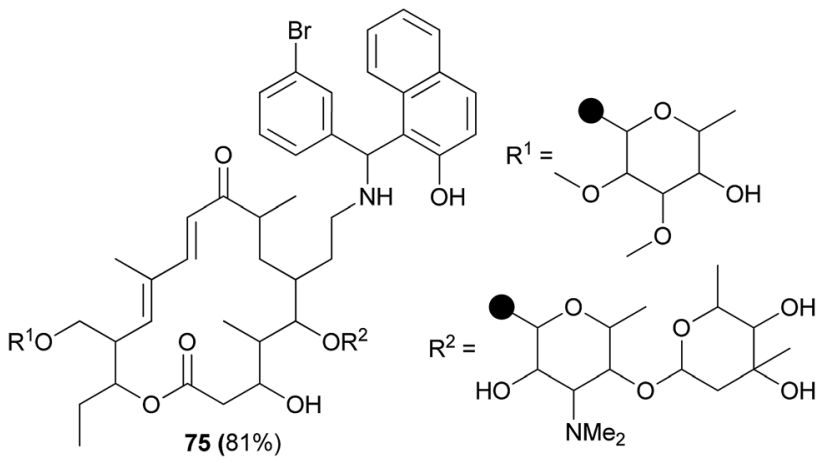

Scheme 42 Synthesis of Betti base derivatives of tylosin (75).

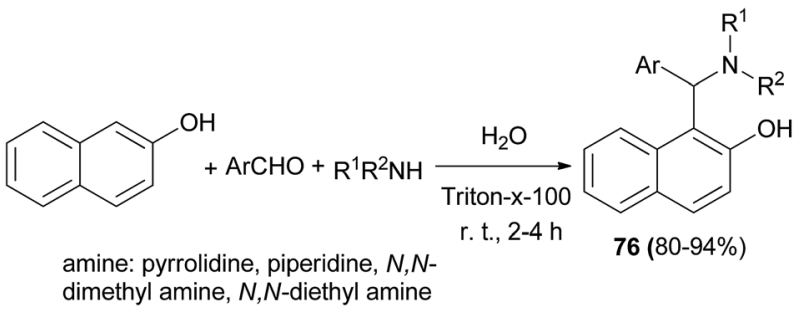

Scheme 43 Non-ionic surfactant-catalyzed synthesis of Betti bases 76 in water.

between nonracemic Betti base and dialdehydes in the presence of benzotriazole. Reduction of oxazines 37 with $\mathrm{LiAlH}_{4}$ afforded chiral ligands 35 in yields of 89-94\%. Moreover, oxazines 38 can be arylated with $\mathrm{ArMgBr}$, followed by reduction with $\mathrm{LiAlH}_{4}$ to

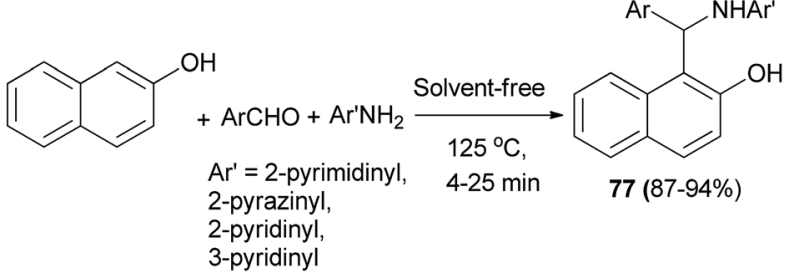

Scheme 44 Synthesis of $N$-heteroarylaminonaphthols 77.<smiles>Oc1ccc2ccccc2c1</smiles>

Scheme 45 Synthesis of racemic 2-naphthol Mannich bases 78.

give a group of potential chiral ligands 36 in $84-92 \%$ yield (Scheme 19).

The aminonaphthols 39a-c were obtained in high yields (8994\%) from the reaction of oxazines $40 a-c$ with $\mathrm{LiAlH}_{4}$ within half hour at -5 to $0{ }^{\circ} \mathrm{C}$. Also, by using compound $40 \mathrm{~b}$ as a model, the arylation at its $\alpha$-position was carried out by treating it with $\mathrm{ArMgBr}$ at -5 to $0{ }^{\circ} \mathrm{C}$ to give a series of diastereopure compounds 41 after $2-3 \mathrm{~h}$ in $73-85 \%$ yields. Reductions of 41 via $\mathrm{LiAlH}_{4}$ at $0{ }^{\circ} \mathrm{C}$ within $0.5 \mathrm{~h}$ yielded a group of highly hindered 1,3-aminophenols (42) in $84-92 \%$ yields, which could serve as potential chiral ligands in catalytic asymmetric reactions (Scheme 20). ${ }^{29}$

$\mathrm{Wu}$ et al. ${ }^{30}$ introduced a fluorescent chemosensor (43) containing aminonaphthol, which selectively recognizes fluoride anions with high sensitivity. A fluoride anion can strongly interact with a hydrogen-donating group such as hydroxyl or amide through hydrogen bonding interaction to form $\mathrm{HF}$. Aminonaphthol 43 was synthesized from the reaction of 2naphthol and 4-aminoantipyrine in ethanol at reflux for $4 \mathrm{~h}$. Then reduction with $\mathrm{NaBH}_{4}$ in EtOH afforded the desired product after $4 \mathrm{~h}$ in $80 \%$ yield (Scheme 21 ).

Chiral tertiary aminonaphthol ligand $\mathbf{4 4}$ was synthesized via the condensation of 1-naphthaldehyde, (S)-(-)-N,R-dimethylbenzylamine and 2-naphthol in the absence of solvent at $85{ }^{\circ} \mathrm{C}$ for $72 \mathrm{~h}$ in $51 \%$ yield. It served as a highly efficient ligand for the asymmetric catalytic phenyl transfer to aromatic aldehydes and a variety of chiral diarylmethanols was prepared in toluene at $-15{ }^{\circ} \mathrm{C}$ for $15 \mathrm{~h}$ with high ee values (ee up to $99 \%$ ) and in $87-95 \%$ yields (Scheme 22). ${ }^{31}$

Total syntheses of enantiopure alkaloidal natural products $(2 S, 6 R)$-dihydropinidine (as hydrochloride) and $(2 S, 6 R)$-isosolenopsins (as hydrochlorides) (45) were achieved in four steps and in $80-82 \%$ total yields by using a synthetic strategy involving the formation and cleavage of 1,3-oxazinane. $(S)$-Betti base proved to be an excellent chiral auxiliary and a novel Pd/C- 


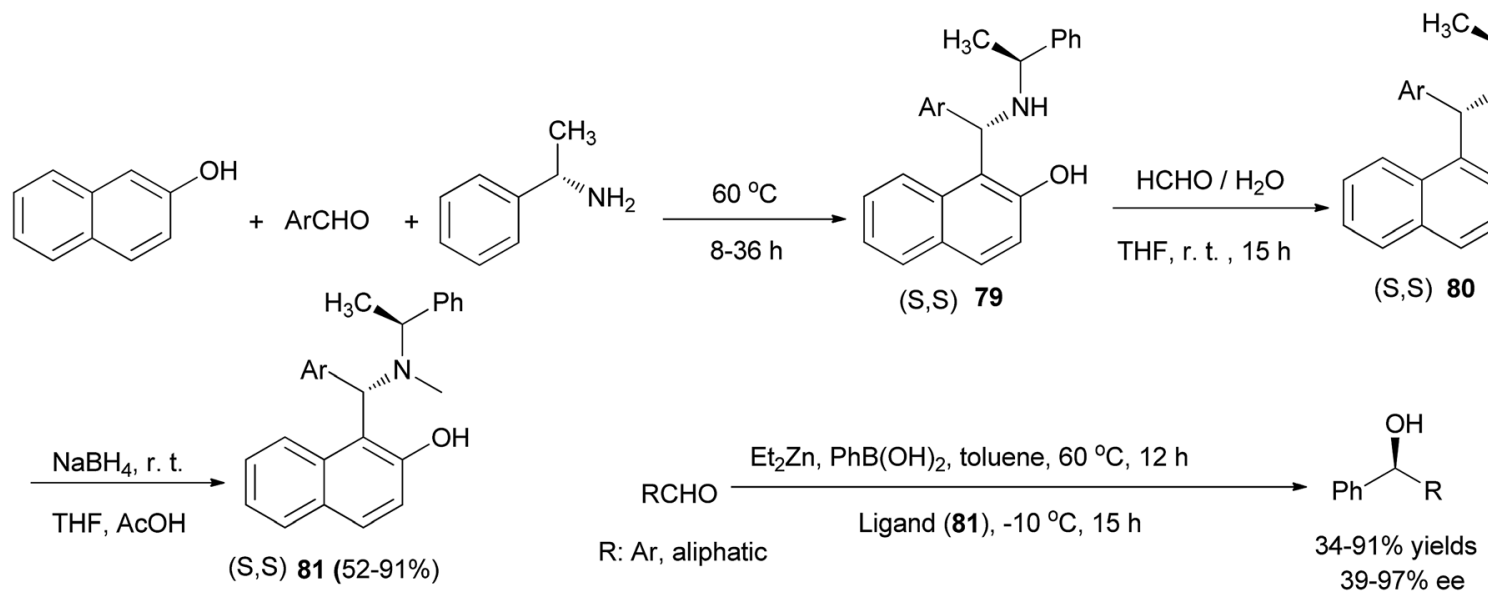

Scheme 46 The preparation of chiral aminonaphthol ligands 79 and 81 .

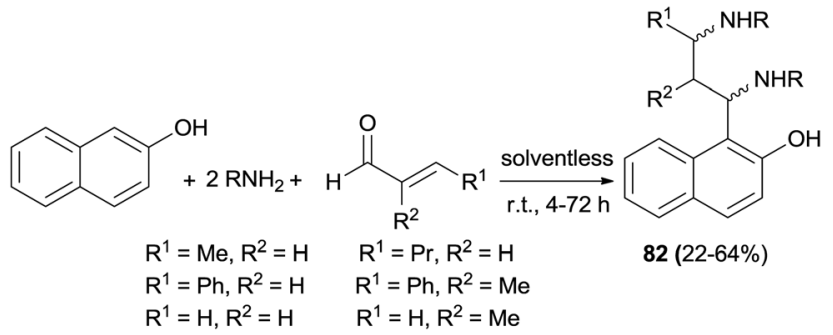

Scheme 47 Stereoselective synthesis of vicinal diaminoalkylnaphthols 82.

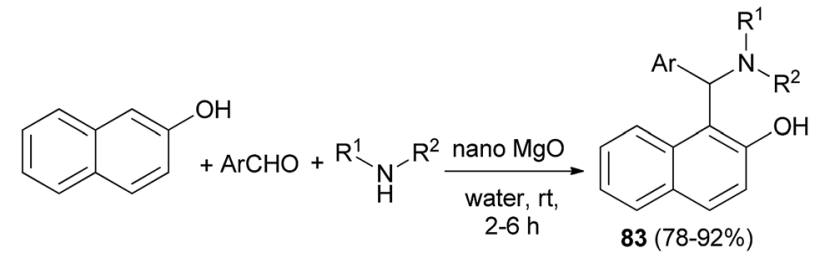

Scheme 48 Synthesis of Betti bases 83 over nanocrystalline $\mathrm{MgO}$ catalyst.

catalyzed $\mathrm{N}$-debenzylation straightforwardly to amine hydrochloride in the presence of $\mathrm{CH}_{2} \mathrm{Cl}_{2}$ was developed (Scheme 23). ${ }^{32}$

Optically active aminonaphthol derivatives 46 were obtained by condensation of 2-naphthol, substituted benzaldehyde, and $(S)$-methylbenzylamine in THF at $73{ }^{\circ} \mathrm{C}$ for $17-18 \mathrm{~h}$ under an argon atmosphere in $48-81 \%$ yields. The addition of diethylzinc to aromatic aldehydes was considerably accelerated by the presence of a catalytic amount of crystalline 46 in toluene at room temperature for $24 \mathrm{~h}$ to give, after hydrolysis, the corresponding 1-phenylpropanol in good enantiomeric purity (up to $>99 \%$ ee) and $80-92 \%$ yields (Scheme 24$){ }^{33}$

Solvent-free synthesis of 1 - $(\alpha$ - or $\beta$-hydroxynaphthyl)1,2,3,4-tetrahydroisoquinolines 47 and 48 has been described by Fulop et al. ${ }^{34}$ via nucleophilic addition of 1- or 2naphthol to 3,4-dihydroisoquinolines in MeCN at room temperature for 10-14 days under solvent-free conditions or using microwave irradiation at $70-90{ }^{\circ} \mathrm{C}$ within $40-60 \mathrm{~min}$. The reactions yielded the corresponding products in $35-85 \%$ yields (Scheme 25).

A self-catalytic aza-Friedel-Crafts method was employed to generate various chiral 1-naphtholyl tetrahydroisoquinoline products (THIQNOL) 49 from 3,4-dihydroisoquinoline and naphthols at 60 and $90{ }^{\circ} \mathrm{C}$ under neat conditions after $16 \mathrm{~h}$ (Scheme 26). A marked electronic effect was observed in the reaction: 2-naphthols with electron-donating substituents gave excellent yields (62-97\%), whereas 2-naphthols with electron-withdrawing substituents gave lower yields (12-54\%). A method was developed to resolve the two enantiomers of a THIQNOL derivative. The enantiomerically pure derivative showed moderate catalytic activity in the asymmetric diethylzinc addition to aldehydes and afforded, enantioselectively, 1-propanol derivatives (up to $70 \%$ ee) in heptane-toluene at $0{ }^{\circ} \mathrm{C}$ within $72 \mathrm{~h}$ in $55-85 \%$ yields. ${ }^{35}$

2 '-Aminobenzothiazolomethylnaphthols or 5 - $\left(2^{\prime}\right.$ aminobenzothiazolomethyl)-6-hydroxyquinolines $\mathbf{5 0}$ could also be achieved in $88-96 \%$ yields by warming aldehydes and 2-aminobenzothiazole with 2-naphthol or 6-hydroxyquinoline in water containing $\mathrm{LiCl}$ as ionic solute for the increasing hydrophobic effect of water at $90{ }^{\circ} \mathrm{C}$ after $5-7 \mathrm{~h}$ (Scheme 27). When the reaction was carried out in the absence of $\mathrm{LiCl}$, a decreased yield (12-16\%) was obtained. ${ }^{36}$

In 2007, Alfonsov et al. ${ }^{37}$ reported a new approach to the synthesis of benzylidene derivatives of 1-( $\alpha$-aminobenzyl)-2naphthols (Betti bases) 51, by reaction of 2-naphthol with 1,3,5-triaryl-2,4-diazapenta-1,4-dienes (3:2) 52 in refluxing benzene for $5-17 \mathrm{~h}$. This method provides desired products in high yields (70-96\%) and purity, facilitating subsequent separation into the individual enantiomers (Scheme 28).

Palmieri et $a l .^{38}$ introduced a short and stereoselective synthesis of vicinal aminodiols, diamines and diaminols in good yields, through a three-component aromatic Mannichtype reaction. Initially, the reaction of 2-naphthol, enantiopure aldehydes containing stereogenic centres and amines at room temperature in solventless conditions for $12-36 \mathrm{~h}$ 
<smiles>CC(C)(C)OC(=O)NC(c1ccccc1[N+](=O)[O-])c1c(O)ccc2ccccc12</smiles>

$84(53 \%)$<smiles>CC(C)(C)[N+](=O)c1cccc(C=O)c1[N+](=O)[O-]</smiles>

$80^{\circ} \mathrm{C}, 47 \mathrm{~h}$<smiles>Oc1ccc2ccccc2c1</smiles>

$80^{\circ} \mathrm{C}, 32 \mathrm{~h}$<smiles>N[14C](=O)[O-]</smiles><smiles>O=C(O)NC(c1ccccc1[N+](=O)[O-])c1c(O)ccc2ccccc12</smiles>

$87(76 \%)$

1. TFA, r. t., $10 \mathrm{~min}$ 2. $\mathrm{Na}_{2} \mathrm{CO}_{3}$<smiles>NC(c1ccccc1[N+](=O)[O-])c1c(O)ccc2ccccc12</smiles>

$5(90 \%)$
$1.5 \mathrm{~h}$

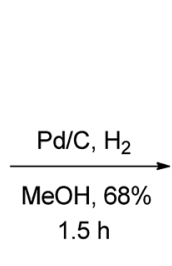<smiles>Nc1ccccc1C(N)c1c(O)ccc2ccccc12</smiles>

86

$\mathrm{Pd} / \mathrm{C}, \mathrm{H}_{2}$

$\mathrm{MeOH}, 69 \%$

$2 \mathrm{~h}$

Scheme 49 Synthesis of 1-(amino(2-aminophenyl)methyl)-2-naphthol 87.

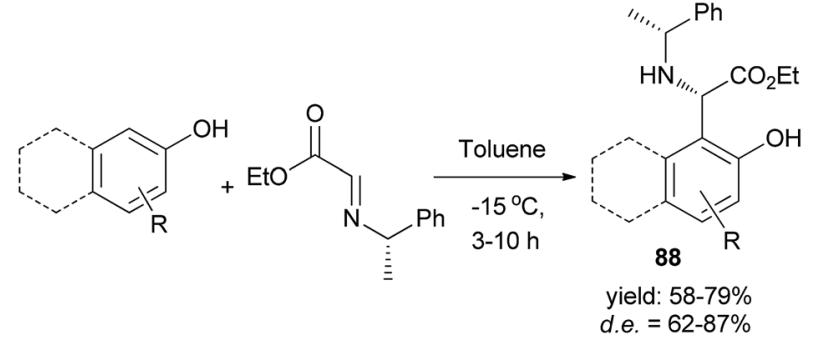

Scheme 50 Spontaneous asymmetric synthesis of non-natural hydroxyaryl glycinates 88 .

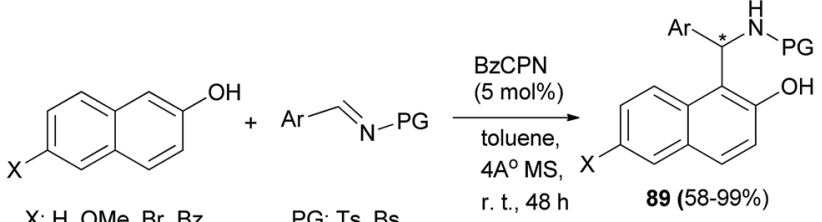
$99.5: 0.5 \mathrm{er}$

Scheme 51 BzCPN-catalyzed asymmetric synthesis of aza-FriedelCrafts products 89

afforded a mixture of two diastereomers of aminoalkylnaphthols 52 in $8-62 \%$ yields. Then, the obtained aminoalkylnaphthols 52 were subjected to acid hydrolysis ( $\mathrm{HCl}$

$$
\begin{aligned}
& \mathrm{Ar}-\mathrm{OH}+\underbrace{\mathrm{R}^{1}-\mathrm{R}^{2}=-\left(\mathrm{CH}_{2}\right)_{3^{-}}}_{\mathrm{R}^{2}} \\
& \mathrm{R}^{1}-\mathrm{R}^{2}=-\left(\mathrm{CH}_{2}\right)_{4^{-}} \\
& \mathrm{R}^{1}-\mathrm{R}^{2}:
\end{aligned}
$$

Scheme 52 Synthesis of aminocycloalkylnaphthols 90 and 91

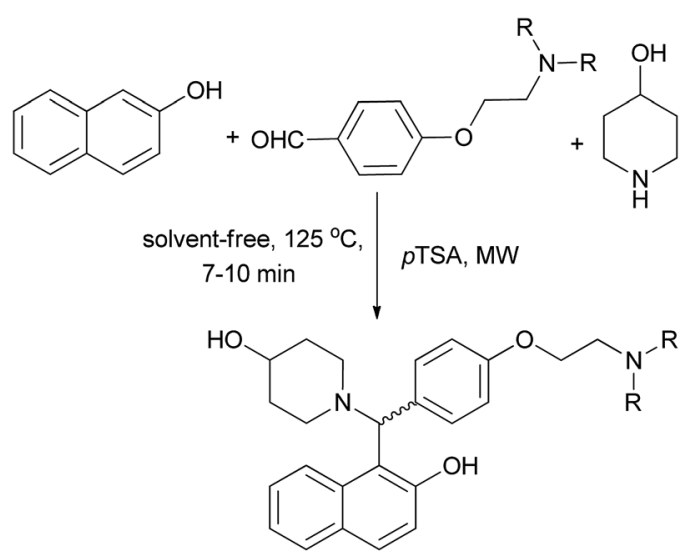

$92(38-47 \%)$

$-\mathrm{NR}_{2}: \mathrm{NMe}_{2}, \mathrm{NEt}_{2}, \mathrm{~N}^{\mathrm{P} P \mathrm{P}_{2}}$, pyrrolidinyl, piperidinyl, morpholinyl, 4-Me-piperidinyl, homopiperidinyl

Scheme 53 Synthesis of racemic Betti bases 92.

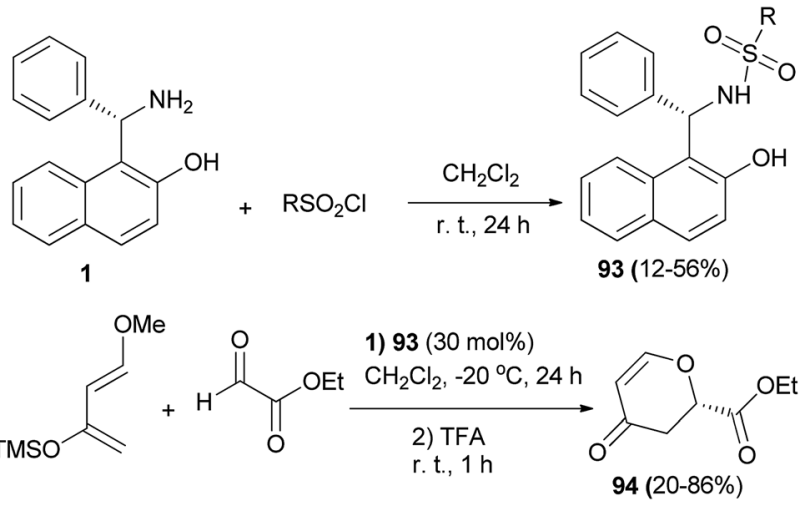

Scheme 54 Sulfonamide 93-catalyzed asymmetric hetero-DielsAlder reaction of ethyl glyoxylate with Danishefsky's diene. 


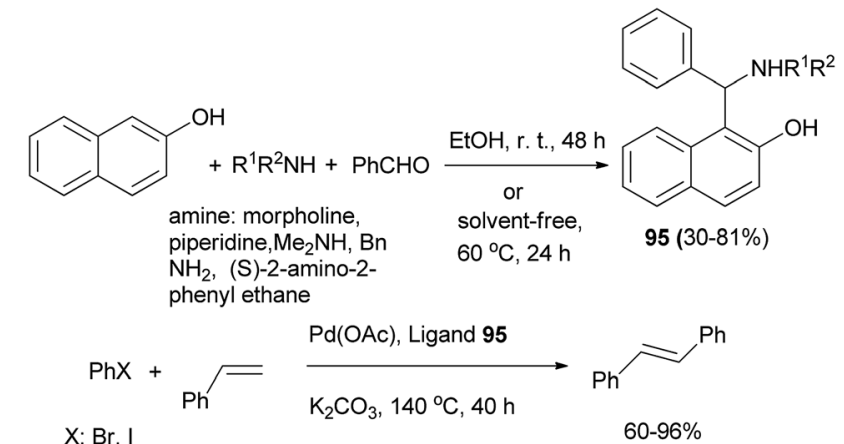

Scheme 55 Pd-catalyzed Mizoroki-Heck reaction with Betti bases 95

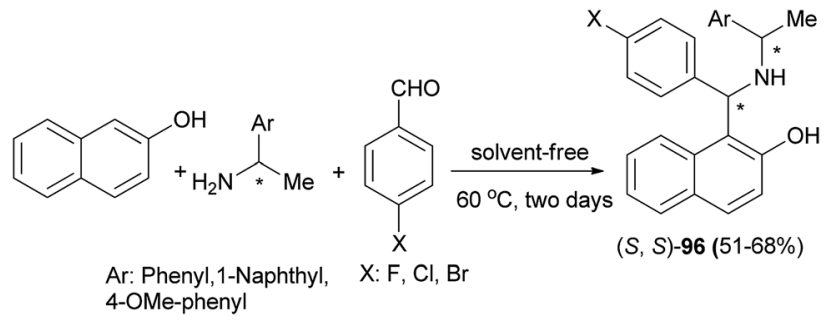

Scheme 56 Stereoselective Betti reaction between 2-naphthol, arylaldehydes and (R)- or (S)-1-arylethylamine.

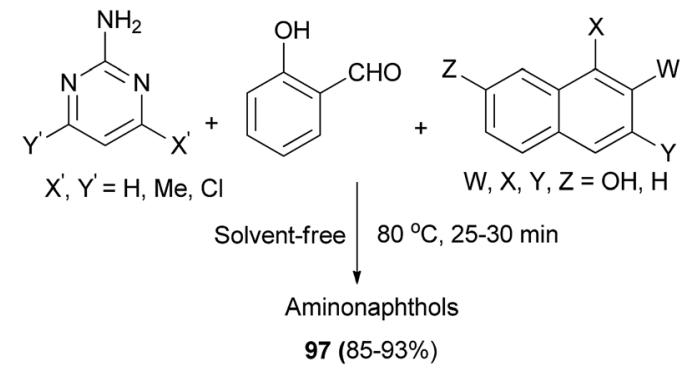

Scheme 57 Green synthesis of aminonaphthols 97.

aq./THF) under reflux conditions for $2 \mathrm{~h}$, to deprotect amino and hydroxyl groups in aldehydes resulting in enantiopure aminoalkylnaphthols 53 in $40-95 \%$ yields (Scheme 29).

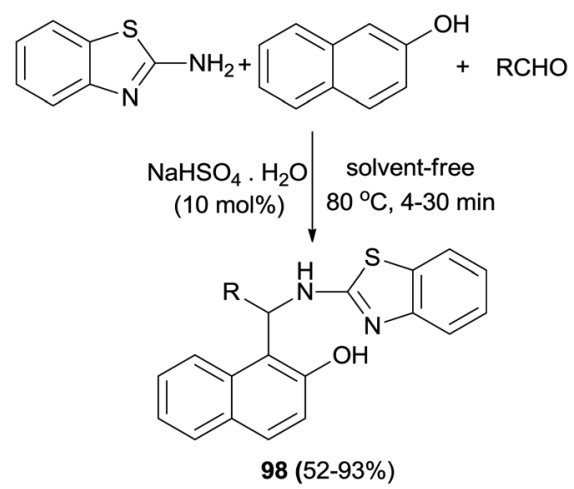

$\mathrm{R}=$ aromatic, aliphatic, heterocyclic ring

Scheme 58 Synthesis of 1-(benzothiazolylamino)methyl-2-naphthols 98 catalyzed by $\mathrm{NaHSO}_{4} \cdot \mathrm{H}_{2} \mathrm{O}$.

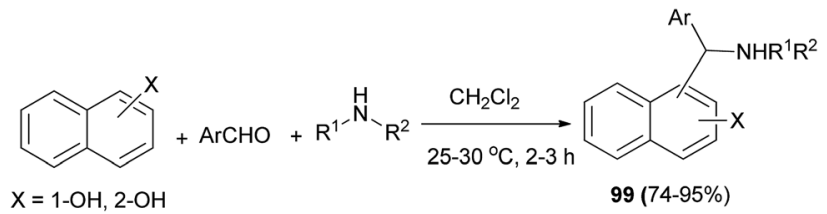

Scheme 59 Synthesis of aminoalkylnaphthols 99 at room temperature in $\mathrm{CH}_{2} \mathrm{Cl}_{2}$.

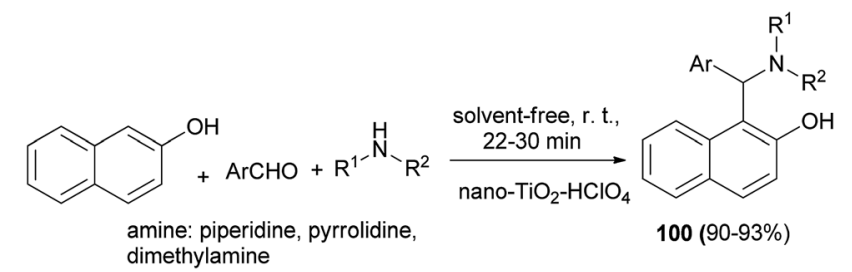

Scheme 60 Nanocrystalline $\mathrm{TiO}_{2}-\mathrm{HClO}_{4}$-catalyzed synthesis of 1-( $\alpha$ aminoalkyl)-2-naphthols 100

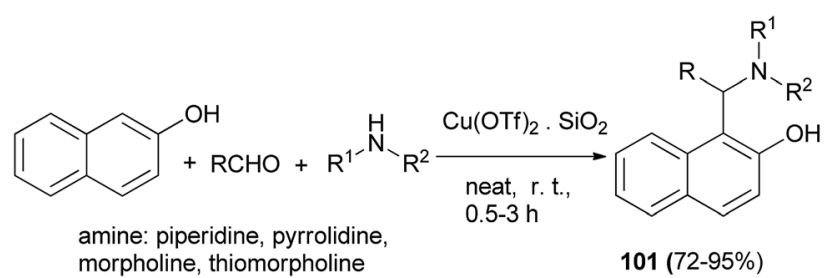

Scheme 61 Supported copper triflate-catalyzed synthesis of Betti bases 101 .

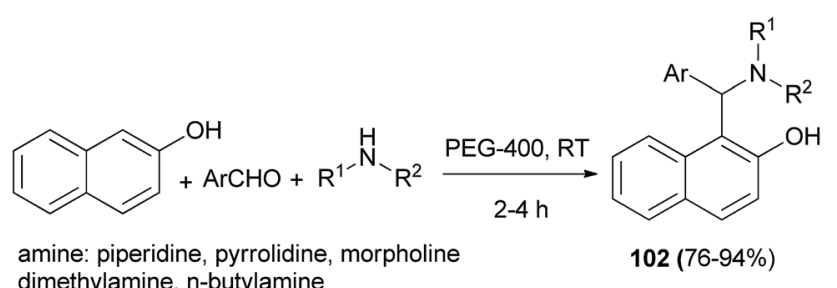
dimethylamine, $n$-butylamine

Scheme 62 Catalyst-free synthesis of Betti bases 102 in PEG-400.

Fulop et al. ${ }^{39}$ achieved optically active aminonaphthols $\mathbf{5 4}$ and 55 by condensation of 2-naphthol, benzaldehyde and $(R)$ $(+)-1-(1-n a p h t h y l) e t h y l a m i n e \quad$ or $\quad(R)-(+)-1-(2-n a p h t h y l) e t h y l-$ amine at $65^{\circ} \mathrm{C}$ within $72 \mathrm{~h}$ under solvent-free conditions. Then, the reaction of aminonaphthols 54 and 55 with paraformaldehyde in toluene at room temperature for 10 and $12 \mathrm{~h}$ afforded naphthoxazines 56 and 57, respectively. Naphthoxazines were reduced to chiral aminonaphthols 58 and 59 in THF at room temperature in 4 and $6 \mathrm{~h}$ by $\mathrm{LiAlH}_{4}$ (Scheme 30).

Ghandi et $a .^{40}$ described the reaction of 2-naphthol, aromatic aldehyde, and heteroarylamine in water at room temperature for 25-65 min, furnishing the 1(aryl(heteroarylamino)methyl)naphthalene-2-ols 60 in 95-98\% yields for the first time (Scheme 31). 
<smiles>[NH3+]C(c1ccccc1)c1c(O)ccc2ccccc12</smiles><smiles>[R]N[C@H](c1ccccc1)c1c(O)ccc2ccccc12</smiles>

THF

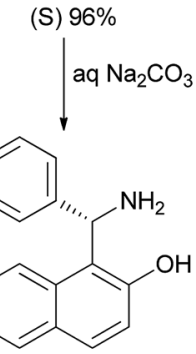

(S) $103 a(95 \%)$ $99 \%$ ee water as solvents under microwave conditions in modified three-component Mannich reactions. Depending on the solid ammonia source, the yields of the desired products obtained were 68-92\% (Scheme 32). solid ammonia sources to prepare different (aminoalkyl)naphthols 61 and 62 and (aminoalkyl)quinolinols 63 in ethanol and

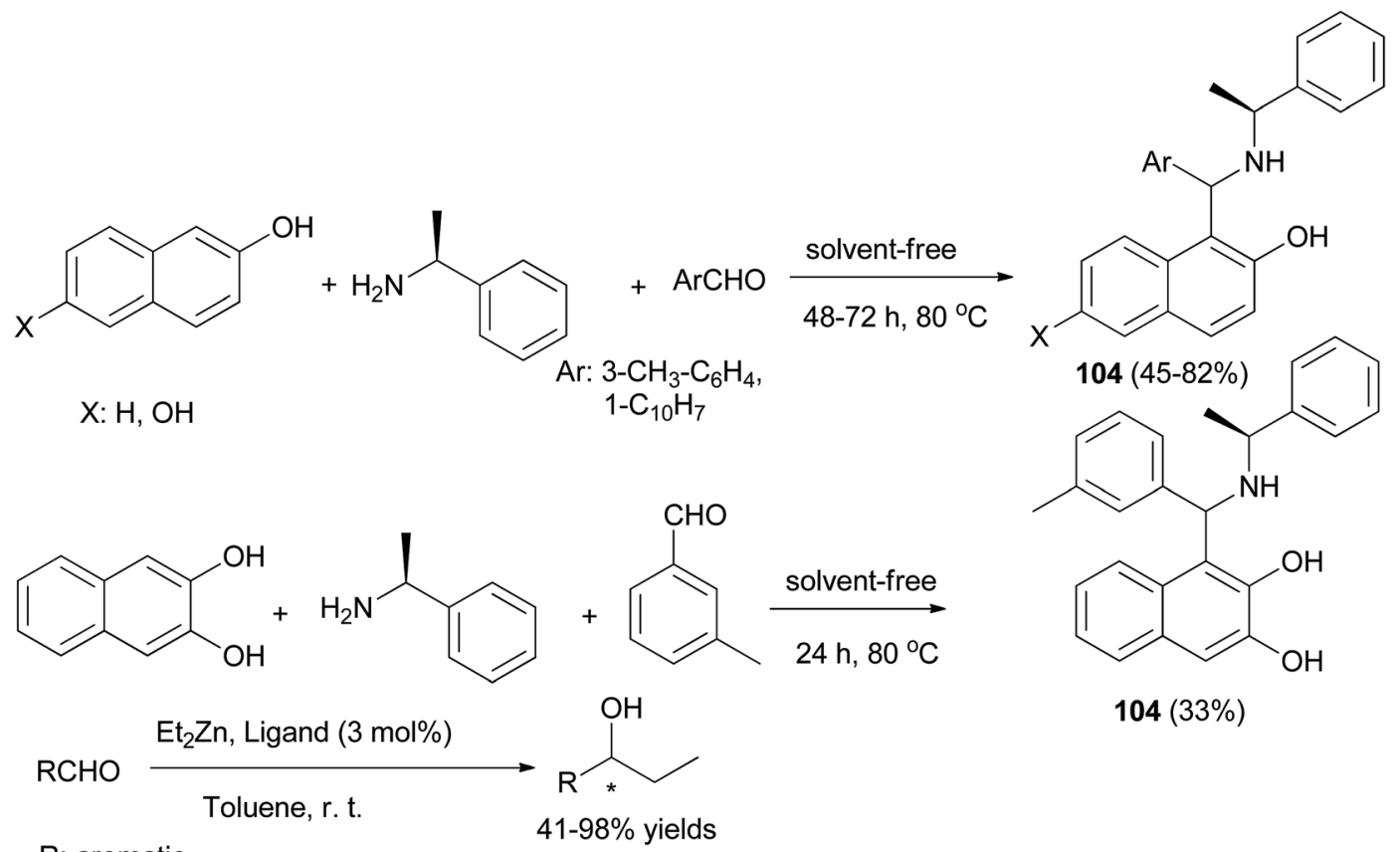

R: aromatic, aliphatic
$41-98 \%$ yields

$13-98 \%$ ee

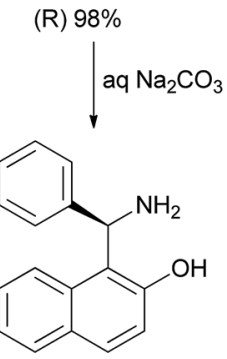

(R) $103 \mathrm{~b}(90 \%)$

Scheme 63 Resolution of Betti bases 103 by $(R)-1,1^{\prime}$-binaphthalene-2,2' -diyl sodium phosphate.

Also, Fulop et al. ${ }^{41}$ reported that ammonium carbamate and 


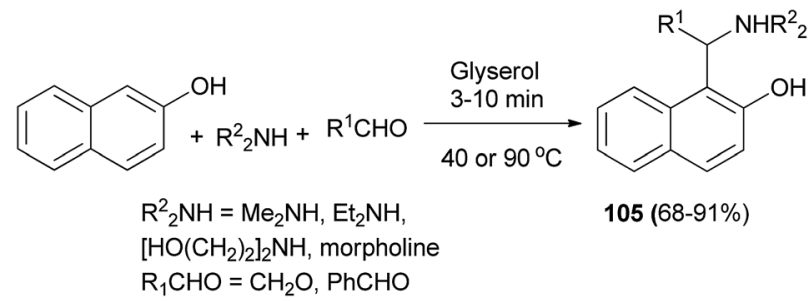

Scheme 65 Betti reaction in glycerol.<smiles>[X]c1ccc2ccccc2c1[X]</smiles>

$\mathrm{X}: \mathrm{H}, \mathrm{Y}: \mathrm{OH}$ $\mathrm{X}: \mathrm{OH}, \mathrm{Y}: \mathrm{H}$ [omim] $\left[\mathrm{BF}_{4}\right] \downarrow$ r. t., 1-6 h<smiles>[R2]NCc1c(O)ccc2ccccc12</smiles>

$106(70-99 \%)$<smiles>[R][X]c1ccc2ccccc2c1O</smiles>

$107(54-60 \%)$
Scheme 66 Aminomethylation of naphthols in the presence of [omim] $\left[\mathrm{BF}_{4}\right]$ ionic liquids.

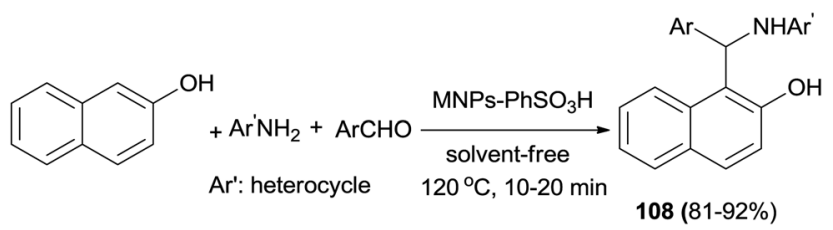

Scheme 67 MNPs-PhSO ${ }_{3} \mathrm{H}$-catalyzed synthesis of 1-aminoalkyl-2naphthols 108 .

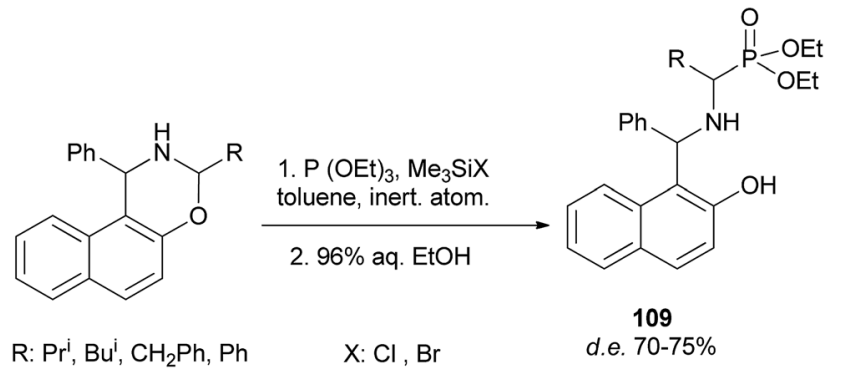

Scheme 68 Diastereoselective synthesis of $\alpha$-aminoalkylphosphonic acid derivatives 109 .

The reaction of 2-naphthol, 3-aminopyridine, and aromatic aldehydes in water at $50{ }^{\circ} \mathrm{C}$ afforded a number of $N$-heteroarylaminonaphthols 64 after 5-55 $\mathrm{min}$ in 91-97\% yields (Scheme 33). ${ }^{42}$

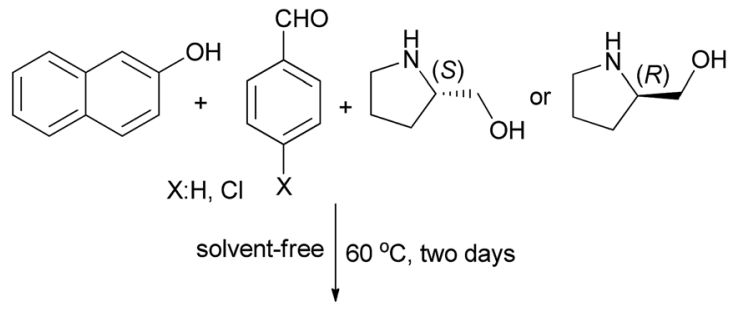<smiles>[X]c1ccc(C(c2c(O)ccc3ccccc23)N2CCC[C@H]2CO)cc1</smiles>

$(S, S)-110(36-37 \%)$<smiles>[X]c1ccc(C(c2c(O)ccc3ccccc23)N2CCC[C@H]2CO)cc1</smiles>

$(R, R)-111(36-37 \%)$
Scheme 69 Synthesis of aminobenzylnaphthols 110 and 111.<smiles>[R]C1NC(c2ccccc2)c2c(ccc3ccccc23)O1</smiles>

2) $96 \%$ aq. EtOH<smiles>[R]C(NC(c1ccccc1)c1c(O)ccc2ccccc12)P(=O)(OCC)OCC</smiles>

112

d.e. up to $75 \%$

Scheme 70 Diastereoselective synthesis of $\alpha$-aminoalkylphosphonic acid derivatives of Betti base 112
Scheme 71 Synthesis of 4-aminoantipyrine derivatives 113 derived from Betti-type reaction.<smiles>[R]C(=O)c1c(O)ccc2ccccc12</smiles>

$\mathrm{R}: \mathrm{H}, \mathrm{Ar}$ $n=1,2$

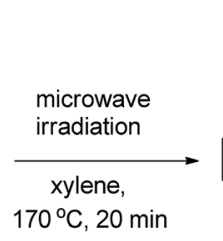<smiles>[R]C(c1c(O)ccc2ccccc12)N1CCCC1</smiles>

$114(60-74 \%)$
Scheme 72 Synthesis of Betti bases 114. 


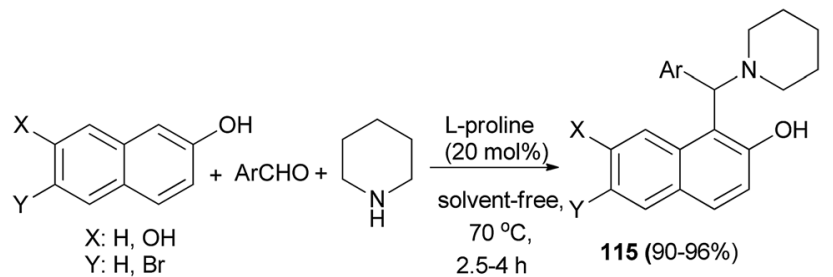

Scheme 73 L-Proline-catalyzed synthesis of Betti bases 115.

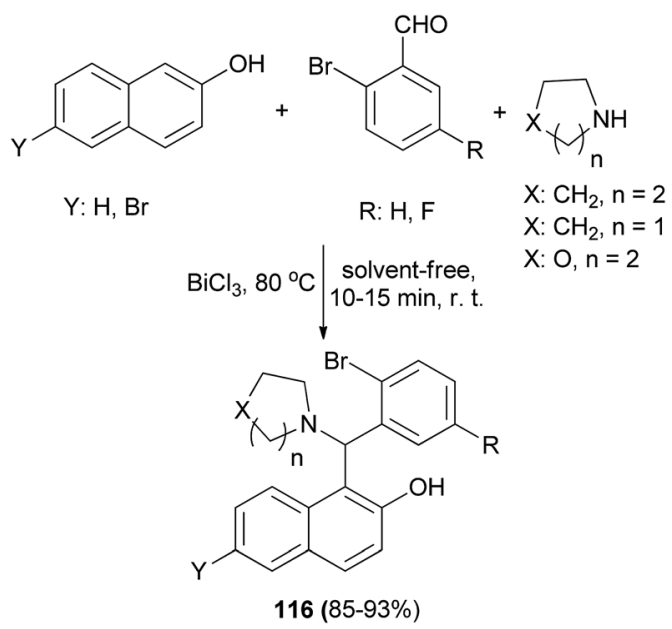

Scheme $74 \mathrm{BiCl}_{3}$-catalyzed synthesis of Betti bases 116<smiles>Nc1nc2ccccc2s1</smiles>

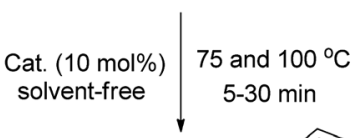<smiles>Oc1ccc2ccccc2c1C([Al])Nc1nc2ccccc2s1</smiles>

Scheme 75 Synthesis of 1-(benzothiazolylamino)methyl-2-naphthols 117 catalyzed by $\left[\left(\mathrm{CH}_{2}\right)_{3} \mathrm{SO}_{3} \mathrm{HMIM}\right]\left[\mathrm{HSO}_{4}\right]$.

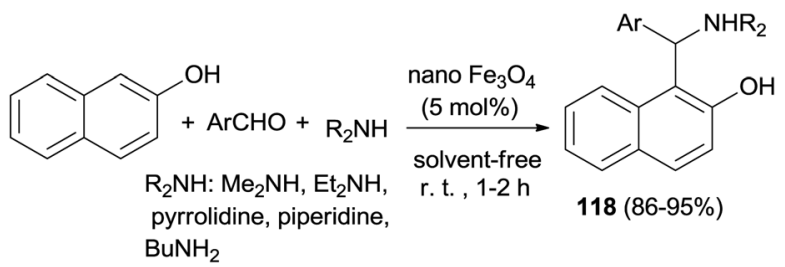

Scheme 76 Synthesis of Betti bases 118, catalyzed by nano $\mathrm{Fe}_{3} \mathrm{O}_{4}$ at room temperature.
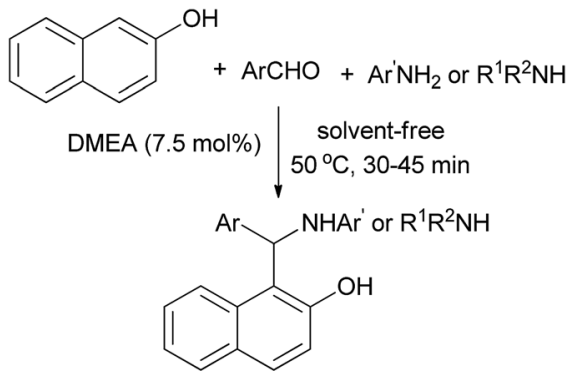

$119(83-95 \%)$

amine: morpholine, piperidine, aromatic and heteroaromatic amine

Scheme 77 Synthesis of arylaminonaphthols 119 using DMEA under solvent-free conditions.

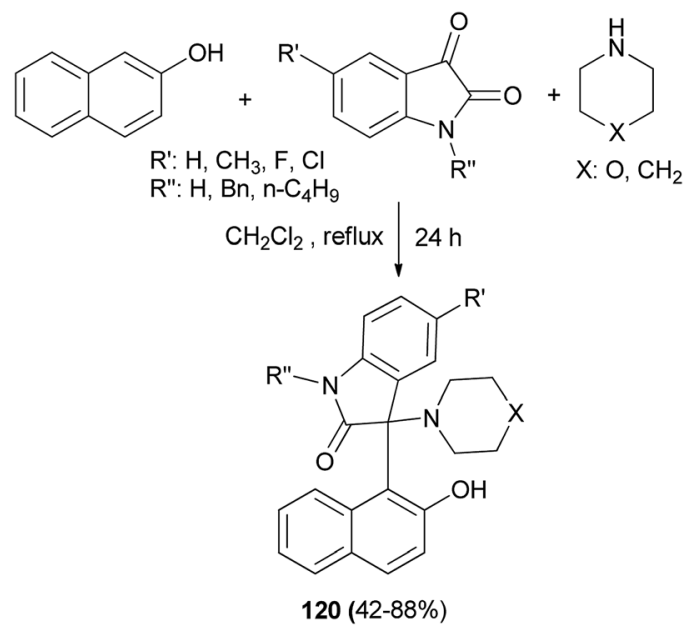

Scheme 78 Synthesis of Betti bases 120 via three-component reaction of 2-naphthol, cyclic amines and isatins.

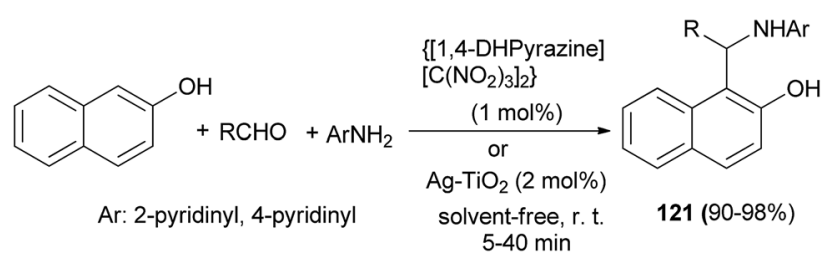

Scheme 79 Synthesis of 1-( $\alpha$-aminoalkyl)-2-naphthols 121.

Palmieri et al. ${ }^{43}$ demonstrated that 1-(aminoalkyl)naphthols 65 can be used as ligands in the nickel-catalyzed enantioselective addition of organozinc to chalcones in $\mathrm{CH}_{3} \mathrm{CN}$ at $-30{ }^{\circ} \mathrm{C}$ to room temperature for $4 \mathrm{~h}$ and afforded the corresponding products 66 in 15-99\% yields and 14-64\% ee (Scheme 34).

Kumar et al. ${ }^{\mathbf{4 4}}$ succeeded in the preparation of Betti bases 67 from secondary amine, aromatic aldehydes and 2-naphthol using a non-ionic surfactant (Triton X-100, 5 mol\%) at room temperature. All the aromatic aldehydes reacted almost equally well to afford Betti bases after 2-4.5 h in excellent yields (8094\%) (Scheme 35). 
<smiles>[R1]c1ccc(C(C)N)cc1</smiles>

Scheme 80 Synthesis of Betti base derivatives 122

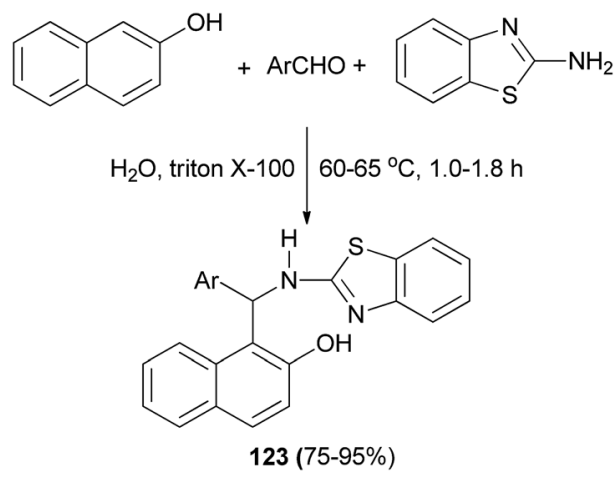

Scheme 81 Triton X-100-catalyzed synthesis of 2-aminobenzothiazolomethylnaphthol derivatives 123 .<smiles></smiles>

$124(52-95 \%)$

Scheme 82 Synthesis of bifunctional phosphorus Betti bases 124

Kumar et $a l .{ }^{45}$ have devoted considerable attention to a sodium dodecylsulfate (20 mol\%)-catalyzed aminoalkylation of 2-naphthols with aldehydes and 2-aminobenzothiazole in water at reflux. The corresponding products 68 were isolated after $1-5 \mathrm{~h}$ in $71-93 \%$ yields (Scheme 36 ).

A series of novel $N$-heteroaryl $\alpha$-arylglycines 69 containing naphthol rings has been prepared by one-pot, three-component

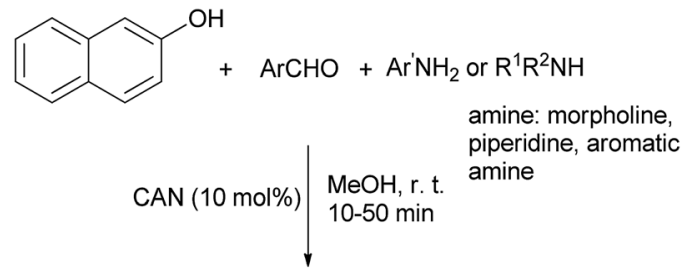<smiles></smiles>

$125(80-92 \%)$

Scheme 83 Synthesis of Betti bases 125 catalyzed by CAN.

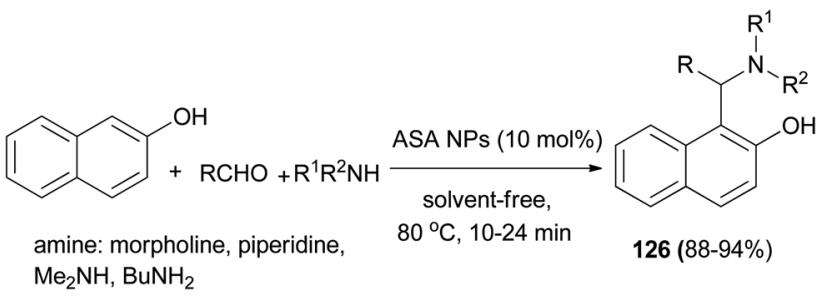

Scheme 84 Synthesis of 1-( $\alpha$-aminoalkyl)-2-naphthol derivatives 126 in the presence of ASA NPs.

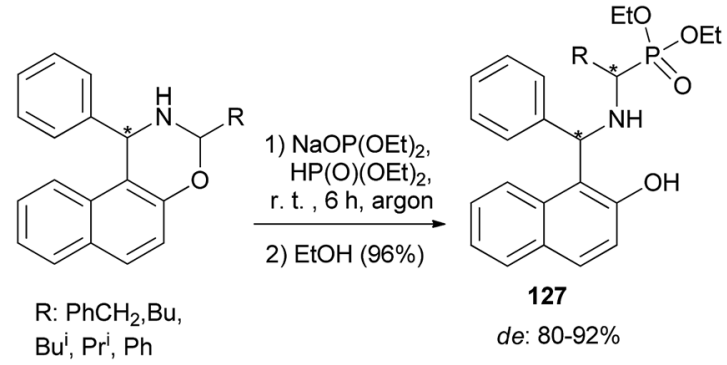

Scheme 85 Diastereoselective synthesis of $\alpha$-aminophosphonates 127.

condensation reactions of glyoxalic acid, heteroarylamines and naphthols. The reactions were performed in water at ambient temperature within 3.5-20 h which afforded desired products in $75-90 \%$ yields (Scheme 37$).{ }^{46}$ A one-pot procedure was reported by Foroughifar et al. for the preparation of 4,9-dihydroxy-1,3diaryl-2,3-dihydro-2-zaphenalenes 70 in 78-92\% yields after 8$15 \mathrm{~h}$ from aromatic aldehydes, 2,7-naphthalenediol and ammonium hydrogen phosphate $\left(\left(\mathrm{NH}_{4}\right)_{2} \mathrm{HPO}_{4}\right)$ in a mixture of ethanol-water (3:1) under reflux conditions (Scheme 38). ${ }^{47}$

A self-catalytic protocol was developed using an aza-Friedel-Crafts method to generate 1-naphthoyltetrahydroisoquinoline products 71 and 72 in $12-100 \%$ yields under solvent-free conditions. The reaction proceeded at 60, 80 and $90{ }^{\circ} \mathrm{C}$ within $16 \mathrm{~h}$ in the absence of any additional catalyst (Scheme 39). ${ }^{48}$ 


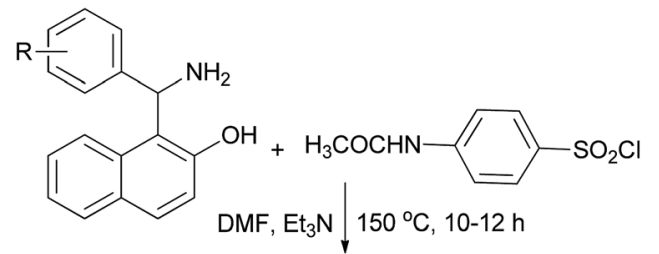<smiles>[R][R]1ccc(C(NS(=O)c2ccc(NC(C)=O)cc2)c2c(O)ccc3ccccc23)cc1</smiles>

Scheme 86 Synthesis of N-(4-(N-((2)-hydroxynaphthelen-1$\mathrm{yl}$ (phenyl)methyl)sulfamoyl)phenyl)acetamide derivatives 128<smiles>Nc1nc2ccccc2s1</smiles>

Scheme 87 Synthesis of compounds 129 catalyzed by oxalic acid.

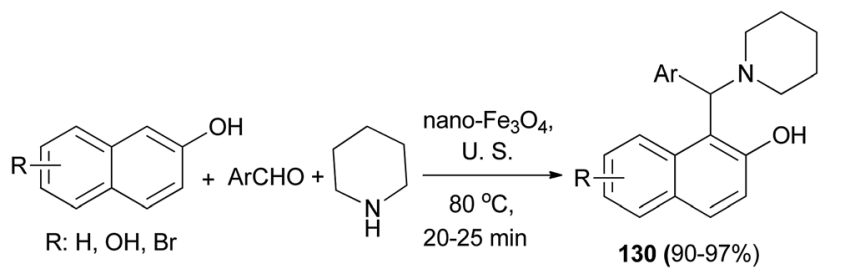

Scheme $88 \quad \mathrm{Fe}_{3} \mathrm{O}_{4}$ is an efficient and robust catalyst for the one-pot synthesis of Betti bases 130.

Hui et $a l .{ }^{49}$ have reported an asymmetric aza-FriedelCrafts reaction of 2-naphthol with tosylimines catalyzed by a dinuclear zinc complex. The expected products 73 were obtained in $76-95 \%$ yields and good to excellent enantioselectivities of $74-98 \%$ ee in toluene at $30{ }^{\circ} \mathrm{C}$ after $48 \mathrm{~h}$ (Scheme 40).

Addition of (R)-3-phenyl-3,4-dihydroisoquinoline to 2naphthols in water at $80{ }^{\circ} \mathrm{C}$ overnight led to the formation of $(S)-(R)$-1,3-disubstituted tetrahydroisoquinolines $\mathbf{7 4}$ as chiral ligands in $40-69 \%$ yields (Scheme 41$).{ }^{50}$ These chiral ligands were then used to catalyze asymmetric addition of diethylzinc to aldehydes in toluene at $0{ }^{\circ} \mathrm{C}$ for $72 \mathrm{~h}$ and the desired

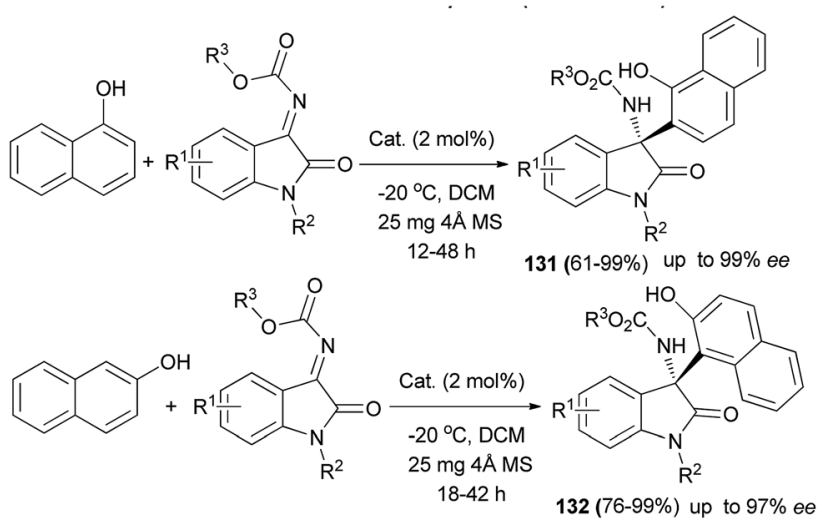

Scheme 89 Reaction scope of aza-Friedel-Crafts reaction of naphthols to isatin ketimines.

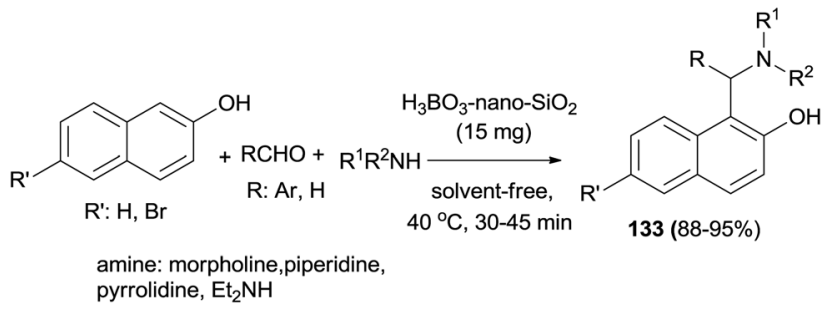

Scheme 90 One-pot synthesis of aminonaphthols 133, using nano$\mathrm{SiO}_{2}-\mathrm{H}_{3} \mathrm{BO}_{3}$ as a catalyst.

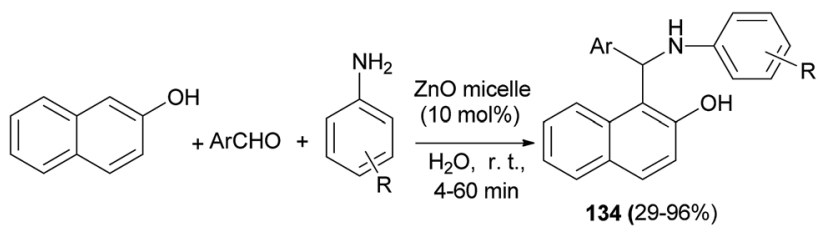

Scheme 91 Synthesis of Betti base derivatives 134 catalyzed by reverse $\mathrm{ZnO}$ nanomicelles.

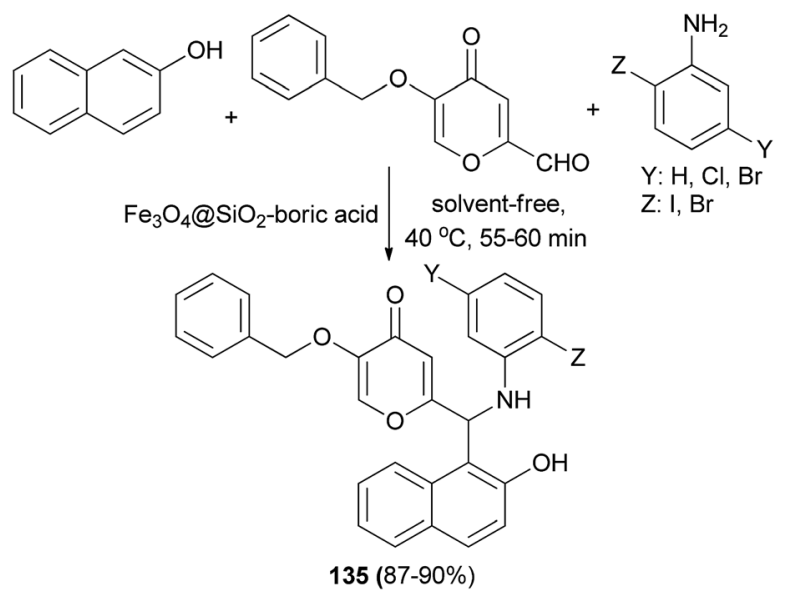

Scheme 92 Synthesis of Betti bases 135 based on kojic acid derivatives. 
<smiles>[Y]c1ccc(C=O)cc1</smiles><smiles>[X]c1ccc(C(Nc2cccc(C)n2)c2ccc3cccnc3c2O)cc1</smiles>

$136(80-98 \%)$

Scheme 93 Synthesis of Betti bases 136 by a modified Betti reaction.

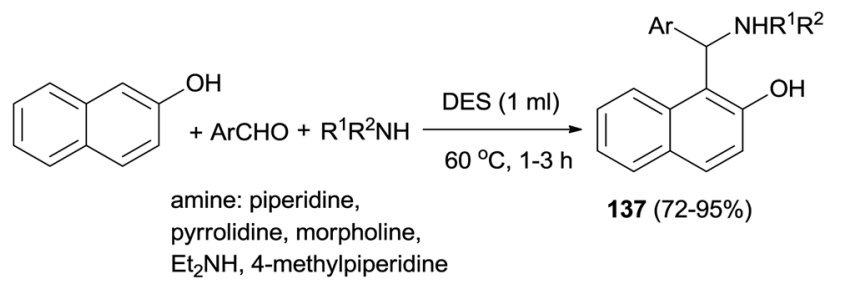

Scheme 94 Synthesis of 1-aminoalkyl-2-naphthols 137 in deep eutectic solvent (DES).

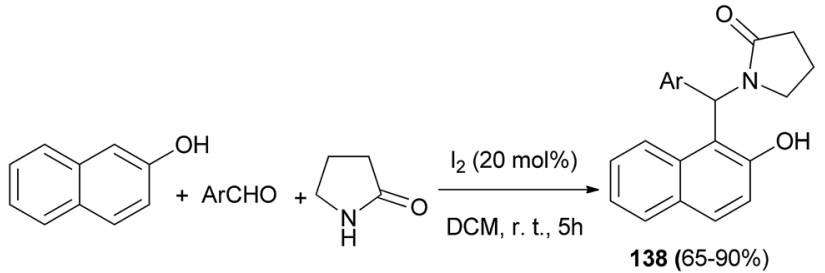

Scheme 95 lodine-catalyzed synthesis of 1-((2-hydroxynapthalen-1yl)(aryl))pyrrolidin-2-ones 138.<smiles>COc1cc(C(Nc2ccc([N+](=O)[O-])cc2)c2c(O)ccc3ccccc23)ccc1O</smiles>

Scheme 96 Synthesis of vanillin-based aminoalkylnaphthol 139.

products were achieved in 57-93\% yields with high enantioselectivities (up to $97 \%$ ee).

TBN ( $N$-tylosil-1- $\alpha$-amino(3-bromophenyl)methyl-2-naphthol; 75) was prepared from the reaction of tylosin tartrate, the Betti base 1- $\alpha$-amino(3-bromophenyl)methyl-2-naphthol and formic acid in EtOH at room temperature for $24 \mathrm{~h}$ in $81 \%$ yield (Scheme

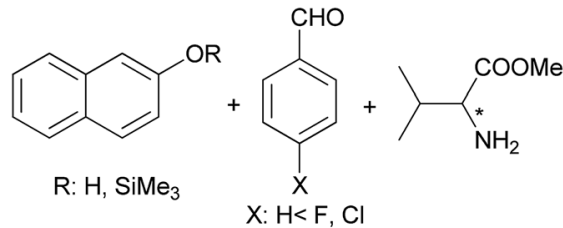

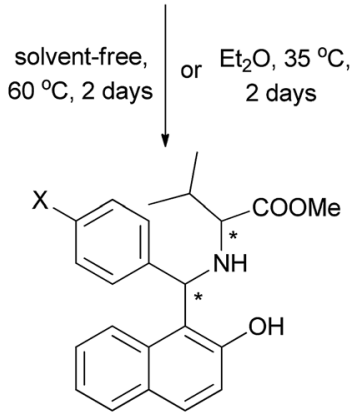

$140(35-68 \%)$

Scheme 97 Synthesis of aminobenzylnaphthol 140 bearing two stereogenic centers.

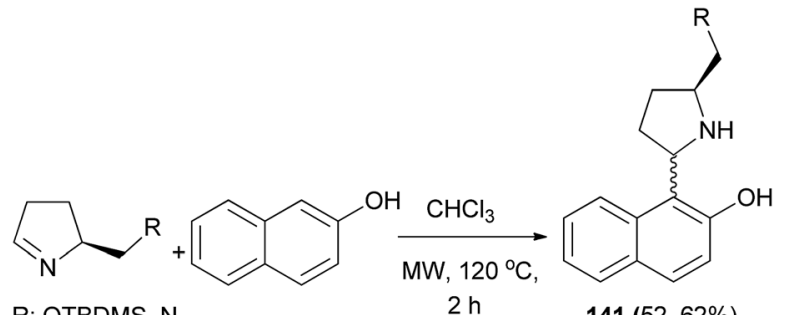

R: OTBDMS, $\mathrm{N}_{3}$

$2 \mathrm{~h}$

$141(52,62 \%)$

Scheme 98 Synthesis of Betti bases 141.

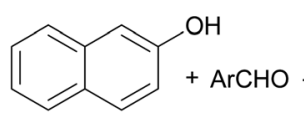

amine: piperidine,

pyrrolidine, morpholine, $\mathrm{n}$ -

$\mathrm{BuNH}_{2}$, cyclopentylamine,

isopentylamine, benzylamine<smiles>[R1]NC([Al])c1c(O)ccc2ccc([R16])cc12</smiles>

solvent-free,

$142(37-92 \%)$
Scheme 99 MK30-catalyzed synthesis of Betti bases 142.

42). Investigation of results indicated that TBN is a potent modulator of the P-gp membrane pump and that the compound could be of clinical relevance to improve the efficacy of chemotherapy in MDR cancers. ${ }^{51}$

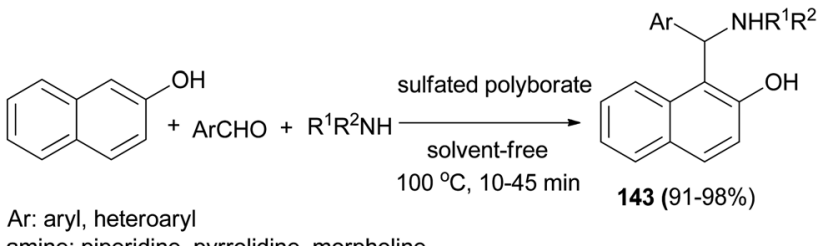

amine: piperidine, pyrrolidine, morpholine

Scheme 100 Solvent-free synthesis of Betti bases 143 catalyzed by sulfated polyborate. 


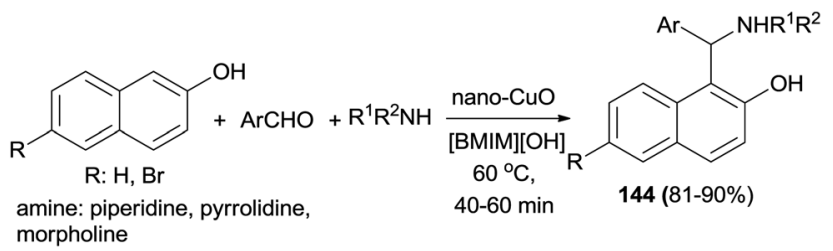

Scheme 101 Synthesis of Betti bases 144 catalyzed by nano-CuOionic liquid.

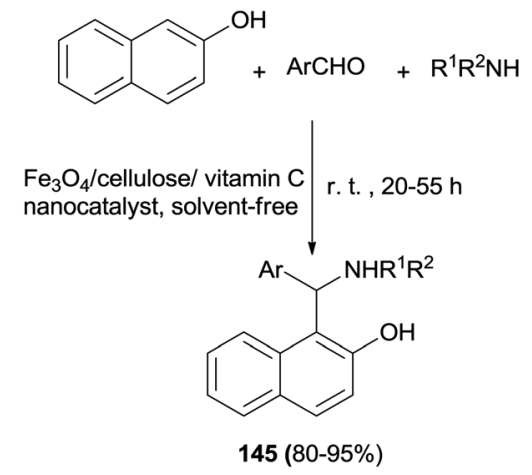

amine: piperidine, pyrrolidine, $\mathrm{Me}_{2} \mathrm{NH}, \mathrm{BuNH}_{2}$, aniline, 2-aminopyridine, 2-aminopyrimidine

Scheme 102 Nanocomposite of $\mathrm{Fe}_{3} \mathrm{O}_{4}$ /cellulose/vitamin $\mathrm{C}$ as a new biopolymer catalyst for synthesis of 1-( $\alpha$-aminoalkyl)naphthols 145.

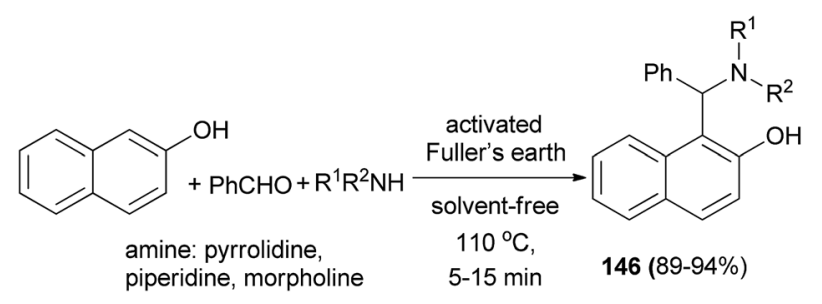

Scheme 103 Activated Fuller's earth-catalyzed synthesis of 1-(amido/ amino)alkyl-2-naphthols 146.

Triton X-100 as a non-ionic surfactant catalyst was used for the synthesis of Betti bases $\mathbf{7 6}$ from secondary amine, aromatic aldehydes, and 2-naphthol using Mannich-type reaction in water at room temperature. The catalyst gave the best results and the reaction proceeds through imine formation, which is stabilized by colloidal dispersion and undergoes nucleophilic addition to afford the corresponding $N, N$-dialkylated Betti bases in excellent yields (80-94\%) after 2-4 h (Scheme 43). ${ }^{52}$

Olyaei et $a .^{53}$ demonstrated a convenient and efficient method for the synthesis of $N$-heteroarylaminonaphthols 77 by using heteroarylamines such as 2-aminopyrimidine, 2-aminopyrazine, 2-aminopyridine and 3-aminopyridine under solventfree conditions at $125{ }^{\circ} \mathrm{C}$. The reactions completed in 4-25 min with products obtained in $87-94 \%$ yields (Scheme 44 ).

Jha et al. ${ }^{54}$ have devoted considerable attention to an efficient synthesis of 1-((2-hydroxynaphthalen-1-yl)arylmethyl)piperidin4-ol prototypes 78 as racemic mixtures via the Mannich reaction protocol from 2-naphthol, 4-piperidinol, and different

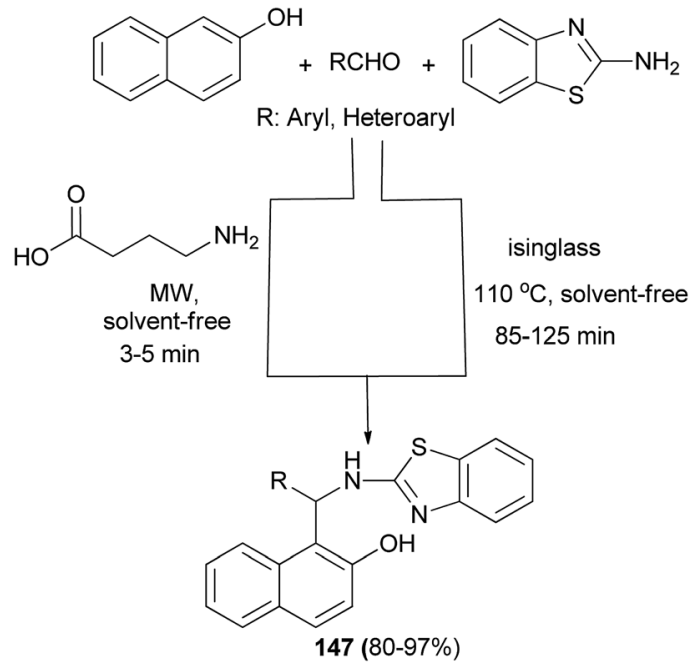

Scheme 104 Synthesis of compounds 147.<smiles>[X]c1ccc2cc(O)ccc2c1</smiles>
$\left[\mathrm{Fe}_{3} \mathrm{O}_{4} @ \mathrm{SiO}_{2} @\right.$ Triazol $\left.] \mathrm{Fc}\right]\left[\mathrm{HCO}_{3}\right] \mid \begin{gathered}\mathrm{EtOH}-\mathrm{H}_{2} \mathrm{O} \\ \text { r. t., } 40-50 \mathrm{~min}\end{gathered}$<smiles>[R][X]c1ccccc1NC(c1cc(=O)c(OCc2ccccc2)co1)c1c(O)ccc2cc([X])ccc12</smiles>

$148(85-96 \%)$

Scheme 105 Synthesis of Betti bases 148 using $\left[\mathrm{Fe}_{3} \mathrm{O}_{4}\left(\mathrm{aSiO}_{2}(\mathrm{aTriazol}-\right.\right.$ $\mathrm{Fc}]\left[\mathrm{HCO}_{3}\right]$ nanocatalyst.

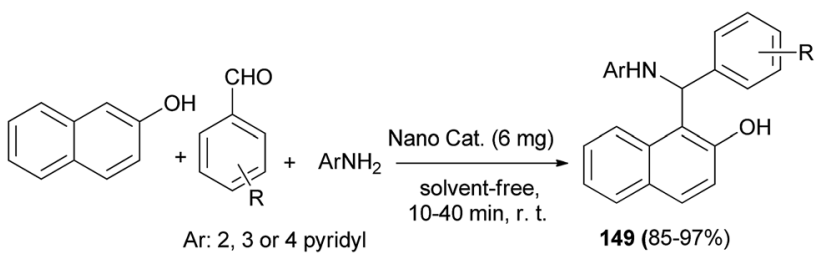

Scheme 106 Synthesis of 1-( $\alpha$-aminoalkyl)-2-naphthols 149 with $\mathrm{Fe}_{3} \mathrm{O}_{4} @ \mathrm{CSiO}_{2} \mathrm{aMoSB}$.

aromatic aldehydes. The reaction proceeded in the presence of $p$-TSA as catalyst in ethanol at reflux and was complete within $72 \mathrm{~h}$ to produce the corresponding products in $6.5-85 \%$ yields (Scheme 45). These chiral Mannich bases were then resolved utilizing an enzyme-assisted chemo-, regio-, and enantioselective (Novozyme 435®) acetylation process in $\mathrm{CHCl}_{3}$. 


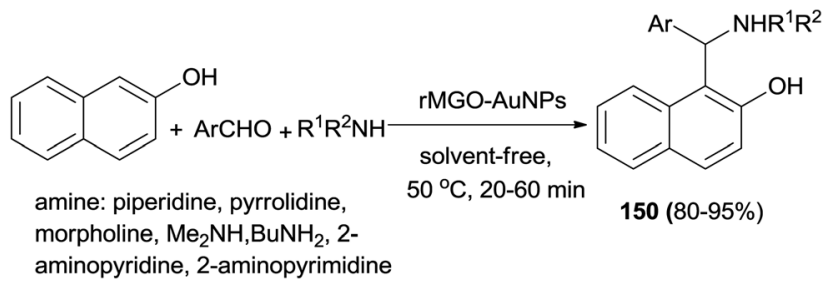

Scheme 107 Preparation of 1 -( $\alpha$-aminoalkyl)naphthols 150 using rMGO-AuNPs.

Chan et $a l .{ }^{55}$ reported the synthesis of chiral aminonaphthol ligands 79 from the reaction of 2-naphthol, $(S)$-1-phenylethylamine, and aldehydes at $60{ }^{\circ} \mathrm{C}$ under solvent-free conditions within 8-36 h. Then, the reaction of aminonaphthols 79 with $35 \%$ aqueous formaldehyde in $\mathrm{THF}$ at room temperature afforded naphthoxazines $\mathbf{8 0}$, and addition of $\mathrm{NaBH}_{4}$ to the solution of naphthoxazines in THF and $\mathrm{AcOH}$ at room temperature led to the formation of chiral tertiary aminonaphthol ligands 81 in $52-91 \%$ yields. The results of asymmetric phenyl transfer to aromatic aldehydes catalyzed by these chiral ligands in toluene indicated that enantioselectivities (up to $97 \%$ ee) were greatly influenced by the electronic and steric effects of the ligands 81 (Scheme 46).

In 2011, stereoselective synthesis of vicinal diaminoalkylnaphthols 82 in $22-64 \%$ yields was reported by

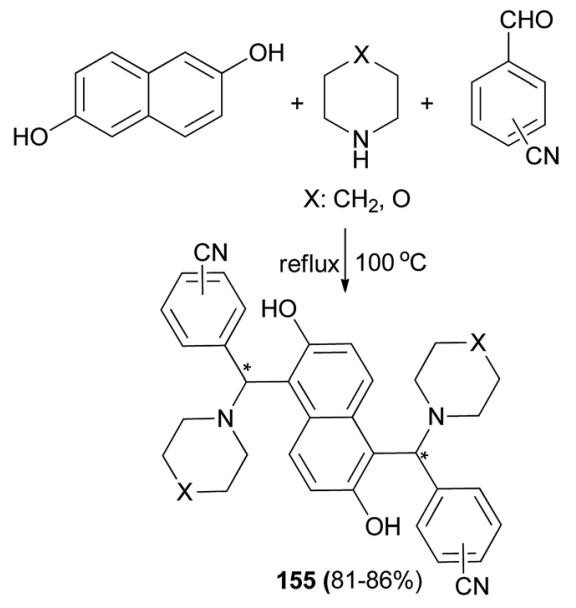

Scheme 109 One-pot preparation of bis-Betti bases 155.

Cimarelli et al. ${ }^{56}$ The desired products were obtained by threecomponent Mannich-type reaction of $\alpha, \beta$-unsaturated aldehydes with 2-naphthol and amines (benzylamine, pyrrolidine and 1-phenylethanamine) under solventless condition at room temperature within 4-72 h (Scheme 47). The relative and absolute configurations of the products obtained were assigned on the basis of the ${ }^{3} J$ values of ${ }^{1} \mathrm{H}$ NMR spectra, in combination with the conformational analysis of the molecules done by molecular modelling.

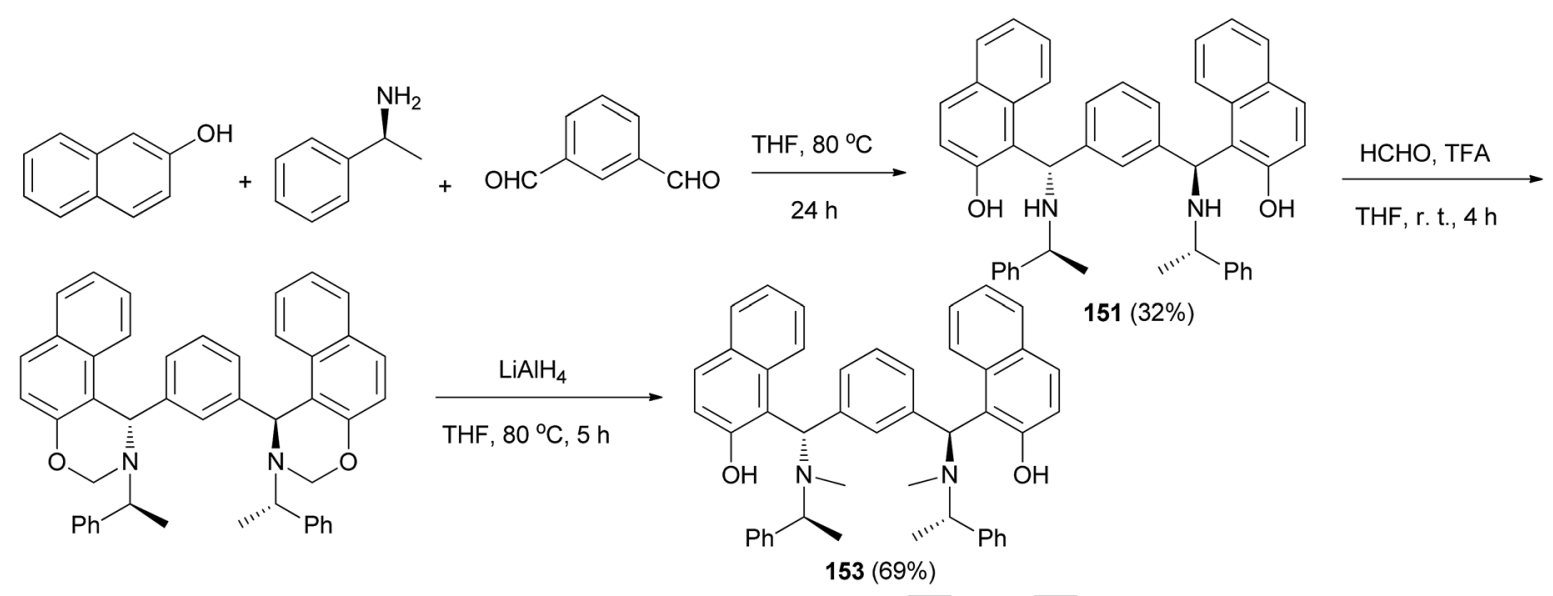

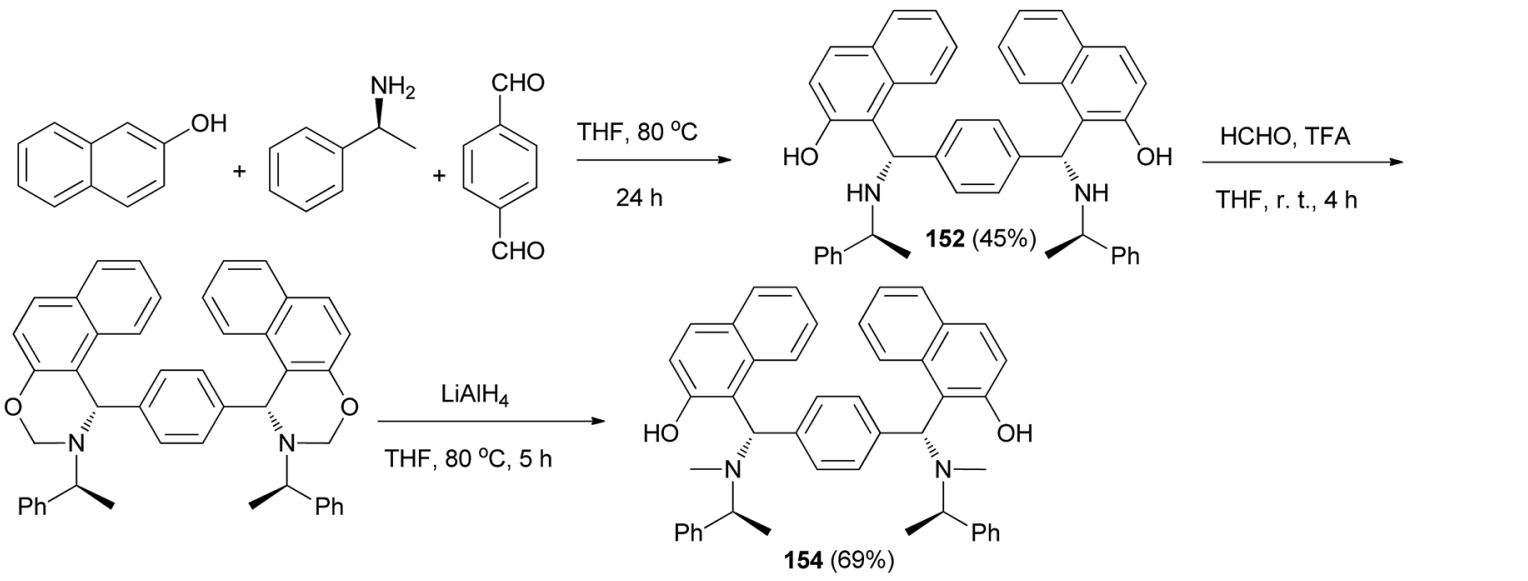

Scheme 108 Synthesis of bis-Betti bases 151-154. 

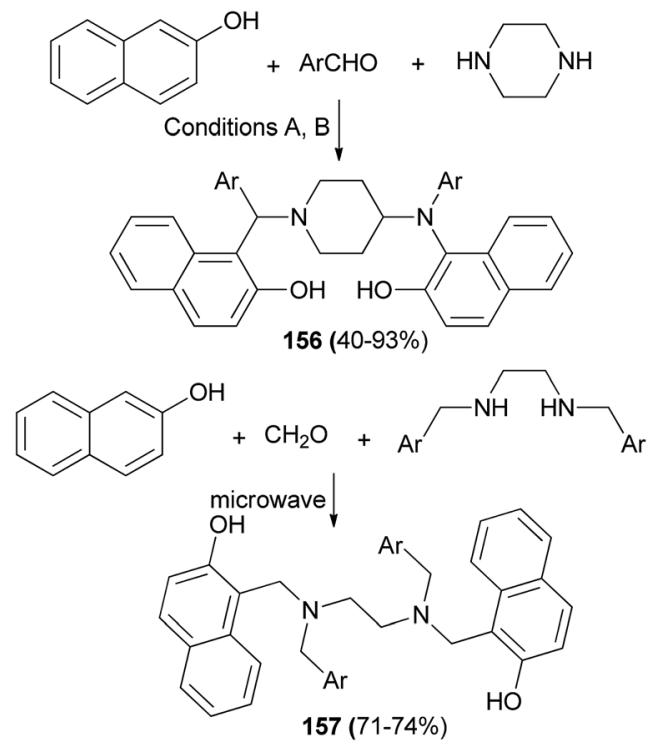

Scheme 110 Synthesis of bis-Mannich bases 156 and 157.

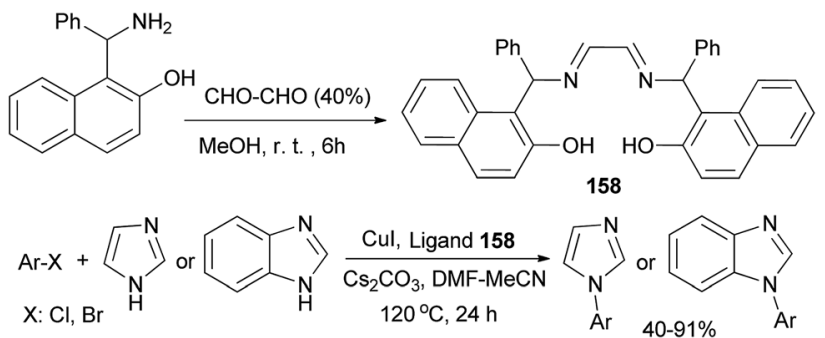

Scheme 111 Synthesis of bis-Betti base 158 and application in coppercatalyzed $\mathrm{N}$-arylation of imidazoles.

An eco-friendly method for the synthesis of the Betti bases 1$(\alpha$-aminoalkyl)naphthols $\mathbf{8 3}$ has been carried out over a basic nanocrystalline $\mathrm{MgO}$ catalyst in aqueous condition at room temperature. The reactions worked well with almost all the aldehydes and aliphatic amines within 2-6 $\mathrm{h}$ and gave the corresponding products in $78-92 \%$ yields (Scheme 48).

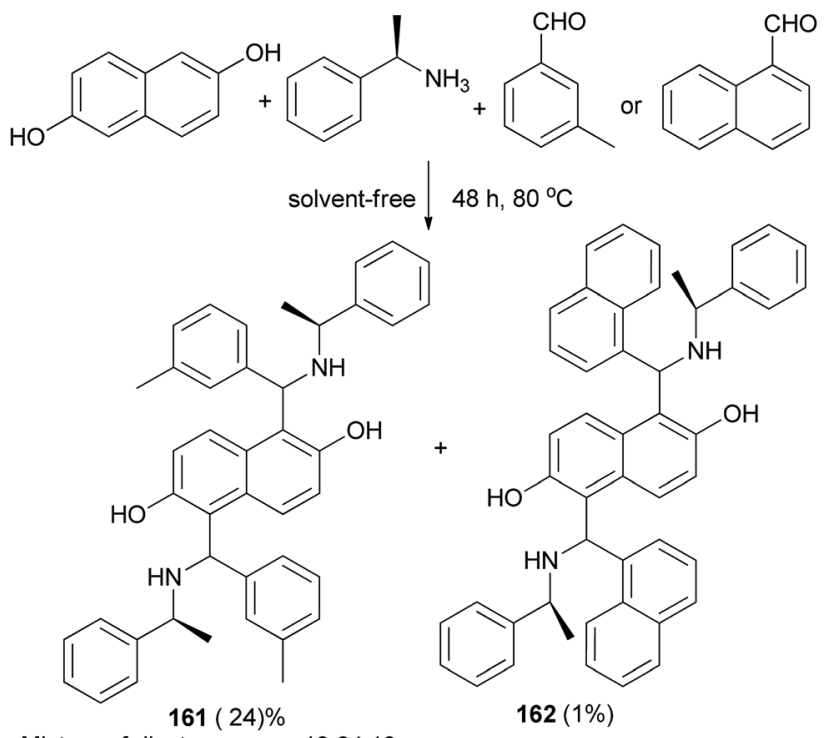

Mixture of diastereomers: 18:64:18 Mixture of diastereomers: 9:82:9

Scheme 113 Diastereoselective synthesis of bis-Betti bases 161 and 162.

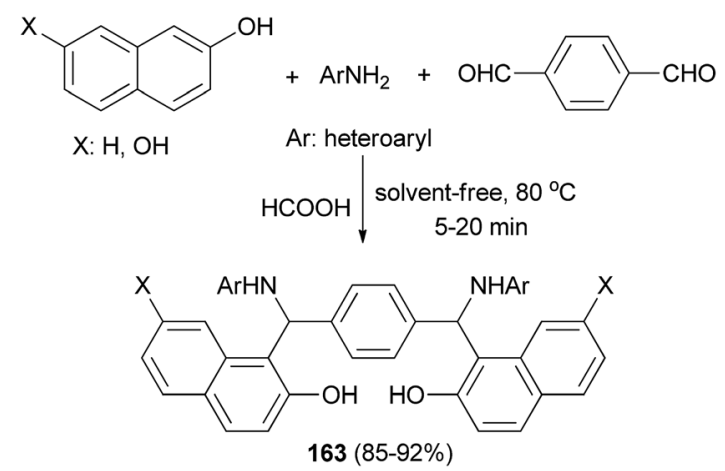

Scheme 114 Synthesis of bis-Betti base derivatives 163.

Surprisingly, the reaction was not successful with aromatic amines which might be due to their reduced nucleophilicity. ${ }^{57}$

Nitro derivative $\mathbf{8 4}$ was achieved from treatment of 2-naphthol, 2-nitrobenzaldehyde and tert-butyl carbamate under

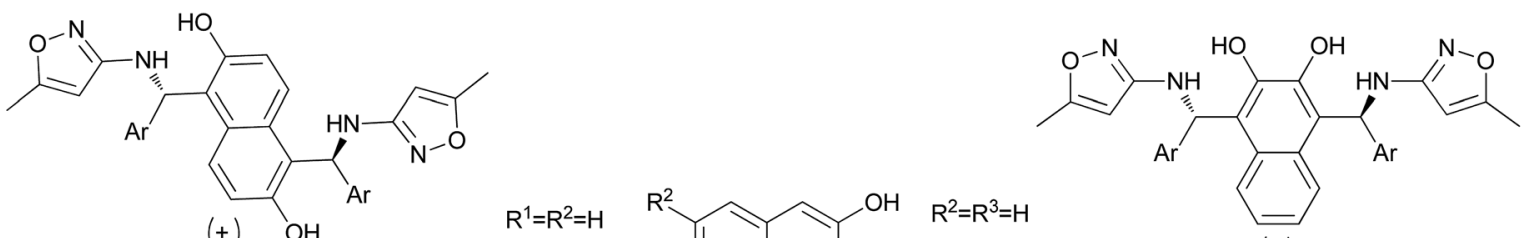<smiles></smiles><smiles>Cc1cc(N[C@@H](Br)c2c(O)ccc3c([C@@H](Br)Nc4cc(C)on4)c(O)ccc23)no1</smiles><smiles>[R]O[R]=C([R])C=C(C=C([R])C)C=C(C)C</smiles><smiles>Cc1cc(NC(Br)c2c(O)c(O)c([C@@H](Br)Nc3cc(C)on3)c3ccccc23)no1</smiles>

Scheme 112 Synthesis of bis-Betti bases 159 and 160 under solvent-free conditions. 
<smiles>[Y]c1[X]c(N)nc([Y])c1</smiles>

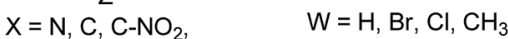
$\mathrm{Y}=\mathrm{H}, \mathrm{CH}_{3}, \mathrm{Cl}$

$\mathrm{Z}=\mathrm{H}, \mathrm{CH}_{3}$

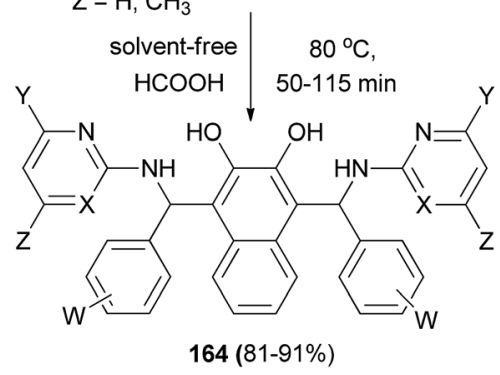

Scheme 115 One-pot synthesis of bis-Betti bases 164

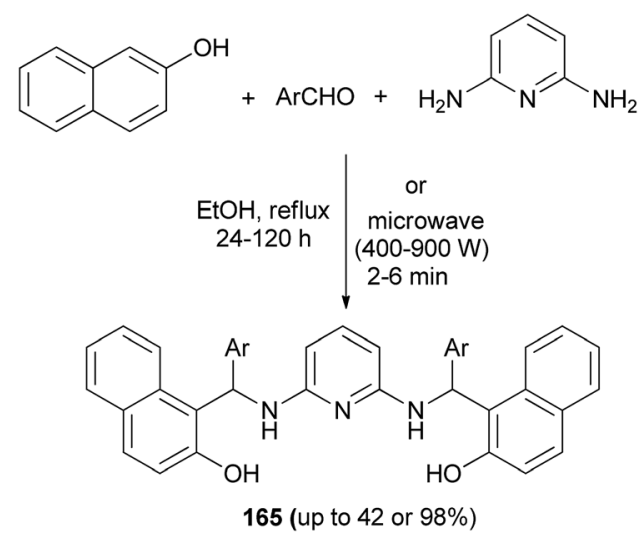

Scheme 116 Synthesis of bis-Betti bases 165

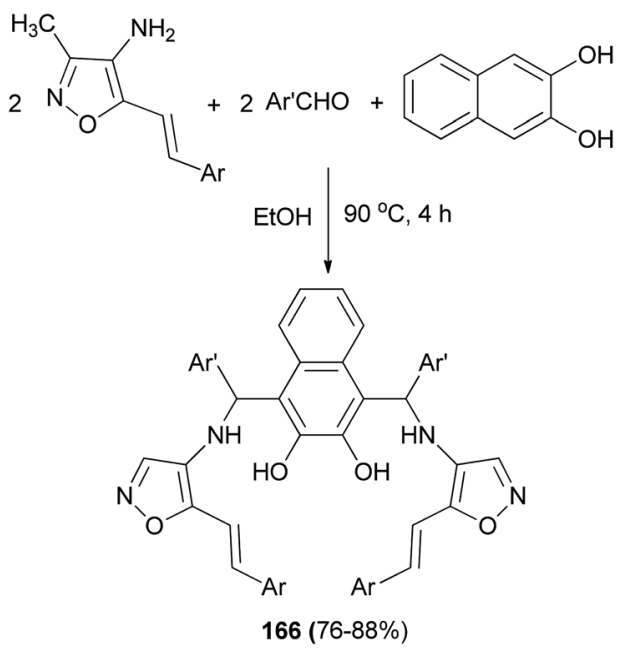

Scheme 117 Synthesis of bis-Betti bases 166.

solvent-free conditions for $47 \mathrm{~h}$ at $80{ }^{\circ} \mathrm{C}$ in $53 \%$ yield. In the following experiment, the Boc group was removed with trifluoroacetic acid, resulting in $\mathbf{8 5}$ in $90 \%$ yield. This step was followed by reduction of the nitro group by means of catalytic $(\mathrm{Pd} / \mathrm{C})$ hydrogenation, yielding 1-(amino(2-aminophenyl) methyl)-2-naphthol (86) (68\%). Also, using the reaction of 2naphthol, 2-nitrobenzaldehyde and benzyl carbamate under solvent-free conditions, 87 was synthesized at $80{ }^{\circ} \mathrm{C}$ after $32 \mathrm{~h}$ in $76 \%$ yield. Removal of the protecting group and reduction of the nitro group were accomplished in one step by catalytic $(\mathrm{Pd} / \mathrm{C})$ hydrogenation, yielding 86 (69\%) (Scheme 49). ${ }^{58}$

A synthesis of useful enantiomerically pure arylglycinates $\mathbf{8 8}$ via spontaneous reaction between phenol or naphthol derivatives and enantiopure $\alpha$-imino glyoxylate in toluene at $-15{ }^{\circ} \mathrm{C}$ within $3-10 \mathrm{~h}$ in the absence of an acid catalyst was reported. A library of enantiopure substituted phenol or naphthol glycinates was obtained in $58-79 \%$ yields and high diastereoselectivities (62-87\%) (Scheme 50). Diastereomerically pure aryl glycinates were obtained via flash chromatographic separation of the crude reaction mixture. ${ }^{59}$

The cupreine-derived bifunctional organocatalyst BzCPN efficiently catalyzes the formation of aza-Friedel-Crafts products 89 in toluene and $4 \AA$ MS as the additives from naphthols and $N$-sulfonylimines within $48 \mathrm{~h}$ in good to excellent yields (up to $99 \%$ ) with high enantioselectivities (up to $99.5: 0.5$ er) under mild reaction conditions, with a low catalyst loading ( $5 \mathrm{~mol} \%$ ), and in an aerobic environment (Scheme 51). ${ }^{60} \mathrm{~A}$ large library of aminocycloalkylnaphthols $\mathbf{9 0}$ is obtained by the Betti reaction between activated naphthols (1-naphthol, 2-naphthol and 4methoxy-1-naphthol) and five- and six-membered cyclic imines in $\mathrm{CH}_{2} \mathrm{Cl}_{2}$ within $3-7 \mathrm{~h}$ at room temperature in $49-81 \%$ yields. Betti base derivatives 90 were methylated at the nitrogen atom by cyclization with formaldehyde to the corresponding oxazolidines, followed by reduction with sodium triacetoxyborohydride in THF, to form the corresponding products 91 in yields of 79 and $85 \%$ (Scheme 52). ${ }^{61}$

Aminoalkylnaphthol derivatives 92 were obtained in $38-47 \%$ yields by performing a Mannich reaction between 2-naphthol, 4piperidinol and appropriate 4-(2-(dialkylamino)ethoxy)benzaldehydes in the presence of catalytic amounts of $p$-toluenesulfonic acid in a microwave reactor after 7-10 min (Scheme $53)^{62}$

(S)-Betti base 1 was converted into sulfonamide organocatalysts 93 by the reaction with corresponding sulfonyl chlorides in the presence of pyridine in $\mathrm{CH}_{2} \mathrm{Cl}_{2}$ at room temperature for $24 \mathrm{~h}$ in $12-56 \%$ yields. Next, the hetero-Diels-Alder reaction of ethyl glyoxylate with Danishefsky's diene was carried out in a catalytic manner using the chiral sulfonamide $93(30 \mathrm{~mol} \%)$ in $\mathrm{CH}_{2} \mathrm{Cl}_{2}$ at $-20{ }^{\circ} \mathrm{C}$ for $24 \mathrm{~h}$, followed by treatment with TFA at room temperature for $1 \mathrm{~h}$ to obtain corresponding 2-substituted 2,3-dihydropyran-4-ones 94 in 20-86\% yields (Scheme 54 ). ${ }^{63}$

Bedekar and Chaudhary ${ }^{64}$ achieved 1-( $\alpha$-aminobenzyl)-2naphthols 95 by the reaction of 2-naphthol, benzaldehyde and primary or secondary amines in absolute alcohol at room temperature for $48 \mathrm{~h}$ or under solvent-free condition at $60{ }^{\circ} \mathrm{C}$ for $24 \mathrm{~h}$ in $\mathbf{3 0 - 8 1 \%}$ yield. Compounds 95 were used as ligands in palladium-catalyzed Mizoroki-Heck reaction in dimethylacetamide in the presence of $\mathrm{K}_{2} \mathrm{CO}_{3}$ at $140{ }^{\circ} \mathrm{C}$ for $40 \mathrm{~h}$ with a variety of substrates and afforded trans-stilbene in $60-96 \%$ yields. High turnover numbers are observed for the reactions with both aryl 
bromides and iodides, while aryl chlorides are inert (Scheme 55).

$(S, S)$-Aminobenzylnaphthols 96 were obtained by a Betti reaction of 2-naphthol, benzaldehyde or $p$-halobenzaldehyde with $(R)$ - or $(S)$-1-arylethylamine for two days at $60{ }^{\circ} \mathrm{C}$ without any solvent in 51-68\% yields (Scheme 56). The crystal structures of $(S, S)$-aminobenzylnaphthols, easily produced by a chromatography-free highly stereoselective Betti reaction, were investigated by means of single-crystal X-ray diffraction analysis, and the main intra- and intermolecular interactions were described. ${ }^{65}$

An efficient catalyst-free synthesis of Betti base derivatives via Mannich-type one-pot three-component condensation reaction of 2-aminopyrimidine derivatives, salicylaldehyde and naphthols (2-naphthol, 1-naphthol, 2,7-naphthalenediol and 2,3-naphthalenediol) under solvent-free conditions has been described. The reactions were carried out at $80{ }^{\circ} \mathrm{C}$ within $25-$ $30 \mathrm{~min}$, affording the desired aminonaphthols 97 in 85-93\% yields (Scheme 57). ${ }^{66}$

Hosseinian et $a l .{ }^{67}$ have reported that 1(benzothiazolylamino)methyl-2-naphthol derivatives $\mathbf{9 8}$ are achieved from one-pot, three-component condensation of aldehydes, 2-naphthol, and 2-aminobenzothiazole in the presence of sodium hydrogen sulfate as an effective catalyst at $80^{\circ} \mathrm{C}$ after 4-30 min. The reactions worked well with a variety of heterocyclic aldehydes, aliphatic aldehydes, and aryl aldehydes including those bearing electron-withdrawing and electrondonating groups, and the desired compounds were obtained in 52-93\% yields (Scheme 58).

A methodology has been developed for the multicomponent one-pot synthesis of aminoalkylnaphthols 99 in 74-95\% yields in dichloromethane under catalyst-free conditions at room temperature within 2-3 h. Secondary amines such as piperidine, pyrrolidine, morpholine, $N$-methylpiperazine, and dimethylamine were used in the reaction and the yields of the desired products were moderate to excellent (Scheme 59). ${ }^{68}$

Nanocrystalline $\mathrm{TiO}_{2}-\mathrm{HClO}_{4}$-catalyzed three-component preparation of 1-( $\alpha$-aminoalkyl)-2-naphthols 100 in $90-93 \%$ yields under solvent-free condition at room temperature within 22-30 min has been reported by Shaterian et al. This white acidic heterogeneous catalyst is very stable under the reaction conditions and was reused several times without significant loss of activity (Scheme 60). ${ }^{69}$

Jeong et al. $^{70}$ described $\mathrm{Cu}(\mathrm{OTf})_{2} \cdot \mathrm{SiO}_{2}(10 \mathrm{~mol} \%)$-catalyzed three-component coupling of aldehyde, 2-naphthol, and alicyclic amine to generate Betti bases 101 in $72-95 \%$ yields under neat conditions at room temperature to $40{ }^{\circ} \mathrm{C}$ after $0.5-3 \mathrm{~h}$ without additional co-catalyst or additive in air (Scheme 61).

Betti bases 102 were obtained in $76-94 \%$ yields via the condensation reaction of aromatic aldehydes, secondary amines and 2-naphthol in PEG-400 as solvent in the absence of catalyst at room temperature after 2-4 h. In this reaction, aromatic aldehydes and heteroaromatic carbaldehydes worked satisfactorily, but the reaction with aromatic amines was not successful (Scheme 62). ${ }^{71}$

Song et $a .^{72}$ developed a new method for the synthesis of enantiomerically pure Betti bases 103. By using trifluoroacetic acid to replace the more traditionally used hydrochloric acid, the hydrolysis procedure used in the classical synthesis of racemic Betti base was carried out at $50{ }^{\circ} \mathrm{C}$ in $\mathrm{CH}_{2} \mathrm{Cl}_{2} / \mathrm{H}_{2} \mathrm{O}$ with an improved yield (up to $96 \%$ ), which was followed by a new and efficient resolution using recyclable $(R)-1,1^{\prime}$-binaphthalene-2,2' diyl sodium phosphate to provide enantiomerically pure $(S)$ Betti base 103a in 95\% yield with up to $99 \%$ ee and $(R)$-Betti base 103b in $93 \%$ yield with $90 \%$ ee in one resolution step (Scheme 63).

A series of chiral aminonaphthols $\mathbf{1 0 4}$ has been synthesized diastereoselectively in 33-82\% yields by applying a solvent-free 'Betti-type' condensation using 2,6- and 2,3-dihydroxynaphthalenes, 2-naphthol, $(S)$-phenylethylamine as a chiral auxiliary, and aldehydes at $80{ }^{\circ} \mathrm{C}$ after 24 and $72 \mathrm{~h}$ (Scheme 64). The major diastereomers (90-96\%) formed could be isolated in pure form..$^{73}$

These chiral aminonaphthols have been used as precatalysts for the addition of diethylzinc and alkynylzinc reagents to aldehydes in toluene at room temperature with enantioselectivities of up to $98 \%$ and $50 \%$ ee, respectively. Ganesan et al. ${ }^{74}$ described the Betti reaction in glycerol solvent. The expected Betti bases 105 were obtained at 40 or $90{ }^{\circ} \mathrm{C}$ after 3-10 min in 68-91\% yields. The reaction works well for representative cyclic, acyclic and aliphatic aldehydes (Scheme 65).

Naimi-Jamal et $a{ }^{75}$ published a simple procedure for the three-component one-pot aminomethylation of various aromatic electron-rich compounds using [omim] $\left[\mathrm{BF}_{4}\right]$ ionic liquids as the catalyst and solvent at room temperature. The process led to an efficient synthesis of Mannich bases 106 and 107 after 1-6 h in 54-99\% yields under mild conditions using no additive or catalyst (Scheme 66).

Sulfanilic acid-functionalized silica-coated nano- $\mathrm{Fe}_{3} \mathrm{O}_{4}$ particles (MNPs- $\mathrm{PhSO}_{3} \mathrm{H}$ ) as an efficient, reusable and magnetically separable catalyst has been studied for the solventfree synthesis of 1-aminoalkyl-2-naphthols 108 at $120{ }^{\circ} \mathrm{C}$. Treatment of a variety of aldehydes and 2-naphthol with heterocyclic amines afforded the corresponding 1-aminoalky-2naphthol derivatives in 81-92\% yields after 10-20 min (Scheme $67)$. The reaction with the usual aromatic amines such as aniline and $p$-toluidine afforded Schiff bases instead of the corresponding aminoalkylnaphthols. ${ }^{76}$

A reaction of triethyl phosphite with 3-alkyl-1phenylnaphthoxazines in the presence of halotrimethylsilanes in toluene with subsequent removal of the trimethylsilyl group by hydrolysis furnished diastereomeric $\alpha$-aminoalkylphosphonic derivatives of Betti base 109. The highest diastereomeric excess was observed in the reaction with bromotrimethylsilane at low temperature (Scheme 68 ). ${ }^{77}$

Aminobenzylnaphthols $\mathbf{1 1 0}$ and $\mathbf{1 1 1}$ were synthesized in 36 and $37 \%$ yields via the reaction of 2-naphthol, arylaldehyde and $(S)$ - or $(R)$-prolinol at $60{ }^{\circ} \mathrm{C}$ under solvent-free conditions for two days (Scheme 69). These aminobenzylnaphthols, synthesized from different components and thus having different structural features, were tested as anti-yeast agents inhibiting Candida albicans. The activity towards C. albicans of these prolinol derivatives was interesting and could represent a promising 
alternative to overcome the problem of strains resistant to the traditional antifungals. ${ }^{78}$

A reaction of triethyl phosphite with 3-alkyl-1phenylnaphthoxazines in the presence of halotrimethylsilanes in toluene at $-30{ }^{\circ} \mathrm{C}$ for $6 \mathrm{~h}$ with subsequent removal of the trimethylsilyl group by hydrolysis furnished diastereomeric $\alpha$ aminoalkylphosphonic derivatives of Betti base 112 with high diastereoselectivity (de up to 75\%) (Scheme 70). ${ }^{79}$

4-Aminoantipyrine derivatives 113 were achieved in 92-95\% yields by the condensation of aromatic aldehyde, 4-aminoantipyrine, and 8-hydroxyquinoline in the presence of fluorite as catalyst in ethanol at room temperature for 10-15 $\mathrm{min}$ (Scheme 71). All derivatives showed in vivo and in vitro antiinflammatory and anthelmintic activities against reference drugs diclofenac and albendazole. ${ }^{80}$

Jana et $a .^{81}$ reported the reaction of 2-hydroxynaphthaldehyde with two equivalents of pyrrolidine in xylene under microwave irradiation at $170{ }^{\circ} \mathrm{C}$ within $20 \mathrm{~min}$, giving 2hydroxy-1-naphthylmethylamine (114) as the major product. Similarly, various aldehydes and ketones were reacted with different cyclic saturated amines producing structurally diverse mono- or di-arylmethylamines 114 in $60-74 \%$ yields (Scheme 72).

The direct three-component modified Mannich reaction via condensation of aromatic aldehydes, 2-naphthol or 2,7-naphthalendiol and piperidine to generate Betti bases 115 in 90-96\% yields has been carried out over L-proline (20 mol\%) with high efficiency under solvent-free conditions at $70{ }^{\circ} \mathrm{C}$ within $2.5-4 \mathrm{~h}$ (Scheme 73). ${ }^{\mathbf{2}}$

$\mathrm{BiCl}_{3}(7.5 \mathrm{~mol} \%)$ as an efficient catalyst has been studied for the synthesis of aminonaphthols 116 via the reaction of naphthols, 2-bromobenzaldehydes and cyclic secondary amines at $80{ }^{\circ} \mathrm{C}$ without solvent within $10-15 \mathrm{~min}$ in $85-93 \%$ yields (Scheme 74). ${ }^{83}$

A Brønsted acidic ionic liquid, [( $\left.\left(\mathrm{CH}_{2}\right)_{3} \mathrm{SO}_{3} \mathrm{HMIM}\right]\left[\mathrm{HSO}_{4}\right]$, as an efficient catalyst has been reported for the synthesis of 1(benzothiazolylamino)methyl-2-naphthols 117 at $100{ }^{\circ} \mathrm{C}$ (or $75{ }^{\circ} \mathrm{C}$ for heterocyclic aldehydes) under solvent-free condition within 5-30 min. A wide range of aldehydes readily undergo condensation with 2-naphthol and 2-aminobenzothiazole to afford the desired products in $53-94 \%$ yields (Scheme 75 ). ${ }^{84}$

Heravi et al. ${ }^{85}$ have shown solventless synthesis of Betti bases 1 -( $\alpha$-aminoalkyl)naphthols 118 catalyzed by $\mathrm{Fe}_{3} \mathrm{O}_{4}$ nanoparticles ( $5 \mathrm{~mol} \%)$ at room temperature. All the aromatic aldehydes and cyclic and acyclic amines reacted with 2-naphthol almost equally well to afford the Betti bases in 86-95\% yields after 1$2 \mathrm{~h}$. The reaction was not successful with aromatic amines, which might be due to their reduced nucleophilicity (Scheme 76).

Shahrisa et al. ${ }^{86}$ have obtained arylaminonaphthols 119 from the condensation of 2-naphthol, aldehydes, and arylamines in the presence of $N, N$-dimethylethanolamine (7.5 mol\%) as an organocatalyst at $50{ }^{\circ} \mathrm{C}$ under solvent-free conditions. The reaction of aromatic and heteroaromatic aldehydes with piperidine, morpholine, aromatic amines and heteroarylamines in the presence of catalytic amounts of DMEA also afforded desired products after 30-45 min in 83-95\% yields (Scheme 77).
The first example of incorporating the oxindole moiety into Betti bases has been reported by Yan et al. ${ }^{87}$ The new type of Betti bases 120 were conveniently synthesized in $42-88 \%$ yields from the three-component reaction of 2-naphthol, isatins and cyclic amines, such as piperidine or morpholine, in $\mathrm{CH}_{2} \mathrm{Cl}_{2}$ at reflux within $24 \mathrm{~h}$ without any other catalyst (Scheme 78). Other secondary amines, such as pyrrolidine, dimethylamine, diethylamine, and di(n-propyl)amine, and $\alpha$-naphthol, resorcinol, and pyrogallol did not afford the expected products under similar reaction conditions.

Pyrazine-1,4-diium trinitromethanide $\{[1,4-\mathrm{DHPyrazine}]$ $\left.\left[\mathrm{C}\left(\mathrm{NO}_{2}\right)_{3}\right]_{2}\right\}$ as a green and novel nanostructured molten salt catalyzed the synthesis of new 1-( $\alpha$-aminoalkyl)-2-naphthol derivatives 121 via the reaction between 2- or 4-aminopyridine, aromatic aldehydes and 2-naphthol at room temperature under solvent-free conditions in comparison with $\mathrm{Ag}-\mathrm{TiO}_{2}$ nanocomposite. The reactions with $\{[1,4-\mathrm{DH}$ yrazine $]$ $\left.\left[\mathrm{C}\left(\mathrm{NO}_{2}\right)_{3}\right]_{2}\right\} \quad(1 \mathrm{~mol} \%)$ and $\mathrm{Ag}-\mathrm{TiO}_{2}(2 \mathrm{~mol} \%)$ afforded the desired products after 5-25 min and 10-40 $\mathrm{min}$ in $92-98 \%$ and 90-95\% yields, respectively (Scheme 79). ${ }^{88}$

$\mathrm{Xu}$ et $a .^{89}$ demonstrated that Betti bases 122 can be easily synthesized without a solvent by condensation of 2-naphthols, aromatic aldehydes, and 1-phenylethylamines at $60{ }^{\circ} \mathrm{C}$ for $4-8 \mathrm{~h}$ under nitrogen atmosphere in 56-92\% yields (Scheme 80). Also, these compounds can be converted to $\gamma$-amino alcohols and downstream pyrrolidine derivatives by highly diastereoselective [1,2]-Wittig rearrangement and intramolecular cyclization with perfect chirality transfer (up to $>99.9 \%$ de) and in good yields.

An efficient method has been described for the synthesis of 2-aminobenzothiazolomethylnaphthol derivatives 123 by onepot three-component reaction of aldehydes, 2-naphthol, and 2-aminobenzothiazole using Triton X-100 as a catalyst in water at $60-65{ }^{\circ} \mathrm{C}$ within $1.0-1.8 \mathrm{~h}$ in $75-95 \%$ yields (Scheme 81 ). It was shown that the synthesized derivatives demonstrated good antimicrobial activity against Gram-positive and Gram-negative bacteria and antifungal activity against fungal strains such as Aspergillus niger, Aspergillus fumigatus, and Aspergillus flavus. ${ }^{90}$

$\mathrm{Wu}$ et al. ${ }^{\mathbf{9 1}}$ demonstrated for the first time a straightforward and one-pot strategy to synthesize the bifunctional phosphorus Betti bases 124 in 52-95\% yields under solvent-free conditions at $180{ }^{\circ} \mathrm{C}$ within $0.5-2 \mathrm{~h}$ via the condensation of 2-naphthol, arylaldehydes and diphenylphosphine oxide in the presence of $p$-toluenesulfonic acid (Scheme 82). The procedure worked well with almost all the aldehydes.

Abdel Hameed et al. ${ }^{92}$ reported an efficient multicomponent, one-pot synthesis of Betti bases 125 catalyzed by cerium(Iv) ammonium nitrate (CAN) (10 $\mathrm{mol} \%)$ in $\mathrm{MeOH}$ as solvent at ambient temperature. The reaction worked well for representative anilines, morpholine, piperidine and aromatic aldehydes, and led to the formation of the desired products after 10-50 $\mathrm{min}$ in $80-92 \%$ yields (Scheme 83 ).

The work of Nasr-Esfahani et al. ${ }^{93}$ demonstrated that various Betti bases 126 could be synthesized in one-pot threecomponent condensation of aldehydes, 2-naphthol, and cyclic and acyclic amines in the presence of aluminatesulfonic acid nanoparticles (ASA NPs) (10 mol\%) as recoverable catalyst at $80{ }^{\circ} \mathrm{C}$ under solvent-free conditions. Aromatic aldehydes 
containing either electron-donating or electron-withdrawing groups reacted successfully and gave the products within 10$24 \mathrm{~min}$ in $88-94 \%$ yields (Scheme 84 ).

Sadkova et al. ${ }^{\mathbf{9 4}}$ developed a diastereoselective (de 80-92\%) synthesis of $\alpha$-aminophosphonates 127 by reaction of diethyl phosphite sodium salt with 3-R-1-phenyl-2,3-dihydro- $1 H^{-}$ naphth[1,2-e]-[1,3]oxazines being the products of aminoacetalization of aldehydes with 1-( $\alpha$-aminobenzyl)-2-naphthol (Betti base). The reaction mixtures were vigorously stirred for $6 \mathrm{~h}$ at room temperature, followed by the addition of $96 \%$ ethanol (Scheme 85).

Meshram et al. ${ }^{95}$ synthesized a series of sulfonamides fused with Betti bases 128 in $63-80 \%$ yields by the reaction of substituted 1-(amino(phenyl)methyl)naphthalen-2-ol and acetamidobenzenesulfonyl chloride in DMF and triethylamine at $150{ }^{\circ} \mathrm{C}$ for 10-12 hours (Scheme 86). On the basis of the results obtained from docking studies, some of the synthesized sulfonamide derivatives $\mathbf{1 2 8}$ might show significant anticancer activity by inhibiting DNA topoisomerase II.

A green protocol for one-pot three-component synthesis of 1(benzothiazolylamino)methyl-2-naphthols 129 via the reaction of aromatic aldehydes, 2-naphthol and 2-aminobenzothiazole catalyzed by oxalic acid ( $20 \mathrm{~mol} \%)$ under thermal and solventfree conditions is described by Maghsoodlou et al. The reaction was carried out under solvent-free condition at $80{ }^{\circ} \mathrm{C}$ for $4-$ $30 \mathrm{~min}$ to give the corresponding products in $57-98 \%$ yields (Scheme 87). ${ }^{96}$

The direct three-component reaction via condensation of aldehydes, 2-naphthols and piperidine has been reported, generating 1-(aryl(piperidin-1-yl)methyl)naphthalene-2-ol derivatives 130 over $\mathrm{Fe}_{3} \mathrm{O}_{4}$ magnetic nanoparticles with high efficiency $(90-97 \%$ yields) under ultrasound irradiation (frequency of $40 \mathrm{kHz}$ and an input power of $600 \mathrm{~W}$ ) and solventfree condition at $80{ }^{\circ} \mathrm{C}$ for $20-25 \mathrm{~min}$ (Scheme 88). ${ }^{97}$

Aza-Friedel-Crafts reaction of $N$-alkoxycarbonyl isatin ketimines with naphthols using a new 2-adamantyl-substituted quinine-derived squaramide catalyst (2 mol\%) and $25 \mathrm{mg} 4 \AA$ molecular sieve in $\mathrm{CH}_{2} \mathrm{Cl}_{2}$ at $-20^{\circ} \mathrm{C}$ for $12-48 \mathrm{~h}$ afforded chiral tetrasubstituted 3-amino-2-oxindoles 131 and 132 with excellent enantioselectivity up to greater than $99 \%$ ee and in $61-99 \%$ yields (Scheme 89). ${ }^{98}$

Nano- $\mathrm{SiO}_{2}-\mathrm{H}_{3} \mathrm{BO}_{3}$ was introduced as an environmentally benign and recyclable heterogeneous catalyst for the synthesis of aminonaphthols 133 at $40{ }^{\circ} \mathrm{C}$ under solvent-free conditions after $30-45 \mathrm{~min}$ in $88-95 \%$ yields without an additional cocatalyst or additive in air by Teimuri-Mofrad et al. ${ }^{99}$ (Scheme 90).

Pei et $a l .{ }^{\mathbf{1 0 0}}$ reported a highly efficient one-pot threecomponent Betti reaction using reverse $\mathrm{ZnO}$ micelles as a recoverable and reusable catalyst. Reactions were conducted with 2-naphthol, aromatic aldehydes, amines and reverse $\mathrm{ZnO}$ nanomicelles (10 mol\%) in water at room temperature within 460 min, affording Betti base derivatives 134 in 29-96\% yields (Scheme 91).

Novel Betti bases 135 based on kojic acid derivatives have been synthesized by coupling 2-naphthol, aniline derivatives and kojic aldehyde in the presence of $\mathrm{Fe}_{3} \mathrm{O}_{4} @ \mathrm{SiO}_{2}$-boric acid nanocatalyst at $40{ }^{\circ} \mathrm{C}$ min under solvent-free condition (Scheme
92). The reactions were carried out efficiently within 55-60 min and the desired products obtained in $87-90 \%$ yields. ${ }^{101}$

Georgieva et al. ${ }^{102}$ synthesized several Betti bases 136 by a modified Betti reaction via the condensation reaction of primary heterocyclic amine, aromatic aldehydes, 8-quinolinol and halogeno-substituted aromatic aldehydes. The reaction mixtures were allowed to stand for 21 days in absolute ethanol at room temperature in a closed flask affording the corresponding products in yields of 80-98\% (Scheme 93).

Synthesis of aminoalkylnaphthols 137 from aldehydes, 2naphthol, and secondary amines in deep eutectic solvent (DES) based on urea and choline chloride has been developed. A broad range of aminoalkylnaphthols can be obtained at $60{ }^{\circ} \mathrm{C}$ within $1-3 \mathrm{~h}$ in $72-95 \%$ yields in biodegradable choline chloride-based DES (urea-ChCl (2:1)). Heteroaromatic as well as sterically hindered aromatic aldehydes also gave good product yields with aliphatic aldehydes failing to produce corresponding Betti bases (Scheme 94). ${ }^{103}$

Iyer et al. ${ }^{104}$ achieved a series of 1-((2-hydroxynaphthalen-1yl)(phenyl)(methyl))pyrrolidin-2-one derivatives 138 in $65-90 \%$ yields by an efficient iodine ( $20 \mathrm{~mol} \%)$-catalyzed domino reaction involving various aromatic aldehydes, 2-pyrrolidinone and 2-naphthol in $\mathrm{CH}_{2} \mathrm{Cl}_{2}$ at room temperature after $5 \mathrm{~h}$ (Scheme 95).

Subsequently they were evaluated for cytotoxicity against breast cancer (MCF-7) and colon cancer (HCT116) cell lines. Regarding the cytotoxicity, the relative inhibition activity was notably found to be moderate to high in MCF-7 cell line. Also, they were docked into the active site of phosphoinositide 3kinase (PI3K) (PDB ID: 4JPS) which is a crucial regulator of apoptosis or programmed cell death. Results showed that the hydrophobic interactions in the binding pockets of PI3K exploited the affinity of the most favorable binding ligands.

Cost-effective green chemical methods are reported for the one-pot multicomponent solventless synthesis of 1-aminoalkyl2-naphthol 139 in 52-90\% yields by the reaction of vanillin, 2naphthol and 4-nitroaniline in the presence of tannic acid as a Lewis acid catalyst. A mixture was stirred by following various green protocols such as oil bath at $120-125{ }^{\circ} \mathrm{C}$ for $10-15 \mathrm{~min}$, microwave irradiation at $100 \mathrm{~W}$ for $1-4 \mathrm{~min}$, hot plate with magnetic stirrer at about $120-125{ }^{\circ} \mathrm{C}$ for $20-25 \mathrm{~min}$, grindstone method for 10-15 min and finally conventional heating method with a few drops of methanol at reflux for 60-90 min (Scheme 96). Antibacterial activity of the synthesized compound against Bacillus subtilis was tested by zone inhibition method, showing negligible inhibition against the growth of this bacterium. ${ }^{\mathbf{1 0 5}}$

Cardellicchio and Capozzi ${ }^{\mathbf{1 0 6}}$ succeeded in the preparation of aminobenzylnaphthol 140 bearing two stereogenic centers from the condensation of 2-naphthol, arylaldehydes and valine methyl ester at $60{ }^{\circ} \mathrm{C}$ under solvent-free condition for two days or in $\mathrm{Et}_{2} \mathrm{O}$ at $35{ }^{\circ} \mathrm{C}$ for two days in $35-68 \%$ yields (Scheme 97).

The Betti bases 141 in 52 and 62\% yields were obtained from the reaction of $(S)-5-\{[$ (tert-butyldimethylsilyl)oxy $]$ methyl $\}$ pyrrolidin-2-one or $(S)$-5-(azidomethyl)pyrrolidin-2-one and 2naphthol in dry $\mathrm{CHCl}_{3}$ under microwave irradiation at $120{ }^{\circ} \mathrm{C}$ for $2 \mathrm{~h}$ (Scheme 98). ${ }^{107}$ 
Bosica et $a .^{108}$ reported that the reaction of 2-naphthol, aromatic aldehydes and amines in the presence of montmorillonite $\mathrm{K} 30$ as a heterogeneous catalyst at $60{ }^{\circ} \mathrm{C}$ under neat conditions yielded aminocycloalkylnaphthols 142 after 2-12 h. The catalyst is fully recoverable and recyclable for up to 5 runs. Furthermore, it could catalyze reactions involving both secondary and primary aliphatic amines to give products usually in $37-92 \%$ yields (Scheme 99 ).

Chaturbhuj et al. ${ }^{109}$ succeeded in the preparation of 1aminoalkyl-2-phenol Betti bases 143 from one-pot threecomponent condensations of aldehyde, 2-naphthol, and morpholine in the presence of sulfated polyborate catalyst, under a solvent-free condition at $100{ }^{\circ} \mathrm{C}$. Various aromatic/ heteroaromatic aldehydes and cyclic amines (morpholine, piperidine, and pyrrolidine) reacted well and afforded higher yields (91-98\%) of Betti base in shorter reaction time (10-45 min) (Scheme 100).

Synthesis of Betti base derivatives 144 catalyzed by nanoCuO-ionic liquid has been reported from the reaction of 2naphthols, aromatic aldehydes and cyclic amines in [BMIM] $[\mathrm{OH}]$ at $60{ }^{\circ} \mathrm{C}$. The desired products were obtained in a short period of time (40-60 min) in good yields (81-90\%) (Scheme 101). All of the synthesized aminonaphthol derivatives 144 exhibit good inhibitory effects toward mild steel corrosion with inhibition efficiencies in the range of $84-95 \%$. Therefore, these compounds can be practically used as effective corrosion inhibitors for acid pickling applications. ${ }^{\mathbf{1 1 0}}$

Janati ${ }^{111}$ introduced a nanocomposite of $\mathrm{Fe}_{3} \mathrm{O}_{4} /$ cellulose/ vitamin $\mathrm{C}$ as a new biopolymer catalyst for synthesis of pharmacologically active 1-( $\alpha$-aminoalkyl)naphthols 145 via a onepot condensation of 2-naphthol, alkylamines and aldehydes at room temperature within $20-55 \mathrm{~h}$ under solvent-free conditions in $80-95 \%$ yields (Scheme 102).

Chaturbhuj et al. ${ }^{112}$ succeeded in preparing 1-(amino)alkyl-2naphthols 146 via one-pot multi-component reaction of benzaldehyde, 2-naphthol and cyclic amines using activated Fuller's earth as a heterogeneous catalyst under solvent-free condition at $110{ }^{\circ} \mathrm{C}$ within $5-15 \mathrm{~min}$ in $89-94 \%$ yields (Scheme 103).

$\gamma$-Aminobutyric acid (GABA) and isinglass, a collagen peptide, have been utilized as highly efficient bifunctional biocatalysts for the efficient and convenient synthesis of 2aminobenzothiazolomethyl-2-naphthols through a one-pot three-component Mannich reaction between diverse aldehydes, 2-naphthol and 2-aminobenzothiazole under solventfree condition in high yields. The reaction in the presence of GABA (10 mol\%) was carried out under a microwave irradiation power of $900 \mathrm{~W}$ for $3-5 \mathrm{~min}$ and with isinglass at $110{ }^{\circ} \mathrm{C}$ for $85-$ $125 \mathrm{~min}$ to afford the desired products 147 in $87-97 \%$ and 80 95\% yields, respectively (Scheme 104). ${ }^{113}$

Application of novel 1,2,3-triazolylferrocene-containing ionic liquid supported on $\mathrm{Fe}_{3} \mathrm{O}_{4}$ nanocatalyst in the synthesis of new pyran-substituted Betti bases 148 has been reported by Safa et al. ${ }^{\mathbf{1 1 4}}$ The catalytic activity of the magnetic nanoparticles was evaluated in the one-pot three-component synthesis of a wide variety of Betti bases 148 in 85-96\% yields from kojic aldehyde, 2-naphthol or 6-bromo-2-naphthol and aniline derivatives in EtOH- $\mathrm{H}_{2} \mathrm{O}$ at room temperature for 40-50 min (Scheme 105).
Synthesis of 1-( $\alpha$-aminoalkyl)-2-naphthol derivatives 149 employing combined ultrasonic/Mo Schiff base complex immobilized on $\mathrm{Fe}_{3} \mathrm{O}_{4}$ nanoparticles $\left(\mathrm{Fe}_{3} \mathrm{O}_{4} @ \mathrm{SiO}_{2} @ \mathrm{MoSB}\right)$ as a heterogeneous acid catalyst has been reported via the reaction of 2-naphthol, aromatic aldehydes and 2-, 3- or 4-aminopyridine under ultrasound irradiation without solvent at room temperature. All the reactions proceeded equally smoothly and afforded the desired products in $85-97 \%$ yields and short reaction time within 10-40 min irrespective of the nature of the substituents (Scheme 106). Additionally, binding interactions of 1-(phenyl(pyridin-2-ylamino)methyl)naphthalen-2-ol with various types of rigid DNA and HSA have been investigated by molecular modeling study. In vitro studies under physiological conditions showed that the desired derivative interacts with calf-thymus DNA via an intercalative binding mode. ${ }^{115}$

Fathalipour et al. ${ }^{116}$ studied aqueous suspension of biocompatible reduced graphene oxide-AuNPs composite (rMGO-AuNPs) as an effective recyclable catalyst in a Betti reaction. In this process, 1 -( $\alpha$-aminoalkyl)naphthols 150 were obtained at $50{ }^{\circ} \mathrm{C}$ under solvent-free conditions after 20-60 min in $80-95 \%$ yields (Scheme 107).

\section{Synthesis of bis-Betti base derivatives and synthetic applications}

Among Betti bases, the bis derivatives are less studied. Zhang et al. ${ }^{117}$ reported new kinds of chiral alkylaminobenzylnaphthols (bis-Betti bases) 151 and 152 enantioselectively synthesized for the first time via the reaction of methylbenzylamine, dialdehydes and 2-naphthol in THF at $80{ }^{\circ} \mathrm{C}$ for $24 \mathrm{~h}$ in 32 and $45 \%$ yields, respectively. Subsequently, treatment of bis-Betti bases 151 and 152 with formaldehyde in the presence of TFA in THF at room temperature for $4 \mathrm{~h}$ followed by reduction with $\mathrm{LiAlH}_{4}$ within $5 \mathrm{~h}$ in THF at $80{ }^{\circ} \mathrm{C}$ afforded bis-Betti bases 153 and 154 in 60 and 69\% yields, respectively (Scheme 108).

Xiong $^{\mathbf{1 1 8}}$ described a short and facile synthesis of bis-Betti bases 155 with two chiral carbon centers via the reaction of 2,6-dihydroxynaphthalene, piperidine or morpholine and cyanobenzaldehyde at $100{ }^{\circ} \mathrm{C}$ under reflux condition, affording the anticipated products in $81-86 \%$ yields (Scheme 109). This reaction has two steps. Firstly, the reaction of 2,6-dihydroxynaphthalene with cyanobenzaldehyde and piperidine or morpholine affords mono-Betti base products. And then, mono-Betti base product is used as 2naphthalene continuously to react with excess cyanobenzaldehyde and piperidine or morpholine to give the final bis-Betti base products.

Microwave-assisted synthesis of bis-Mannich bases 156 and 157 of 2-naphthols derived from aromatic aldehydes and diamines namely piperazine and $N, N^{\prime}$-dialkylethylenediamines was studied under two conditions, as follows: (A) solvent-free microwave irradiation using a CEM Discover S Class microwave oven at $125^{\circ} \mathrm{C}$ for five minutes in the absence of any catalyst; (B) reflux in ethanol for $72 \mathrm{~h}$ in the presence of catalytic amount of $p$ TSA (Scheme 110). ${ }^{119}$

Weng and $\mathrm{Li}^{\mathbf{1 2 0}}$ disclosed that bis-Betti base-derived tetradentate ligand 158 could be synthesized by the reaction of Betti base with glyoxal in $\mathrm{MeOH}$ at room temperature for $6 \mathrm{~h}$. The 
combination of $\mathrm{CuI}, \mathrm{Cs}_{2} \mathrm{CO}_{3}$, DMF-MeCN and the proper amount of $\mathbf{1 5 8}$ was a more efficient system to catalyze the $N$-arylation of imidazoles at $120{ }^{\circ} \mathrm{C}$ within $24 \mathrm{~h}$. To explore the scope of this catalytic system, a variety of aryl bromides and aryl chlorides were examined, and the corresponding products in $40-91 \%$ yields were obtained (Scheme 111).

An efficient, expeditious, and diastereoselective one-pot pseudo-five-component reaction for the synthesis of bis-Betti bases 159 and 160 has been reported. The reaction of 2,3-dihydroxynaphthalene or 2,6-dihydroxynaphthalene, two equivalents of arylaldehydes, and two equivalents of 3-amino-5methylisoxazole was carried out at $80{ }^{\circ} \mathrm{C}$ under solvent-free conditions within 0.5-6 h, affording the corresponding products in $70-95 \%$ yields (Scheme 112). ${ }^{121}$

Bis-Betti bases 161 and 162 have been synthesized diastereoselectively by applying a solvent-free 'Betti-type' condensation using 2,6-dihydroxynaphthalene, $(S)$-phenylethylamine, and $m$ methylbenzaldehyde or 1-naphthaldehyde at $80{ }^{\circ} \mathrm{C}$ for $48 \mathrm{~h}$. The major diastereomers formed could be isolated in pure form (Scheme 113). ${ }^{73}$

A mild, efficient and straightforward method has been developed for the synthesis of bis-Betti bases 163 via a pseudo-fivecomponent, one-pot condensation reaction of heteroarylamines, terephthaldehyde and naphthols in the presence of formic acid as catalyst at $80{ }^{\circ} \mathrm{C}$ within 5-20 min under solvent-free conditions (Scheme 114). A wide range of heteroarylamines with electrondonating and electron-withdrawing groups and naphthols were well tolerated under the reaction conditions and afforded products in $85-92 \%$ yields. ${ }^{\mathbf{1 2 2}}$

A simple and efficient procedure for the synthesis of bis-Betti bases 164 via a one-pot pseudo-five-component reaction of one equivalent of 2,3-dihydroxynaphthalene, two equivalents of arylaldehydes, and two equivalents of heteroarylamines in the presence of formic acid catalyst at $80{ }^{\circ} \mathrm{C}$ for $50-115$ min under solventfree conditions has been described. This reaction worked well with heteroaromatic amines such as 2-aminopyrimidines and 2-aminopyridine derivatives and afforded desired products in $81-91 \%$ yields (Scheme 115). ${ }^{123}$

Abdul and Hussain ${ }^{124}$ have exploited an efficient method for the synthesis of $N, N^{\prime}$-bis-[(2-hydroxynapthalene-1-yl)(substituted phenyl)methyl]-2,6-diaminopyridine derivatives 165 by one-pot three-component reaction of 2-naphthol, 2,6-diaminopyridine and substituted aromatic aldehydes in ethanol at $80^{\circ} \mathrm{C}$ within $24-$ $120 \mathrm{~h}$ and under microwave irradiation within 2-6 min at high power (400-900 W) without any catalyst. The isolated yields in ethanol condition (up to 98\%) are higher than in microwaveassisted solvent-free condition (up to $42 \%$ ) (Scheme 116).

The reaction of 4-amino-3-methyl-5-styrilisooxazole, aromatic aldehydes and 2,3-dihydroxynaphthalene in ethanol at $90{ }^{\circ} \mathrm{C}$ for $4 \mathrm{~h}$ afforded bis-Betti bases 166. In all cases, the products were obtained in 76-88\% yields (Scheme 117). ${ }^{125}$

\section{Conclusions}

The high number of publications in the literature that have recently appeared on the syntheses of Betti bases and bis-Betti base derivatives with different methods using various types of naphthols, amines and aldehydes in various conditions indicates the importance of these compounds. These procedures are commonly classified as Mannich aminoalkylations. The non-racemic nature of the Betti base and derivatives could be of special interest for organic chemists working in the field of ligand-metal catalyzed reactions. It is also clear that the most important area of application of the non-racemic aminonaphthols is their use in asymmetric transformations, either as chiral ligands or as chiral auxiliaries. Investigation of Betti base structures indicated that some of these products possess biological activity. However, in spite of the number of structures reported, it is possible to synthesize and investigate applications of the various structures of these compounds due to their importance.

\section{Conflicts of interest}

There are no conflicts to declare.

\section{Acknowledgements}

The authors thank the Research Council of Payame Noor University for financial support.

\section{Notes and references}

1 S. Berlingozzi, Gazz. Chim. Ital., 1953, 83, 693-719.

2 G. Rosini, Rendiconti Accademia Nazionale delle Scienze, Memorie di Scienze Fisiche Naturali, 2003, 27, 1-35.

3 M. Betti and R. Schiff, Gazz. Chim. Ital., 1897, 27(II), 206.

4 M. Betti and R. Schiff, Ber. Dtsch. Chem. Ges., 1897, 30, 1337.

5 (a) M. Betti, Gazz. Chim. Ital., 1923, 53, 417; (b) M. Betti, Trans. Faraday Soc., 1930, 26, 337-347.

6 R. Noyori, Asymmetric Catalysis in Organic Synthesis, New York, John Wiley and Sons, 1994.

7 M. Betti, Gazz. Chim. Ital., 1900, 30 II, 310-316.

8 M. Betti, Org. Synth., 1929, 9, 60.

9 M. Betti, Gazz. Chim. Ital., 1906, 36 II, 392-394.

10 F. F. Blicks, The Mannich reaction in Organic Reactions, Springer, New York, 1942, vol. 1.

11 M. Betti, Gazz. Chim. Ital., 1900, 30 II, 301-309.

12 H. E. Smith and N. E. Cooper, J. Org. Chem., 1970, 35, 22122215.

13 M. Betti, Org. Synth., John Wiley \& Sons, New York, 1941, vol. 1, pp. 381-383.

14 J. B. Littman and W. R. Brode, J. Am. Chem. Soc., 1930, 52, 1655-1659.

15 C. Cardellicchio, G. Ciccarella, F. Naso, E. Schingaro and F. Scordari, Tetrahedron: Asymmetry, 1998, 9, 3667-3675.

16 C. Cardellicchio, G. Ciccarella, F. Naso, F. Perna and P. Tortorella, Tetrahedron, 1999, 55, 14685-14692.

17 D.-X. Liu, L.-C. Zhang, Q. Wang, C.-S. Da, Z.-Q. Xin, R. Wang, M. C. K. Choi and A. S. C. Chan, Org. Lett., 2001, 3, 2733-2735.

18 M. R. Saidi, N. Azizi and M. R. Naimi-Jamal, Tetrahedron Lett., 2001, 42, 8111-8113. 
19 Y. Gong and K. Kato, Tetrahedron: Asymmetry, 2001, 12, 2121-2127.

20 A. Shari, M. Mirzaei and M. R. Naimi-Jamal, Monatsh. Chem., 2001, 132, 875-880.

$21 \mathrm{~J} . \mathrm{Lu}, \mathrm{X} . \mathrm{Xu}, \mathrm{C} . \mathrm{Wang}, \mathrm{J}$. He, Y. Hu and H. Hu, Tetrahedron Lett., 2002, 43, 8367-8369.

22 C. Cimarelli, G. Palmieri and E. Volpini, Tetrahedron: Asymmetry, 2002, 13, 2417-2426.

23 T. Szatmari, T. A. Martinek, L. Lazar and F. Fulop, Tetrahedron, 2003, 59, 2877-2884.

24 M. R. Saidi and N. Azizi, Tetrahedron: Asymmetry, 2003, 14, 389-392.

25 J.-X. Ji, L.-Q. Qiu, C. W. Yip and A. S. C. Chan, J. Org. Chem., 2003, 69, 1589-1590.

26 M. R. Saidi and N. Azizi, Tetrahedron: Asymmetry, 2003, 14, 389-392.

27 Y. Dong, J. Sun, X. Wang, X. Xu, L. Cao and Y. Hu, Tetrahedron: Asymmetry, 2004, 15, 1667-1672.

28 X. Xu, J. Lu, Y. Dong, R. Li, Z. Ge and Y. Hu, Tetrahedron: Asymmetry, 2004, 15, 475-479.

29 X. Xu, J. Lu, Z. Ge, Y. Dong and Y. Hu, Synlett, 2004, 122124.

30 J.-S. Wu, J.-H. Zhou, P.-F. Wang, X.-H. Zhang and S.-K. Wu, Org. Lett., 2005, 7, 2133-2136.

31 J.-X. Ji, J. Wu, T. T.-L. Au-Yeung, C.-W. Yip, R. K. Haynes and A. S. C. Chan, J. Org. Chem., 2005, 70, 1093-1095.

32 X. Wang, Y. Dong, J. Sun, X. Xu, R. Li and Y. Hu, J. Org. Chem., 2005, 70, 1897-1900.

33 L. Xu, X. Shen, C. Zhang and K. Mikami, Chirality, 2005, 17, 476-480.

34 I. Szatmari, L. Lazar and F. Fulop, Tetrahedron Lett., 2006, 47, 3881-3883.

35 P. D. MacLeod, Z. Li, J. Feng and C.-J. Li, Tetrahedron Lett., 2006, 47, 6791-6794.

36 A. Shaabani, A. Rahmati and E. Farhangi, Tetrahedron Lett., 2007, 48, 7291-7294.

37 V. F. Zheltukhin, K. E. Metlushka, D. N. Sadkova, C. E. McKenna, B. A. Kashemirov and V. A. Alfonsov, Mendeleev Commun., 2007, 17, 239-240.

38 L. Cappannini, C. Cimarelli, S. Giuli, G. Palmieri and M. Petrini, Tetrahedron: Asymmetry, 2007, 18, 1022-1029.

39 I. Szatmari, R. Sillanpaa and F. Fulop, Tetrahedron: Asymmetry, 2008, 19, 612-617.

40 M. Ghandi, A. Olyaei and S. Raoufmoghaddam, Synth. Commun., 2008, 38, 4125-4138.

41 I. Zatmari and F. Fulop, Synthesis, 2009, 775-778.

42 M. Ghandi, A. Olyaei and S. Raoufmoghaddam, J. Heterocycl. Chem., 2009, 46, 914-918.

43 C. Cimarelli, D. Fratoni and G. Palmieri, Synth. Commun., 2009, 39, 3184-3190.

44 A. Kumar, M. K. Gupta and M. Kumar, Tetrahedron Lett., 2010, 51, 1582-1584.

45 A. Kumar, M. S. Rao and V. K. Rao, Aust. J. Chem., 2010, 63, 1538-1540.

46 A. Olyaei, E. Chehrehgosha Parashkuhi, S. Raoufmoghaddam and M. Sadeghpour, Synth. Commun., 2010, 40, 3609-3617.
47 N. Foroughifar, A. Mobinikhaledi and H. Moghanian, Synth. Commun., 2010, 40, 1812-1821.

48 P. D. MacLeod, Z. Li and C.-J. Li, Tetrahedron, 2010, 66, 1045-1050.

49 L.-F. Niu, Y.-C. Xin, R.-L. Wang, F. Jiang, P.-F. Xu and X.-P. Hui, Synlett, 2010, 765-768.

50 P. D. MacLeod, A. M. Reckling and C.-J. Li, Heterocycles, 2010, 80, 1319-1337.

51 N. Gyemant, H. Engi, Z. Schelz, I. Szatmari, D. Toth, F. Fulop, J. Molnar and P. A. M. Witte, Br. J. Cancer, 2010, 103, 178-185.

52 A. Kumar, M. K. Gupta and M. Kumar, Tetrahedron Lett., 2010, 51, 1582-1584.

53 A. Olyaei, S. Raoufmoghaddam, M. Sadeghpour and B. Ebadzadeh, Chin. J. Chem., 2010, 28, 825-832.

54 C. Mukherjee, E. D. MacLean, T. S. Cameron and A. Jha, J. Mol. Catal. B: Enzym., 2010, 62, 46-53.

55 H. Wei, L. Yin, H. Luo, X. Li and A. S. C. Chan, Chirality, 2011, 23, 222-227.

56 C. Cimarelli, D. Fratoni and G. Palmieri, Tetrahedron: Asymmetry, 2011, 22, 1560-1567.

57 B. Karmakar and J. Banerji, Tetrahedron Lett., 2011, 52, 4957-4960.

58 R. Csutortoki, I. Szatmari, A. Koch, M. Heydenreich, E. Kleinpeter and F. Fulop, Tetrahedron, 2011, 67, 85648571.

59 C. Cimarelli, D. Fratoni, A. Mazzanti and G. Palmieri, Tetrahedron: Asymmetry, 2011, 22, 591-596.

60 P. Chauhan and S. S. Chimni, Eur. J. Org. Chem., 2011, 1636-1640.

61 C. Cimarelli, D. Fratoni, A. Mazzanti and G. Palmieri, Eur. J. Org. Chem., 2011, 2094-2100.

62 Y. Yadav, E. D. MacLean, A. Bhattacharyya, V. S. Parmar, J. Balzarini, C. J. Barden, C. K. L. Too and A. Jha, Eur. J. Med. Chem., 2011, 46, 3858-3866.

63 T. Kanemitsu, Y. Asajima, T. Shibata, M. Miyazaki, K. Nagata and T. Itoh, Heterocycles, 2011, 83, 2525-2534.

64 A. R. Chaudhary and A. V. Bedekar, Synth. Commun., 2012, 42, 1778-1785.

65 C. Cardellicchio, M. A. M. Capozzi, A. Alvarez-Larena, J. F. Piniella and F. Capitelli, CrystEngComm, 2012, 14, 3972-3981.

66 A. Olyaei, M. Zarnegar, M. Sadeghpour and M. Rezaei, Lett. Org. Chem., 2012, 9, 451-456.

67 A. Hosseinian and H. R. Shaterian, Phosphorus, Sulfur Silicon Relat. Elem., 2012, 187, 1056-1063.

68 C. Mukhopadhyay, S. Rana and R. J. Butcher, Synth. Commun., 2012, 42, 3077-3088.

69 H. R. Shaterian and M. Mohammadnia, Res. Chem. Intermed., 2012, 39, 4221-4237.

70 S. D. Dindulkar, V. G. Puranik and Y. T. Jeong, Tetrahedron Lett., 2012, 53, 4376-4380.

71 M. Kidwai and R. Chauhan, Asian J. Org. Chem., 2013, 2, 395-398.

72 G. Bian, S. Yang, H. Huang and L. Song, Synthesis, 2013, 45, 899-902. 
73 M. Marinova, K. Kostova, P. Tzvetkova, M. TavlinovaKirilova, A. Chimov, R. Nikolova, B. Shivachev and V. Dimitrov, Tetrahedron: Asymmetry, 2013, 24, 1453-1466.

74 S. S. Ganesan, N. Rajendran, S. I. Sundarakumar, A. Ganesan and B. Pemiah, Synthesis, 2013, 45, 1564-1568.

75 A. Yaghoubi Arzephonia, M. R. Naimi-Jamal, A. Sharifi, M. S. Abaee and M. Mirzaei, J. Chem. Res., 2013, 216-218.

76 H. Moghanian, A. Mobinikhaledi, A. G. Blackman and E. Sarough-Farahani, RSC Adv., 2014, 4, 28176-28185.

77 K. E. Metlushka, D. N. Sadkova, L. N. Shaimardanova, K. A. Nikitina, A. I. Tufatullin, O. N. Kataeva and V. A. Alfonsov, Russ. Chem. Bull., 2014, 63, 1390-1394.

78 M. A. M. Capozzi, C. Cardellicchio, A. Magaletti, A. Bevilacqua, M. Perricone and M. R. Corbo, Molecules, 2014, 19, 5219-5230.

79 K. E. Metlushka, D. N. Sadkova, L. N. Shaimardanova, K. A. Nikitina, A. I. Tufatullin, O. N. Kataeva and V. A. Alfonsov, Russ. Chem. Bull., 2014, 63, 1390-1394.

80 I. Mohanram and J. Meshram, ISRN Org. Chem., 2014, 639392, DOI: 10.1155/2014/639392.

81 S. Mahato, M. A. Haque, S. Dwari and C. K. Jana, RSC Adv., 2014, 4, 46214-46217.

82 S. Zahiri, M. Mokhtary and M. Torabi, Iran. J. Catal., 2015, 5, 149-153.

83 A. Shahrisa, R. Teimuri-Mofrad and M. GholamhosseiniNazari, Synlett, 2015, 26, 1031-1038.

84 H. R. Shaterian and A. Hosseinian, Res. Chem. Intermed., 2015, 41, 793-801.

85 F. Janati, M. M. Heravi and A. Mir Shokraie, Synth. React. Inorg., Met.-Org., Nano-Met. Chem., 2015, 45, 1-5.

86 A. Shahrisa, R. Teimuri-Mofrad and M. GholamhosseiniNazari, Mol. Diversity, 2015, 19, 87-101.

87 H. Gao, J. Sun and C.-G. Yan, Chin. Chem. Lett., 2015, 26, 353-356.

88 M. A. Zolfigol, S. Baghery, A. R. Moosavi-Zare and S. M. Vahdat, J. Mol. Catal. A: Chem., 2015, 409, 216-226.

89 C.-Y. Wang, C. Dong, Z.-J. Zheng, Z. Xu, K.-F. Yang and L.-W. Xu, RSC Adv., 2015, 5, 55819-55824.

90 P. K. Sahu, D. Thavaselvam, A. M. Alafeefy and D. D. Agarwal, Med. Chem. Res., 2015, 24, 725-736.

91 F. Liu, G. Li, J. Jiang, F. Zheng and M. Wu, Tetrahedron Lett., 2015, 56, 5054-5056.

92 R. A. Mekheimer, A. M. Asiri, A. M. Abdel Hameed, R. R. Awed and K. U. Sadek, Green Process. Synth., 2016, 5, 365-369.

93 M. Nasr-Esfahani, M. Montazerozohori and M. Taei, C. $R$. Chim., 2016, 19, 986-994.

94 K. A. Nikitina, K. E. Metlushka, D. N. Sadkova, L. N. Shaimardanova and V. A. Alfonsov, Mendeleev Commun., 2016, 26, 395-396.

95 K. D. Shanti, M. D. Shanti and J. S. Meshram, J. Comput. Methods Mol. Des., 2016, 6, 13-19.

96 M. T. Maghsoodlou, M. Karima, M. Lashkari, B. Adrom and J. Aboonajmi, J. Iran. Chem. Soc., 2017, 14, 329-335.

97 M. Mokhtary and M. Torabi, J. Saudi Chem. Soc., 2017, 21, S299-S304.
98 S. Karahan and C. Tanyeli, New J. Chem., 2017, 41, 91929202.

99 R. Teimuri-Mofrad, M. Gholamhosseini-Nazari, S. Esmati and A. Shahrisa, Res. Chem. Intermed., 2017, 43, 6845-6861.

100 J. Mou, G. Gao, C. Chen, J. Liu, J. Gao, Y. Liu and D. Pei, RSC Adv., 2017, 7, 13868-13875.

101 R. Teimuri-Mofrad, M. Gholamhosseini-Nazari, S. Esmati and A. Shahrisa, J. Chem. Sci., 2017, 129, 1449-1459.

102 N. V. Georgieva, Z. L. Yaneva, S. D. Simova and G. D. Nikolova, Bulg. Chem. Commun., 2017, 49, 201-208.

103 N. Azizi and M. Edrisi, Res. Chem. Intermed., 2017, 43, 379385.

104 V. P. Muralidharan, M. Alagumuthu and S. K. Iyer, Bioorg. Med. Chem. Lett., 2107, 27, 2510-2514.

105 A. Deepam and J. Viswanadhan, Orient. J. Chem., 2017, 33, 1354-1365.

106 M. A. M. Capozzi and C. Cardellicchio, Tetrahedron: Asymmetry, 2017, 28, 1792-1796.

107 E. Speich, L. Banfi, L. Moni, R. Riva, V. Rocca and A. Basso, Chem. Heterocycl. Compd., 2018, 54, 329-333.

108 G. Bosica, R. Abdilla and K. Demanuele, Eur. J. Org. Chem., 2018, 44, 6127-6133.

109 M. S. Patil, C. K. Khatri and G. U. Chaturbhuj, Monatsh. Chem., 2018, 149, 1453-1457.

110 R. Teimuri-Mofrad, I. Ahadzadeh, M. Gholamhosseini Nazari, S. Esmati and A. Shahrisa, Res. Chem. Intermed., 2018, 44, 2913-2927.

111 F. Janati, Eurasian J. Anal. Chem., 2018, 13, em31.

112 D. S. Rekunge, H. S. Bendale and G. U. Chaturbhuj, Monatsh. Chem., 2018, 149, 1991-1997.

113 M. Fardpour, A. Safari and S. Javanshir, Green Chem. Lett. Rev., 2018, 11, 429-438.

114 M. Gholamhosseini-Nazari, S. Esmati, K. D. Safa, A. Khataee and R. Teimuri-Mofrad, Appl. Organomet. Chem., 2019, 33, e4701.

115 J. Rakhtshah, B. Shaabani, S. Salehzadeh and N. Hosseinpour Moghadam, Bioorg. Chem., 2019, 85, 420430.

116 S. Fathalipour, B. Ataei and F. Janati, Mater. Sci. Eng. C, 2019, 97, 356-366.

117 Z.-M. Li, Y. Sun, X.-M. Shen, L. Ai and C. Zhang, Chin. J. Org. Chem., 2006, 26, 465-469.

118 R.-G. Xiong, Lett. Org. Chem., 2008, 5, 265-268.

119 Po-J. J. Huang, D. Youssef, T. S. Cameron and A. Jha, ARKIVOC, 2008, xvi, 165-177.

120 B. Weng and J.-H. Li, Appl. Organomet. Chem., 2009, 23, 375-378.

121 M. Shafiee, A. H. Khosropour, I. Mohammadpoor-Baltork, M. Moghadam, S. Tangestininejad and V. Mirkhani, Tetrahedron Lett., 2012, 53, 3086-3090.

122 A. Olyaei and M. Rezaei, Lett. Org. Chem., 2013, 10, 311-316. 123 A. Olyaei, E. S. Abforushha and R. Khoeiniha, Lett. Org. Chem., 2017, 14, 103-108.

124 D. A. Abdul and F. H. S. Hussain, Zanco, Ser. A, 2018, 30, 5664.

125 E. Rajanarendar, D. Nagaraju, S. Ramakrishna and B. Kishore, Indian J. Chem., 2014, 53B, 412-418. 